\title{
Hemostatic function and inflammatory activation after weaning from cardio pulmonary bypass
}

\author{
Anki Olsson
}

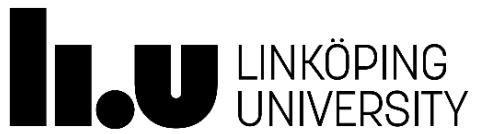

Department of Cardiovascular Medicine

Linköping University

SE-581 83 Linköping, Sweden

Linköping 2018 
Dissertation presented at Linköping University $2018-04-05$ in Berzeliussalen, Universitetssjukhuset, Linköping

Cover by Robin Frejd

(C) Anki Olsson, 2018

All rights reserved.

Papers are reprinted with permission from the respective publishers.

Illustrations are created by the author, Kitty Rydell and Robin Frejd

ISBN 978-91-7685-355-9

ISSN 0345-0082

Printed by Liu-tryck, Linköping 2018 
"The bond that links your true family is not one of blood, But of respect and joy in each other's life."

Richard Bach 



\section{CONTENTS}

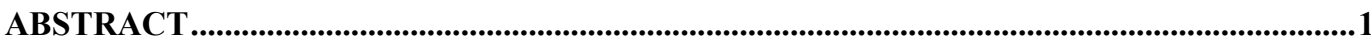

SVENSK SAMMANFATTNING ............................................................................................

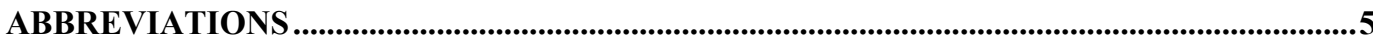

LIST OF PAPERS ……...............................................................................................................

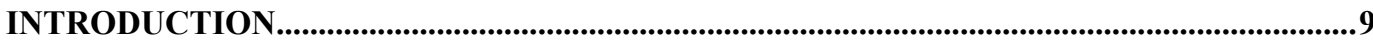

BACKGROUND .................................................................................................................................11

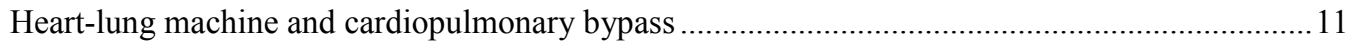

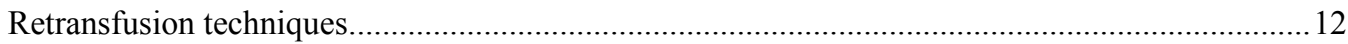

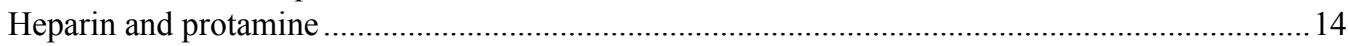

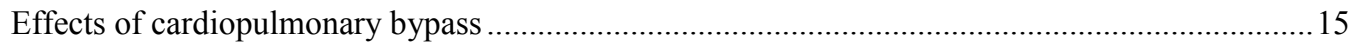

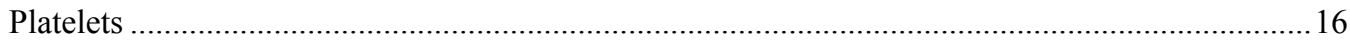

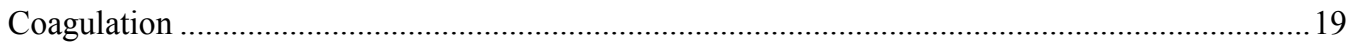

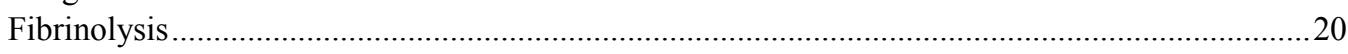

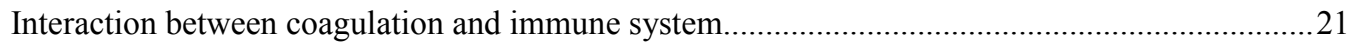

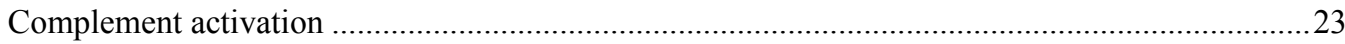

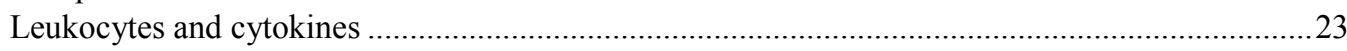

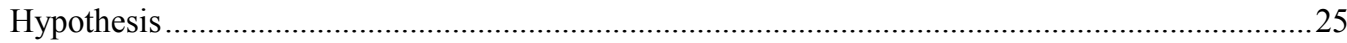

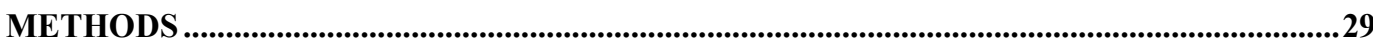

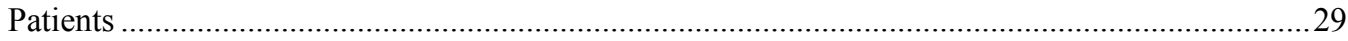

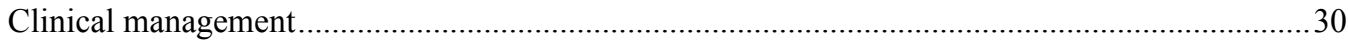

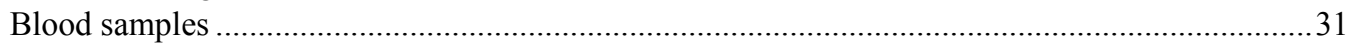

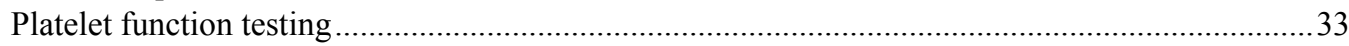

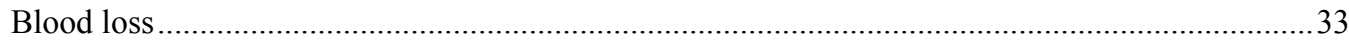

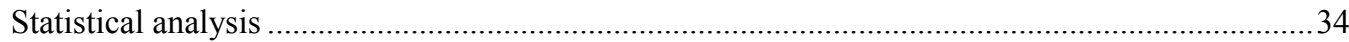

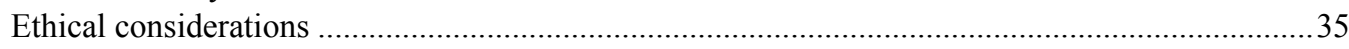

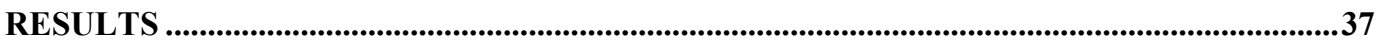

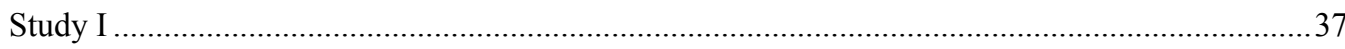

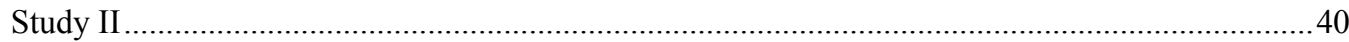

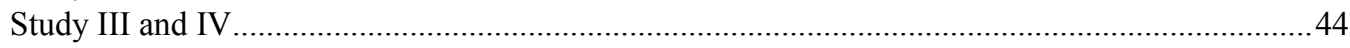

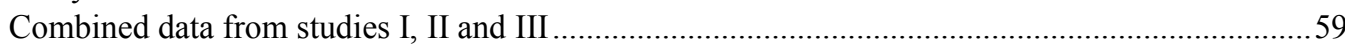

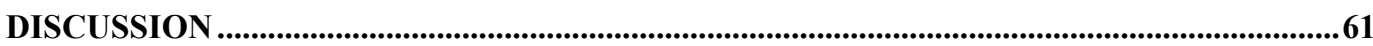

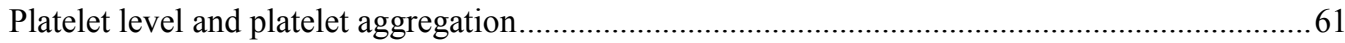

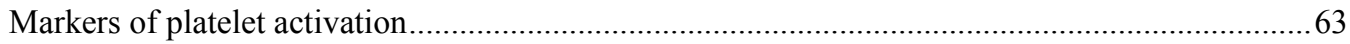

Heparin reversal with protamine ....................................................................................................6

Coagulation and immunological response during $\mathrm{CPB}$ and after weaning......................................64 
Presence of bacteria in the patient and in the retransfused blood .................................................65

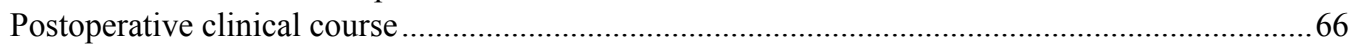

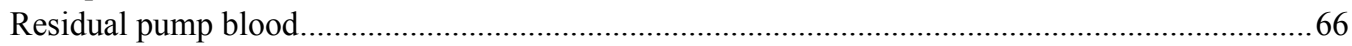

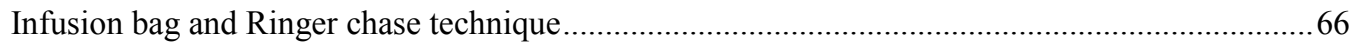

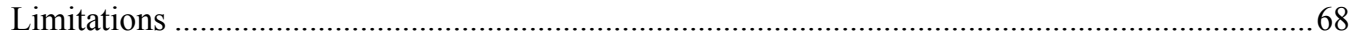

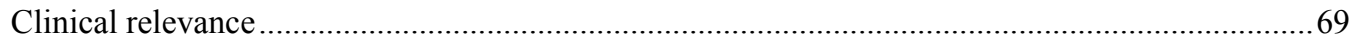

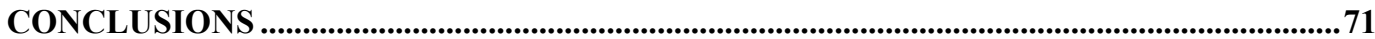

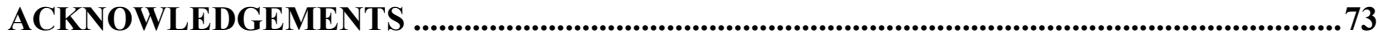

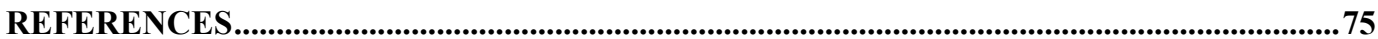




\section{ABSTRACT}

Cardiopulmonary bypass (CPB) contributes to perioperative platelet dysfunction, increased fibrinolysis and impaired coagulation, which can have an impact on postoperative bleeding. During $\mathrm{CPB}$ the blood is exposed to foreign surfaces leading to activation of the coagulation system and a systemic inflammatory response with complement and leukocyte activation. Anticoagulation with heparin is used to prevent immediate blood clotting within the circuit. The heparin effect is reversed with protamine sulfate after weaning from CPB. Protamine has been suggested to impair platelet function in high doses although the mechanism is incompletely understood. Platelet dysfunction can promote bleeding which can necessitate transfusion and sometimes surgical re-exploration.

After weaning from CPB the residual blood in the heart lung machine is usually retransfused to the patient in order to reduce the need for blood transfusion. The most common technique to transfuse residual blood is to collect the blood from the CPB circuit in an infusion bag (IB). An alternative way to re-transfuse the residual blood is by chasing it through the heart lung machine with Ringers solution, the Ringer chase technique (RC).

The aim of this thesis was to examine a possible inhibitory effect of protamine on platelet aggregation. A second aim was to evaluate different techniques for retransfusion after weaning from CPB.

Study I and II in this thesis are focused on the protamine effect on platelet aggregation and study III and IV on the quality of the blood in relation to the two different retransfusion techniques.

In Study I we found that platelet aggregation evaluated by impedance aggregometry was reduced by approximately $50 \%$ after in vivo protamine administration. Protamine added in vitro also reduced platelet aggregation, by itself or in combination with heparin. Study II showed that protamine induces a marked but transient decrease in platelet aggregation already at a protamine-heparin ratio of $0.7: 1$, which also was sufficient to reverse the heparin anticoagulation as measured by activated clotting time (ACT). No further decrease was observed when additional protamine was given within three minutes. Platelet aggregation had begun to recover 20 minutes after protamine administration.

In study III and IV we evaluated possible differences in quality of the retransfused residual blood from the heart-lung machine depending on if it is returned to the patient by the RC-technique or by an IB. Study III focused on biochemical markers of hemostasis, coagulation and fibrinolysis. Study IV concerns biochemical markers of inflammatory activity characterizing the inflammatory response during cardiac surgery with CPB including heparin binding protein (HBP) a new marker of neutrophil activation. $\mathrm{CPB}$ is associated with a marked systemic inflammatory response and levels of HBP indicates a pronounced neutrophil activation as part of a systemic inflammatory process. HBP levels during $\mathrm{CPB}$ was much higher than previously found during severe inflammatory conditions. We also concluded that the handling of the blood after weaning from CPB reduces platelet function, activates coagulation and fibrinolysis, increases hemolysis and the inflammatory response.

Retransfusion of pump blood with the RC-technique was associated with better preserved platelet function, less hemolysis, less signs of activation of coagulation and fibrinolysis and less pronounced inflammatory activity than the commonly used IB technique. In the event of cell salvage technique not being feasible, we suggest that the RC technique is preferable to the IB technique but acknowledge that the clinical importance of this finding in terms of outcomes warrants further investigation 
Hemostatic function and inflammatory activation after weaning from cardiopulmonary bypass 


\section{SVENSK SAMMANFATTNING}

Behandling med hjärt-lungmaskin påverkar koagulation och immunsystem i kroppen. När blodet kommer i kontakt med hjärt-lungmaskinens delar exponeras det för främmande ytor vilket leder till ett system-inflammatoriskt svar med aktivering av komplement och vita blodkroppar. Nedsatt funktion av trombocyterna, ökad fibrinolys och nedsatt koagulationsförmåga är andra kända bieffekter av hjärt-lungmaskinen. För att undvika koagulering i hjärt-lungmaskinen ges heparin före maskinstart. Heparineffekten kan brytas med protamin efter frånkoppling från hjärt-lungmaskinen. Protamin i höga doser har visat sig ha en negativ påverkan på trombocyternas förmåga att aggregera. Trombocyternas försämrade funktion kan bidra till blödning som kan medföra behov av blodtransfusion och ibland även kirurgisk reoperation.

Efter frånkoppling från maskinen finns det blod kvar i hjärt-lungmaskinens krets, det så kallade residualblodet. Genom att re-transfundera residualblodet till patienten är det möjligt att minska behovet av blodtransfusion. Den vanligaste tekniken för att transfundera residualblodet är att tömma ut det kvarvarande blodet $\mathrm{i}$ en infusionspåse (IB) och transfundera det till patienten via en ven. Ett alternativt sätt är att skölja in det genom hjärt- och lungmaskinen med hjälp av Ringer-acetat med så kallad Ringers chase-teknik (RC).

Syftet med denna avhandling var dels att utvärdera effekten av protamin på trombocytaggregation och hemostas, och dels att utvärdera eventuella skillnader i kvalitet på residualblod som retransfunderas till patienten med olika retransfusionstekniker.

Avhandlingen består av fyra studier (I - IV). Studie I och II fokuserar på protaminets effekt på trombocytaggregationen medan studie III och IV fokuserar på att utvärdera eventuell skillnad på blodets kvalitet, beroende på vilken retransfusionsteknik som har använts.

Studie I visade att trombocytaggregation minskade med cirka $50 \%$ efter protaminadministrering in vivo. Protamin tillsatt in vitro reducerade också trombocytaggregation, ensamt eller i kombination med heparin. Studie II visade att protamin inducerar en markant men övergående minskning av trombocytaggregationen redan vid ett protaminheparin-förhållande av $0,7: 1$, vilket också var tillräckligt för att motverka heparins antikoagulerande effekt uppmätt med ACT. Ingen ytterligare minskning av trombocytaggregationen observerades när mer protamin gavs inom tre minuter. Trombocytaggregationen började återhämta sig inom 20 minuter och var nära ursprungsvärdena redan vid ankomst till intensivvårdsavdelningen.

I studie III och IV utvärderades möjliga skillnader i residualblodets kvalitet, beroende på om den returneras till patienten genom RC- eller IB tekniken. Studie III fokuserade på biokemiska markörer för hemostas, koagulation och fibrinolys medan studie IV fokuserade på biokemiska markörer för inflammatorisk aktivitet, inklusive HBP, en ny markör för neutrofilaktivering. HBP-nivåerna vid slutet av maskintid indikerar en markant neutrofilaktivering som en del av en systemisk inflammatorisk process som illustrerar den påverkan hjärt-lungmaskinen har under hjärtkirurgi. Nivåerna var mycket högre än tidigare konstaterade nivåer i samband med andra allvarliga inflammatoriska tillstånd. Vi fann också att hanteringen av blodet efter maskinavslut påverkar trombocytfunktionen, stimulerar koagulation och fibrinolys, ger en ökad hemolys samt ökar det inflammatoriska svaret. RC-tekniken innebar en bättre bevarad trombocytfunktion, mindre hemolys, mindre tecken på aktivering av koagulation och fibrinolys samt mindre uttalad inflammatorisk aktivitet i det retransfunderade blodet jämfört med den mer vanliga IB-tekniken.

Sammanfattningsvis var RC-tekniken mer skonsam för residualblodet än IB-tekniken och bör användas i de situationer där cellsaver inte finns att tillgå. Eventuell klinisk betydelse av RC tekniken behöver utvärderas i fortsatta studier. 
Hemostatic function and inflammatory activation after weaning from cardiopulmonary bypass 


\section{ABBREVIATIONS}

AA

ACT

ADP

ANOVA

AT

AUC

$\mathrm{C}_{3}$

$\mathrm{C}_{3 \mathbf{a}}$

C5b-9

CABG

CCL2(MCP-1)

COL

CPB

CS

CXCL10(IP-10)

CXCL8(IL-8)

ECC

FDP

GME

GPIa-IIa

GPIIb-IIIa

GPVI

Hb

HBP

IB

ICAM-1

ICU

IL-6

IRI

LLR-family

LME
Arachidonic acid

Activated clotting time

Adenosine diphosphate

Analysis of variance

Antithrombin

Area under the curve

Complement factor 3

Complement factor 3 a

Complement factor 5b-9 (MAC-complex)

Coronary artery bypass grafting

C-C motif chemokine ligand 2 (monocyte chemoattractant protein-1)

Collagen

Cardiopulmonary bypass

Cardiotomy suction

$\mathrm{C}-\mathrm{X}-\mathrm{C}$ motif chemokine ligand 10 (interferon gamma-inducible protein-10)

C-X-C motif chemokine ligand 8 (Interleukin-8)

Extracorporeal circulation

Fibrin degradation products

Gaseous micro emboli

Glycoprotein Ia-IIa

Glycoprotein IIb-IIIa

Glycoprotein VI

Hemoglobin

Heparin binding protein

Infusion bag

Intercellular adhesion molecule-1

Intensive care unit

Interleukin-6

Ischemia - reperfusion injury

Leucine-rich repeat family

Lipid micro emboli 
LPS Lipopolysaccharide

MAC-1

Macrophage-1 antigen

MPO

Myeloperoxidase

N-GAL

Neutrophil gelatin-associated lipocalin

NO

Nitric oxide

PAI-1

Plasminogen activator inhibitor 1

PI

Plasmin inhibitor

RC

Ringer's chase

TF

Tissue factor

TNF

Tumor necrosis factor

t-PA

Tissue plasminogen activator

TRAP

Thrombin receptor activating peptide- 6

TSP-1

Thrombospondin-1

VCAM-1

Vascular cell adhesion molecule -1

vWF

von Willebrand factor 


\section{LIST OF PAPERS}

This thesis is based on following papers, which will be referred to in the text with Roman numerals (Study I-IV).

I. Olsson A, Alfredsson J, Håkansson E, Svedjeholm R, Berglund J, Berg S (2016) Protamine reduces whole blood platelet aggregation after cardiopulmonary bypass. Scand Cardiovasc $J$ 2016; 50: 58-63.

II. Olsson A, Alfredsson J, Thelander M, Håkansson E, Svedjeholm R, Sanmartin Berglund J, Berg $\mathbf{S}$ Activated platelet aggregation is transiently impaired also after a reduced dose of protamine (Manuscript)

III. Olsson A, Alfredsson J, Ramström S, Svedjeholm R, Kenny D, Håkansson E, Sanmartin Berglund J, Berg S Better platelet function, less fibrinolysis and less hemolysis in retransfused residual pump blood with the Ringer's chase technique - a randomized pilot study. Perfusion 2017 ; in press)

IV. Olsson A, Alfredsson J, Sandholm K, Svedjeholm R, Ekdahl-Nilsson K, Ernerudh J, Sanmartin Berglund J, Berg S Inflammation and neutrophil activation during CPB evaluation of inflammatory activity in retransfused residual pump blood using the Ringer's chase technique (Manuscript) 
Hemostatic function and inflammatory activation after weaning from cardiopulmonary bypass 


\section{INTRODUCTION}

Cardiopulmonary bypass (CPB) provides controlled operating conditions during cardiac surgery and is routinely used around the world. CPB has been associated with platelet dysfunction with an increased risk for postoperative bleeding which is the most common complication after cardiac surgery ${ }^{1}$. The foreign surfaces in the CPB circuit activates both the coagulation system and causes an inflammatory response with release of mediators ${ }^{2}$. Pro-inflammatory cytokines can influence the development of postoperative complications ${ }^{3}$ such as myocardial dysfunction, respiratory failure, renal and neurologic dysfunction and bleeding disorders.

To prevent immediate blood clotting within the CPB circuit anticoagulation is achieved with heparin. The effect is reversed with protamine sulfate after weaning from $\mathrm{CPB}{ }^{1}$. Protamine and the heparinprotamine complex has been suggested to impair platelet aggregation ${ }^{4-6}$ but the mechanism is incompletely understood. Increased knowledge about protamine and a possible effect on platelet aggregation could increase the understanding of hemostatic problems after CPB and improve the treatment of the patient.

Postoperative bleeding often requires blood transfusions which have been associated with increased morbidity and long term mortality ${ }^{7-9}$. A way to minimize blood bank requirements is to re-transfuse the remaining blood in the CPB circuit, the residual pump blood, after weaning from CPB. The residual pump blood in the $\mathrm{CPB}$ circuit contains bioactive agents that are products of coagulation and fibrinolysis as well as free hemoglobin and vasoactive substances ${ }^{10,11}$, products that can be associated with adverse outcomes ${ }^{12,13}$.

Different techniques for re-transfusing the residual pump blood can be used. The most common way is to empty the residual blood from the heart - lung machine into an infusion bag (IB) and transfuse it to the patient. An alternative to this technique is to chase the residual blood through the heart-lung machine with Ringers acetate, the Ringer chase (RC)-technique.

If and how the quality of the blood is affected by the two techniques has to our knowledge not previously been evaluated. Previous studies have suggested that retransfused blood with fibrin fragments can trigger thrombin formation and activate t-PA ${ }^{14}$, and blood with high levels of cytokines can alter the cytokine pattern ${ }^{15,16}$. An evaluation regarding the quality of the residual pump blood, related to different retransfusion techniques is therefore of interest. 
Hemostatic function and inflammatory activation after weaning from cardiopulmonary bypass 


\section{BACKGROUND}

During cardiac surgery the heart-lung machine is used to maintain perfusion to organs and tissues in the body while the surgeon operates on the heart. Cardio pulmonary bypass provides a bloodless surgical field while the heart and lungs are bypassed and the heart lung machine mechanically circulates and oxygenates the blood.

\section{Heart-lung machine and cardiopulmonary bypass}

The first successful CPB was applied by Gibbon in 1953 and was used for closing an atrial septum defect ${ }^{17}$. Between 1954 and 1964 CPB was only used in sporadic cases. In the middle of the 60s, there was a rapid growth in the number of procedures. During the $80 \mathrm{~s}$ and $90 \mathrm{~s}$ CPB became standardized and the development of the modern circuit began.

$\mathrm{CPB}$ can affect hemostatic mechanisms and thrombin generation both through material-dependent and material-independent (blood-air interface, cardiotomy suction, hemolysis etc.) factors ${ }^{18}$. Modulating the surfaces and the oxygenators in the CPB circuit to be more biocompatible reduced the negative the effects of CPB. The philosophy is to mimic the endothelial surface by coating the $\mathrm{CPB}$ circuit and oxygenator with different types of molecules. The first biocompatible circuit was based on heparin bonding, ionic or covalent ${ }^{19}$. Nowadays there are many kinds of biocompatible materials available for clinical use. A meta-analysis done by Marco Ranucci ${ }^{19}$ concluded that the overall effect of biocompatible surfaces is limited and seems insufficient to produce an important clinical benefit.

The CPB circuit is composed of tubings and cannulas (venous and arterial), a cardiotomy/venous reservoir, an oxygenator and sometimes an arterial filter (Figure 1). The venous cannula, placed in the right atrium, is connected to the venous line. The blood is drained by gravity into the cardiotomy/venous reservoir of the heart-lung machine. The main pump of the machine draws the blood from the reservoir and pushes it into the oxygenator where the blood is oxygenated, decarbonated and tempered. From the oxygenator, the blood goes through the arterial filter in to the patients circulation via the arterial line connected to the arterial cannula placed in the patients aorta (Figure 1).

Cardiotomy suction (CS) is used during CPB to return blood from the operating wound to the heartlung machine, making it possible for the perfusionist to retransfuse blood back into the patient. Studies have however suggested that retransfusion of the CS blood can contribute to the postoperative inflammatory response ${ }^{15,16,20}$ and might influence vascular resistance ${ }^{21}$.

A left ventricular venting line, placed in the pulmonary vein, is used to de-air the heart and prevent volume overload during the operation.

Cold blood cardioplegia is administrated through the heart-lung machine with an initial ratio of 4:1, four parts of blood to one part crystalloid cardioplegic solution. More cardioplegic solution is provided, if necessary to protect the heart during surgery

The circuit is normally primed with $1500-2000 \mathrm{ml}$ of crystalloid solution before the patient is connected to the machine. The priming volume dilutes the patients blood. After weaning from bypass there is a corresponding volume of blood left in the circuit, the residual pump blood. 


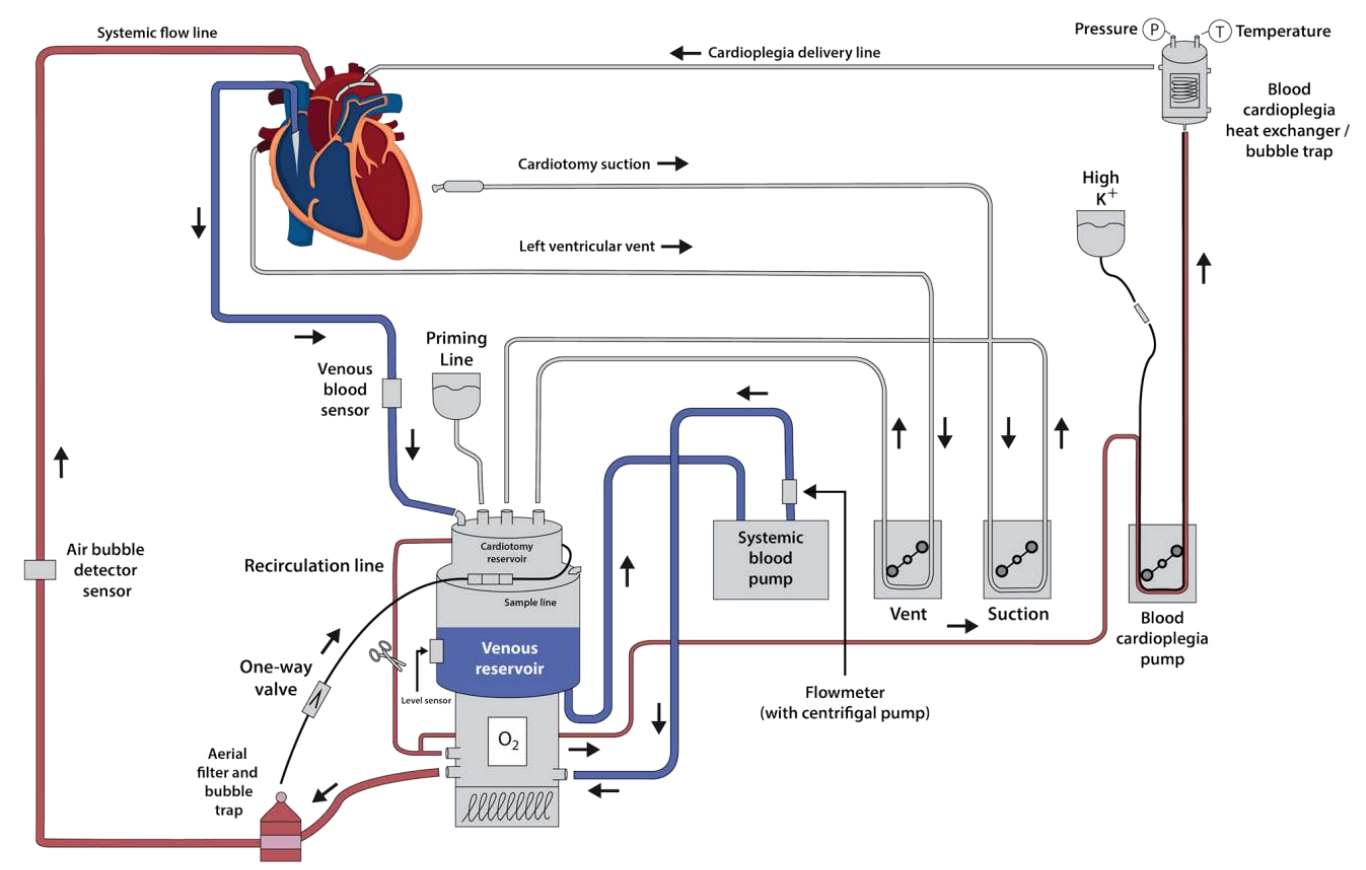

Figure 1. The cardiopulmonary bypass circuit. The venous cannula, placed in the right atrium, is connected to the venous line. The blood is drained by gravity into the cardiotomy/venous reservoir on the heart-lung machine. The machine main pump draws the blood from the reservoir and pushes it into the oxygenator. From the oxygenator, the blood goes through the arterial filter in to the patient circulation via the arterial line connected to the arterial cannula, placed in the patient aorta.

\section{Retransfusion techniques}

It is common to retransfuse the residual pump blood from the CPB circuit to the patient in an attempt to reduce the need for transfusion ${ }^{8,22}$ since allogenic blood transfusion has been associated with both short- and long-term mortality ${ }^{7-9}$. The blood in the circuit after weaning from CPB contains bioactive components such as micro aggregates, free hemoglobin, products of coagulation and vasoactive substances ${ }^{10}$ that could promote coagulation, inflammation and organ damage ${ }^{12,13}$.

The residual blood is usually collected in an infusion bag, in this thesis referred to as the IB technique, and retransfused through a peripheral or central venous line. The infusion bag is retransfused either as it is or washed in a cellsaver ${ }^{23}$. It has been shown that when the blood is washed in a cellsaver the quality is improved ${ }^{10,24,25}$ because heparin, inflammatory mediators and by-products from coagulation and fibrinolysis are removed. In the cellsaver, plasma proteins, clotting factors and viable platelets are washed away ${ }^{25,26}$ and only the erythrocytes will be retransfused to the patient. When the blood loss is excessive and large volumes of blood is washed plasma transfusion will be needed. 
When the IB technique is used, the blood is stagnant or partially stagnant in the circuit for $10-15$ minutes before the perfusionist can drain the blood into the infusion bag, directly or via the venous reservoir. Regardless if the blood is drained into the infusion bag passively or actively, with help from the main pump, there are common factors that could influence the coagulation- and immuneactivation in the blood. The stagnation in the circuit and the exposure to the new plastic surface in the infusion bag, previously containing Ringers acetate used for priming the machine, are factors known to stimulate the inflammatory response. Negative pressure in the system, created by the main pump during active drainage, in combination with exposure to air in the infusion bag, could also augment the inflammatory response in the blood ${ }^{27}$.

There could also be an increased risk for contamination of the infusion bag with small particles and bacteria when the blood is transferred from the machine into the infusion bag.

An alternative way to re-transfuse the blood is by chasing it through the heart and lung machine with Ringers acetate, in this thesis referred to as the Ringers chase (RC) -technique. During this technique, the blood is not exposed to any new surfaces or air beyond the CPB circuit. Another advantage is that retransfusion with the $\mathrm{RC}$ technique starts almost immediately after weaning from $\mathrm{CPB}$ so the blood will not be stagnant in the CPB circuit.

\section{Infusion bag (IB)}

After weaning from $\mathrm{CPB}$, the surgeon decannulates the venous cannula and the blood from the venous line is drained into the venous reservoir. After the venous blood has been retransfused through the machine the surgeon decannulates the arterial cannula. The perfusionist collect the residual blood from the arterial side in the reservoir by reversing the heart lung machine's main pump with a speed of $500-1000 \mathrm{ml} / \mathrm{min}$. The blood, usually $500-600 \mathrm{ml}$, is then transferred into an infusion bag with the pump moving forward with lower speed. The bag is retransfused to the patient through a venous line. The surgeon can use the coronary suction (CS) until the perfusionist has emptied the machine.

\section{The Ringers chase technique ( $R C)$}

The Ringers chase (RC)-technique is an alternative way to retransfuse the residual blood from the heart-lung machine. The principle is that Ringers acetate will chase the residual blood forward in the $\mathrm{CPB}$ circuit and into the patient circulation through the aortic cannula. This technique can be conducted with all types of CPB circuits and starts after the venous blood from the venous cannula has been passively drained into the venous reservoir and infused to the patient. It is important to close the coronary suction before the RC-procedure begins to prevent aspiration of new blood into the cardiotomy reservoir. Blood aspirated after the Ringers acetate is added to the reservoir will not reach the patient.

A calculation of the remaining volume in the oxygenator, arterial filter and tubings has to be made for each circuit. The amount of solution that needs to be added depends on the residual volume in the specific circuit. In our circuit in Karlskrona the residual blood volume is $500 \mathrm{ml}$. When the blood from the venous line has been infused a volume of Ringers acetate, equivalent to that remaining in the circuit, is added to the venous reservoir. With the main pump of the heart-lung machine rotating 
slowly forward, the Ringer's acetate will chase the residual blood forward through the oxygenator, the arterial filter and the arterial tubings into the patient circulation.

Close attention must be paid to filling pressure and blood pressure. It is recommended to limit the speed of the main pump $(100-300 \mathrm{ml} / \mathrm{min})$ to avoid rapid volume overload. Systolic blood pressure should not exceed $110 \mathrm{mmHg}$. Reduced transfusion rate and a head up (reversed Trendelenburg) position can be used during the procedure as help to avoid overfilling and high pressures.

Communication between the perfusionist, anesthesiologist and the surgeon is of great importance.

\section{Heparin and protamine}

$\mathrm{CPB}$ requires anticoagulation and heparin remains the anticoagulant of choice. Heparin is most often manufactured from lung heparin in pigs (porcine lung heparin) and is highly negative charged. A major advantaged with heparin anticoagulation is that it can easily be neutralized with protamine after weaning from bypass. Protamine is derived from salmon sperm and is positively charged.

After a central venous injection of a heparin bolus, maximal ACT prolongation probably occurs within five minutes ${ }^{28}$. The profound anticoagulation increases the surgical bleeding, but since the blood from the surgical field can be returned to the heart-lung machine through the coronary suction it is less important. Anticoagulation with heparin is primarily induced by potentiating the activity of anti-thrombin III (AT III), by a factor of 1000 or more. Heparin also binds to co-factor II, that inactivates thrombin independently of AT III ${ }^{29}$. Insufficient heparin anticoagulation could lead to life-threating clotting in the CPB circuit ${ }^{30}$. It may also result in bleeding diathesis due to consumption of coagulations factors ${ }^{31}$. Heparin also inhibits the effect of thrombin on platelets ${ }^{32}$ and can interact with fibrinolysis ${ }^{33}$.

Protamine can cause various reactions such as hypotension, anaphylaxis and pulmonary hypertensive crisis ${ }^{30}$. The reactions can be managed with disruption of protamine administration, fluids, vasoconstrictors or in worst case scenario return to bypass. Together with heparin it forms a stable complex, neutralizing the anti-coagulative effect of heparin. The heparin-protamine complex has been associated with platelet dysfunction, especially at high ratios of protamine/heparin ${ }^{4,34,35}$. The effect of protamine on platelet receptors stimulated by ADP and TRAP has been studied before but the results are not consistent and varies between receptors. Lindblad et al ${ }^{36}$ was not able to find a relation between protamine and platelet activation whereas Gertler et al ${ }^{6}$ found that both ADP and TRAP induced platelet activation was reduced by protamine. Griffin et al ${ }^{4}$ suggested that protamine alone or in excess of heparin have similar antiplatelet effects and that excessive protamine directly contributes to platelet dysfunction. Protamine has also been found to exert a mild anti-coagulative effect independently of heparin ${ }^{37}$.

The calculation of the protamine dose is usually done with a strategy based on the initial heparin dose and ACT-values. The protamine is given at a fixed-dose ratio with $1.0-1.3 \mathrm{mg}$ of protamine for every $100 \mathrm{U}$ of heparin. Additional doses of protamine are administrated if the ACT is $130 \mathrm{~s}$ or higher or if deemed needed by the attending physician.

Today, many cardiothoracic centers use individualized heparin and protamine management ${ }^{38}$. A point-of-care device, hemostasis management system (HMS), is used to calculate the protamine dose based on the remaining heparin in the patients blood at the time of reversal. This decreases the protamine-to heparin ratio and it has been proven to reduce the incidence of severe blood loss compared to an ACT-based strategy ${ }^{38,39}$. The cause of platelet dysfunction in connection with 
protamine and $\mathrm{CPB}$ is incompletely understood but the dysfunction is associated with postoperative bleeding ${ }^{40,41}$.

How the protamine is administered after weaning from CPB usually depends on the retransfusion technique. During the IB technique protamine administration is initiated in connection to decannulation of the arterial cannula, but $50 \mathrm{mg}$ of the calculated protamine dos is administered after the IB is transfused. When the RC technique is used all protamine is administered in connection to decannulation of the arterial cannula

\section{Effects of cardiopulmonary bypass}

The negative consequences of $\mathrm{CPB}$ are complex, unpredictable and can cause significant morbidity and mortality ${ }^{42}$. Normally, blood cells only interface with the endothelium, but during CPB the entire blood volume is exposed to the foreign surfaces in the $\mathrm{CPB}$ circuit and thereby triggers strong defense reactions that affects the whole body. These reactions could lead to thrombosis, bleeding, inflammatory reactions and temporary organ dysfunction. Thus CPB is associated with development of a whole body inflammatory response, referred to as systemic inflammatory response syndrome (SIRS), caused by the operative trauma, ischemic reperfusion injury (IRI), mechanical shear stress, hemodilution and hypothermia.

\section{Hemodilution}

The CPB circuit is usually primed with $1500-2000 \mathrm{ml}$ crystalloid fluid which was originally thought to improve blood flow to the tissues since the viscosity decreases. The hemodilution causes intercompartmental fluid shifts, fluid retentions and dilution of important plasma proteins. The dilution of the blood causes anemia during CPB and is often a trigger for blood transfusion to prevent hypoxia in the organs. The critical hematocrit level for reduced oxygen supply remains unclear and varies between individuals, but studies show an association between low hematocrit and acute renal failure ${ }^{43,44}$ and stroke ${ }^{45}$.

\section{Ischemia-reperfusion injury}

The tissue damage seen when restitution of blood flow after an ischemic period is called reperfusion injury and is common after myocardial infarction ${ }^{46}$. Cardiac ischemic-reperfusion injury (IRI) is common after cardiac surgery. During surgery a cross-clamp is placed over the aorta and the heart is stopped and devoid of blood flow. In order to protect the heart during the cross-clamp time cold cardioplegia is delivered in the aortic root. Cardiac IRI is manifested by myocardial stunning, reperfusion arrhythmia, myocyte death and endothelial- and microvascular dysfunction ${ }^{47}$.

The endothelial trigger phase starts when the aortic cross-clamp is removed and the blood flow is restored. Reperfusion is followed by a neutrophil amplification phase ${ }^{48}$. Within minutes the endothelium becomes dysfunctional. After about 20 minutes, leukocytes can be seen to adhere to the endothelium and neutrophils migrate into the reperfused tissue. Activated neutrophils release 
cytokines (tumor necrosis factor (TNF), interleukin-1 (IL-1), IL-6 and CXCL8(IL-8), proteases and oxygen-derived free radicals that amplifies the infiltration into the myocardium ${ }^{46,49}$. IRI activates the complement system, resulting in increased cell permeability and release of histamine which induces direct cell injury ${ }^{47}$. Ischemic injury also induces platelet activation that may exacerbate the micro circulatory spasm ${ }^{50}$. Platelets and neutrophils may be stuck within the inflamed capillaries and provoke hypoperfusion in the already hypoxic tissue, called a no-reflow phenomenon ${ }^{51}$.

\section{Systemic embolism}

Embolization is associated with most infusion therapies although the sources of micro emboli during $\mathrm{CPB}$ is multiple, especially from the $\mathrm{CS}^{52}$. Debris from the circuit can be easily be removed with a $0.2 \mu \mathrm{m}$ pre bypass filter ${ }^{53}$ before the patient is connected to the circuit. The particle imbibed from the surgical field, through the CS, will circulate in the machine and return to the patients circulation. The emboli may originate from air, fat, platelet aggregates, fiber or silicone ${ }^{54}$. Emboli can be trapped in small capillaries where they can then cause local tissue damage ${ }^{55}$.

Two types of solid emboli are common, lipid micro emboli (LME) and gaseous micro emboli (GME). LME are associated with neurocognitive impairment after cardiac surgery but high levels has also been found in the kidneys ${ }^{56}$. The main source of LME is blood aspirated from the pleuropericardial cavities ${ }^{57}$ and the most effective way to reduce the LME is to wash the blood from the CS in a cellsaver ${ }^{58,59}$.

The risk for GME is higher during operations when the myocardium or aorta is incised. GME can mechanically obstruct capillaries and ischemia will occur after the obstruction ${ }^{60}$. Major causes of GME are the use of CS, low levels in the venous reservoir, inappropriate venous cannulation and insufficient de-airing procedures of the heart ${ }^{61}$.

\section{Endotoxemia and bacteremia}

Circulating endotoxin, bacterial lipopolysaccharide (LPS), has been identified as an important predictor of adverse outcomes ${ }^{62,63}$ in connection with cardiac surgery. LPS is found in the outer membrane of gram-negative bacteria. Endotoxin is known to stimulate the release of proinflammatory cytokines and nitric oxide $(\mathrm{NO})^{64}$. Systemic endotoxemia is well known to exist during $\mathrm{CPB}^{65}$. It has been suggested that the primary mediator could be gut translocation ${ }^{66}$. Live bacteria found in the $\mathrm{CPB}$ blood on the other hand are mainly those colonizing the patients own skin ${ }^{67}$ so assumingly they also are introduced to the blood through the operation field. No association between positive cultures and an increased postoperative risk for infection has been found ${ }^{65}$.

\section{Platelets}

Platelets have a crucial role in normal hemostasis as well as in thrombotic disorders ${ }^{68}$. They are a fragment of megakaryocyte cytoplasm and are the smallest of blood cells, $2-5 \mu \mathrm{m}$ in diameter. The life span is $7-10$ days and younger platelets have greater ability to function. Apart from their role in hemostasis the platelets are involved in a range of functions such as inflammation, antimicrobial host defense, tumor growth and angiogenesis ${ }^{69}$. 
In the platelet cytoplasm, there are a circumferential coil of microtubules serving as a cytoskeletal support system, but also actomycin filaments involved in shape change upon activation and contraction of the hemostatic plug.

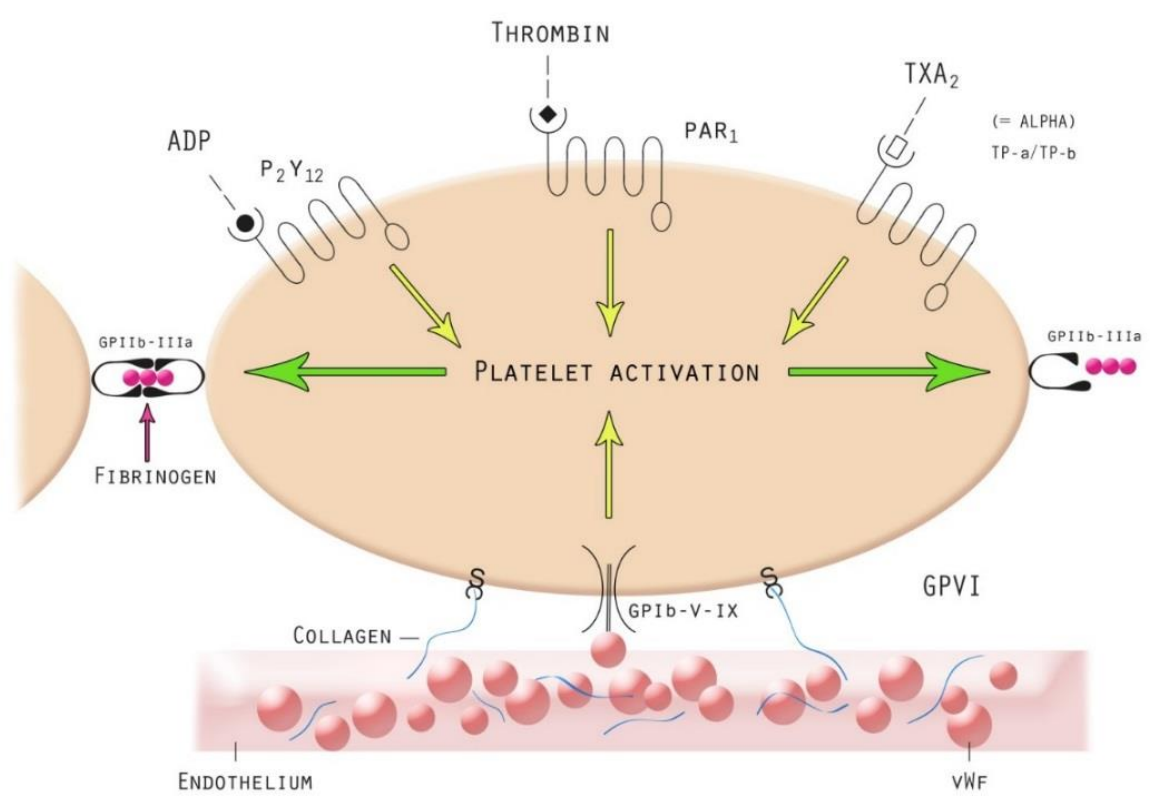

Figure 2. Platelet receptors, $\mathrm{ADP}=$ Adenosine phosphate, $\mathrm{TXA}_{2}=$ Thromboxane $\mathrm{A} 2, \mathrm{GP}=\mathrm{Glycoprotein}$, GPVI $=$ Glycoprotein VI, vWF $=$ Von Willebrand factor

\section{Platelet receptors}

The platelet has no nucleus and hence cannot adapt to different situations, but one way to alter their "phenotype" is through the many types of receptors present on the platelet surface. The specific cellular identity of the platelet is determined by the surface receptor together with their granulae. The receptors are divided into different families. In this thesis on ly a few families and receptors are mentioned.

Integrins are a major class of adhesive and signaling molecules present on both platelets and other cell types ${ }^{70}$. Integrins usually exist in two affinity states, low or high. The fibrinogen receptor, GPIIb-IIIa, is the only integrin expressed exclusively on platelets. There are $50000-80000$ copies on each platelet and the binding to fibrinogen is essential to platelet aggregation. The second most important platelet receptor is the GPIa-IIa ${ }^{71}$ with $2000-4000$ copies per platelet. The platelets first binds to collagen by the GPIa-IIa receptor and is then activated by a second receptor ${ }^{72}$, the GPVI. 
GPVI is a member of the immunoglobulin (Ig) superfamily and is a major platelet receptor for collagen.

During conditions with high sheer stress, neither GPIa-IIa nor GPVI, are adequate to initiate adhesion. This makes the binding between the complex GPIb - von Willebrand factor (vWF) and collagen, essential for the platelet interaction. The GPIb-IX-V complex is a member of the LuecineRich Repeat (LRR) family and is the second most represented receptor on the platelet with approximately 50000 copies per platelet.

The major agonist receptor family, the seven-transmembrane receptor family, are very well represented on the platelets. The most common are the thrombin receptors, PAR-1 and PAR-4, the ADP receptors $\mathrm{P}_{2} \mathrm{Y}_{1}$ and $\mathrm{P}_{2} \mathrm{Y}_{12}$ and the thromboxane (TX) receptors, TP- $\alpha$ and TP- $\beta$ (Figure 2).

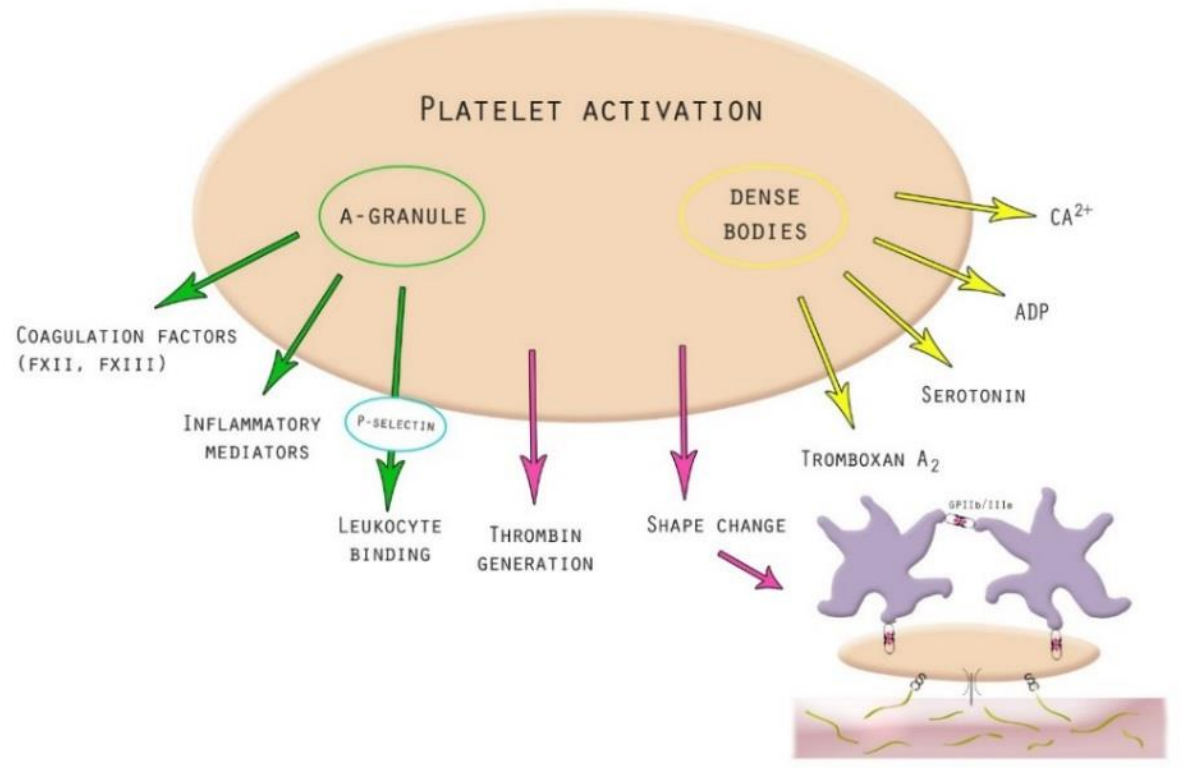

Figure 3. Platelet activation and release of granule and dense bodies. $\mathrm{F}=$ factor, $\mathrm{CA}^{2+}=\mathrm{Calcium}, \mathrm{ADP}=$ Adenosine Phosphate, GP = Glycoprotein

\section{Platelet activation}

When the platelets circulate in the blood they are normally shaped as discs. Loss of endothelial cells due to a vessel injury is the main trigger for platelet activation. The sub endothelial matrix will expose collagen and collagen fibrils will capture platelets in the circulation. The platelets will then adhere to the collagen by the GPIb-IX-V, GPVI and GPIa-IIa receptors. After the adhesion platelets 
will change shape and secrete the granulae and dence bodies in the microtubules which leads to activation of the GPIIb-IIIa receptor (Figure 3). Once the GPIIb-IIIa receptor is activated a formation of a platelet plug will take place.

Further recruitment of additional platelets to strengthen the platelet plug is mediated by ADP and thromboxane $\mathrm{A}_{2}$, secreted from the activated platelet. Thrombin, produced on the surface of activated platelets, also mediates the recruitment. ADP bind to the $\mathrm{P}_{2} \mathrm{Y}_{12}$ receptor, thromboxane $\mathrm{A}_{2}$ to the TP receptors and thrombin binds to the PAR-1 and PAR-4 receptors. Thrombin is the most potent platelet activator and when it binds to the receptors it creates a positive feedback mechanism amplifying the G-protein mediated signals in platelet activation ${ }^{73}$.

During CPB the platelets are activated by several factors such as the foreign surfaces in the circuit, complement (C5b-9), plasmin, hypothermia and pharmaceuticals ${ }^{41}$. Activated platelets secrete soluble and bound P-Selectin by which they bind to monocytes and neutrophils to form aggregates.

\section{Coagulation}

The coagulation cascade can be initiated through two pathways, the extrinsic pathway and the intrinsic pathway. The extrinsic pathway is the physiological way initiated by tissue factor (TF) exposed by endothelial structures and monocytes when vascular damage occurs. TF binds to circulating FVIIa and the complex activates FX, FVII and FIX. Activated FX, FXa, will together with FVa activate prothrombin (FII) to thrombin (FIIa) on the surface of the activated platelet. The thrombin generation is essential in the coagulation as it cleaves the fibrinogen to fibrin which forms the clot. The intrinsic pathway is initiated by FXII as a reaction of blood contact with foreign surfaces or materiel. The activation of FXII results in activation of FXI and FIX. The two pathways converge in to a common pathway at the level of FX with thrombin generation as a result ${ }^{74}$ (Figure 4). The final step in the coagulation is the propagation of the platelet plug when thrombin converts fibrinogen to fibrin. Thrombin will also activate Factor XIII (FXIII), a fibrin stabilizing factor, that crosslinks the fibrin.

The blood that bleeds into the pericardium during operation is activated through both the intrinsic and the extrinsic pathway. The high amount of FVIIa in combination with blood stagnation in the pericardial cavity leads to increased thrombin formation and platelet activation. Thrombin is inhibited by antithrombin (AT) and together they form the complex thrombin-antithrombin (TAT). The concentration of TAT in the plasma is a marker for the thrombin generation, but says nothing about of the actual thrombin generation or activity in the blood ${ }^{75}$. Thrombin generation occurs during $\mathrm{CPB}$, despite anticoagulation with heparin, resulting in soluble fibrin in the circulating blood 75 


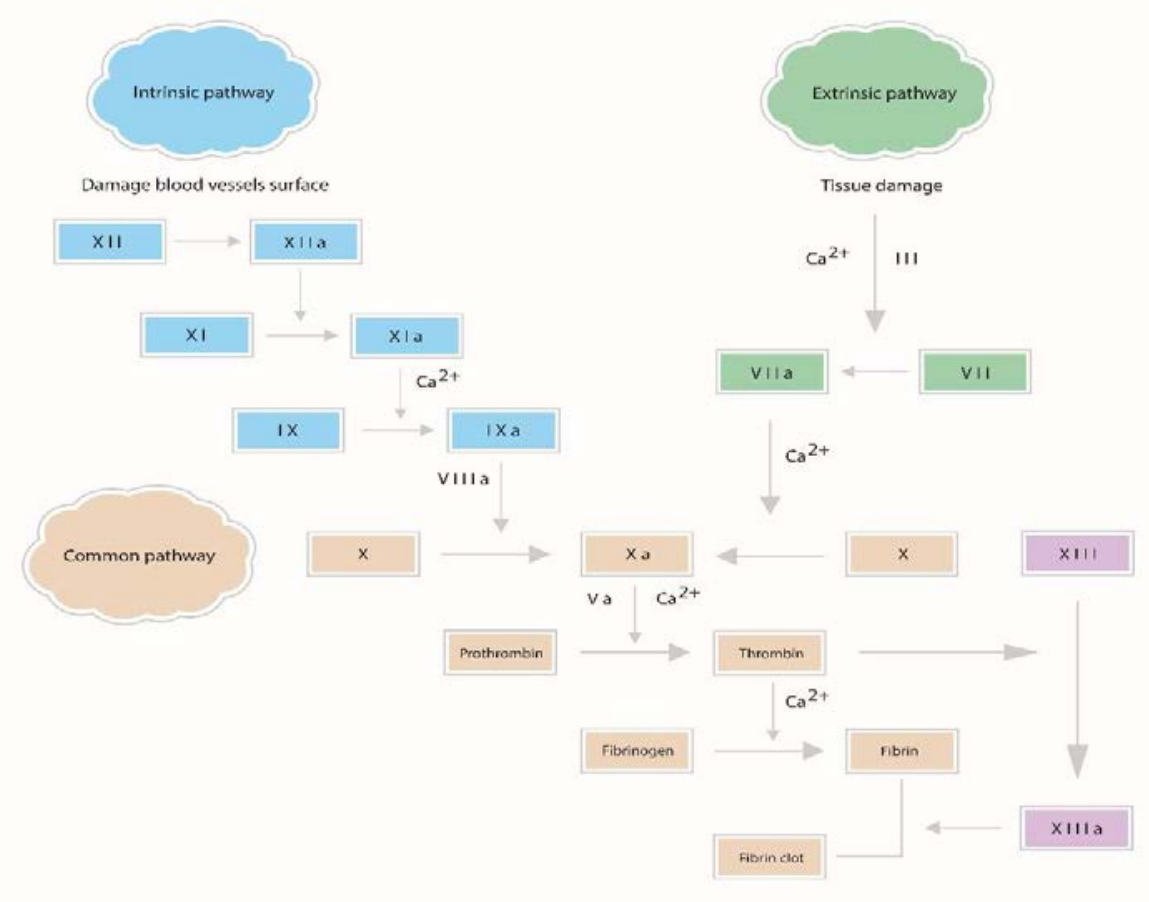

Figure 4. The coagulation cascade (coagulation factors) via the intrinsic pathway and extrinsic pathway. Both pathways converge into the common pathway and leads to thrombin formation. $\mathrm{Ca}^{2+}=$ Calcium.

\section{Fibrinolysis}

The mechanism when the fibrin clot is physiologically degraded by plasmin is called fibrinolysis (Figure 5). Plasmin is formed when the circulating plasminogen in the blood is activated by t-PA (tissue plasminogen activator). T-PA is synthesized in the endothelial cells and the secretion could increase five-fold during CPB although individual variations can be seen ${ }^{76,77}$. The increased t-PA does not increase the fibrinolytic activity in the absence of fibrin. During CPB the soluble and circuit bound fibrin will increase the plasminogen activation ${ }^{78}$. The hyper-fibrinolytic state consumes fibrinogen and in addition large amounts of plasmin will affect the platelets to be less responsive to ADP and arachidonic acid (AA) ${ }^{79,80}$. 
When fibrin is degraded, fibrin degradation products (FDP) are formed. The FDPs, such as D-dimer, can be measured in the blood and serves as an indication of the fibrinolytic activity in the body.

Plasminogen is inhibited by plasminogen activator inhibitor 1 (PAI-1) which is secreted in large amount from platelets ${ }^{81}$. Free plasmin in the blood will immediately bind to plasmin inhibitor (PI) alpha 2-antiplasmin, and form the plasmin-antiplasmin (PAP) complex ${ }^{82}$. Plasmin bound to fibrin will not be inhibited by PI. The fibrinolytic activity is therefore localized to the fibrin clot. Plasmin will also be mildly inhibited by anti-thrombin $(\mathrm{AT})^{83}$.

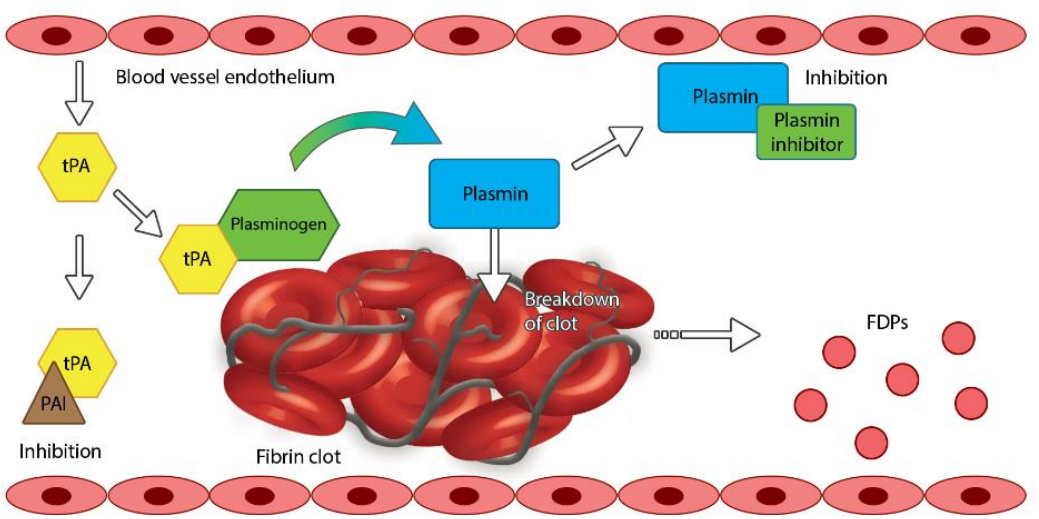

Figure 5. The fibrinolytic system. $\mathrm{tPa}=$ Tissue plasmin activator, $\mathrm{PAI}=$ Plasmin activator inhibitor, FDPs = Fibrin degradation products

\section{Interaction between coagulation and immune system}

The platelets activated during CPB will upregulate P-selectin on their surface membranes ${ }^{84}$. The Pselectin will bind to P-selectin glycoprotein ligand -1 (PSGL-1) on the leukocytes ${ }^{85}$, promoting monocyte activation resulting in secretion of cytokines such as IL-6, C-X-C motif chemokine ligand (CXCL)-8(IL-8) and C-C motif chemokine ligand - (CCL-) 2 also known as monocyte chemoattractant protein $1(\mathrm{MCP}-1)^{86}$. Activated monocytes presents tissue factor (TF) on their surface, leading to initiation of the extrinsic coagulation pathway ${ }^{87}$.

When the coagulation system is initiated it will eventually lead to activation of factor X (FX) to factor Xa (FXa). FXa is the start of the common pathway linking the intrinsic and extrinsic pathway together. The activation of FX will lead to thrombin generation resulting in fibrin formation. Both FXa and thrombin has, apart from their pro-coagulant properties, also inflammatory characteristics. Both factors bind to PAR-receptors and activates signaling cascades leading to platelet and leukocyte activation, linking coagulation and inflammation together ${ }^{18,88}$.

Thrombospondins are a gene family that acts as regulators of cell interactions ${ }^{89}$. Thrombospondin-1 (TSP-1) is a glycoprotein first discovered in platelets activated by thrombin ${ }^{90}$ although other cells, such as epithelial cells, also secretes TSP-1 ${ }^{91}$. TSP-1 is transiently released during the early phase of 
inflammation. It activates leukocytes, enhances chemotaxis ${ }^{92}$ and is induced early during wound healing ${ }^{93}$.

Factor XII (FXII) initiates the intrinsic pathway of the coagulation. Active FXII, FXIIa, also results in the formation of bradykinin, a potent vasoactive peptide which alters the endothelial permeability. When bradykinin binds to the receptors on the leukocytes it can alter the activation state and cytokine production ${ }^{94}$.

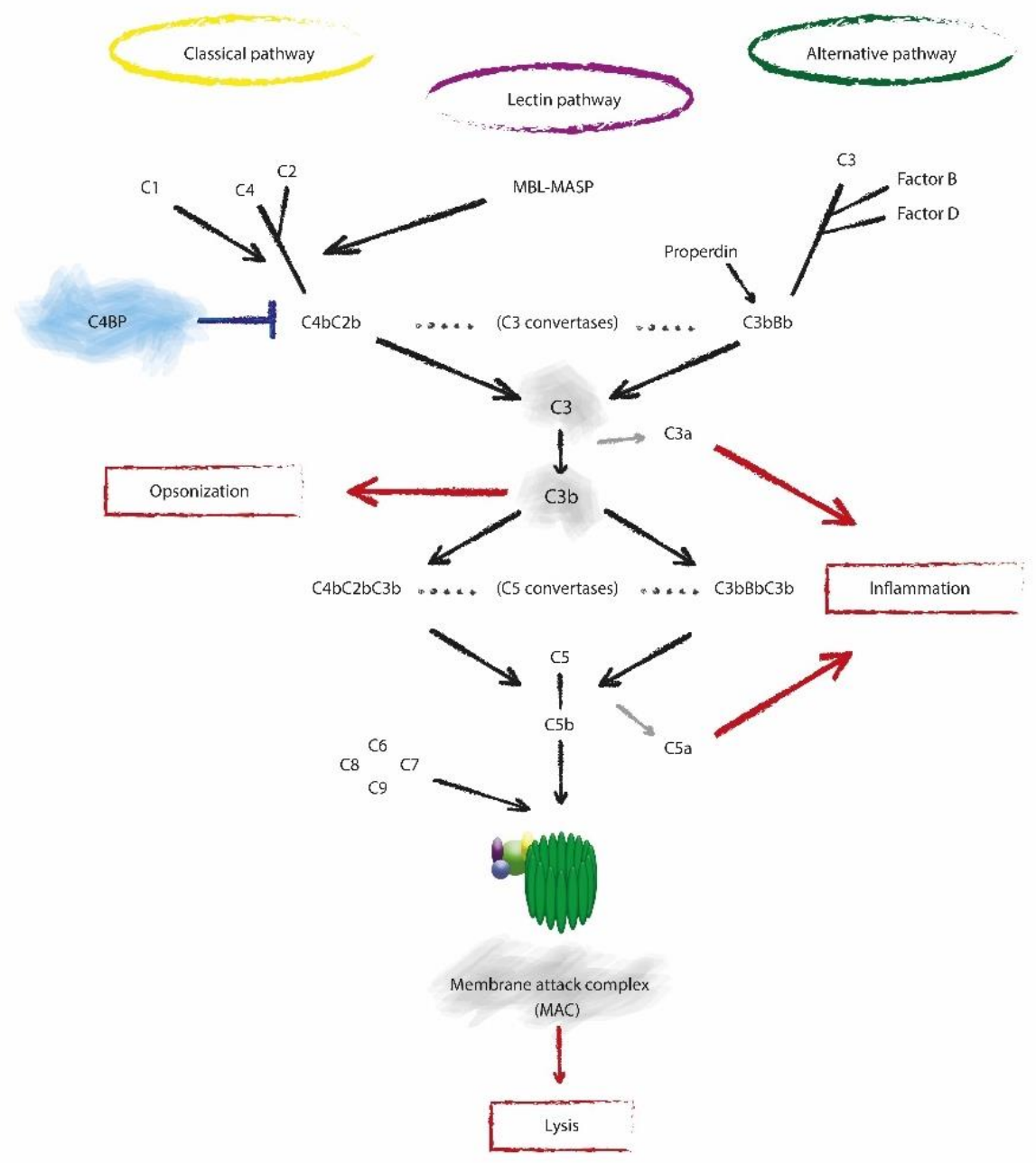

Figure 6. Activation of the complement system, $\mathrm{C}=$ Complement factor, MBL-MASP $=$ mannose binding lectin - associated serine protease, MAC also referred to as C5b-9 


\section{Complement activation}

Complement activation occur via three major pathways, the classic pathway, the alternative pathway and the mannose-binding lectin (MBL) pathway (Figure 6). CPB activates the complement system both via the alternative pathway and the classic pathway.

The predominant pathway during CPB is thought to be the alternative pathway. The pathway is immediately activated when the blood comes in contact foreign material in the CPB circuit ${ }^{95}$. The activation results in spontaneous hydrolysis of $\mathrm{C} 3$ to $\mathrm{C} 3 \mathrm{a}$ and $\mathrm{C} 3 \mathrm{~b}$. $\mathrm{C} 3 \mathrm{~b}$ forms a complex with $\mathrm{Bb}$, a product from cleavage from plasma protein factor $\mathrm{B}(\mathrm{PFB})$. The $\mathrm{C} 3 \mathrm{bBb}$ complex functions as a feedback loop that amplifies compliment activation ${ }^{96}$. The $\mathrm{C} 3 \mathrm{bBb}$ complex also cleaves $\mathrm{C} 5$ to $\mathrm{C} 5 \mathrm{a}$ and C5b. C5b forms together with C6, C7, C8 and C9 the Membrane Attack Complex (MAC), C5b-9 ${ }^{42}$. C5b-9 accelerates thrombin formation via action on the prothrombinase complex ${ }^{97}$.

The surface in the CPB circuit and the release of endotoxins by the intestinal flora activates the classic pathway. The proteins $\mathrm{C} 1, \mathrm{C} 2$ and $\mathrm{C} 4$ forms $\mathrm{C} 3$ convertase which cleaves $\mathrm{C} 3$ into $\mathrm{C} 3 \mathrm{a}$ and $\mathrm{C} 3 \mathrm{~b}^{42}$. At the end of bypass the classic pathway is activated a second time by the heparin-protamine complex ${ }^{98}$.

The complement activation during cardiac surgery with CPB plays an important role in the development of perioperative tissue injury. C3a and especially $\mathrm{C} 5 \mathrm{a}$ are anaphylatoxins that alter the vasomotor tone and increases the capillary permeability with hypotension and airway smooth muscle contraction as a result ${ }^{99}$.

C5a induces IL-6 production from monocytes ${ }^{100}$ but since some of the C5a is absorbed by neutrophils, it is more practical to measure the circulating C5b-9 as an indicator of C5a levels ${ }^{101}$. The C5b-9 complex is formed on bacteria, but also on single activated platelets ${ }^{102}$ and cardiac myocytes ${ }^{103}$. The complex induces cell death caused by calcium influx through the lytic C5b-9 channels ${ }^{104}$.

\section{Leukocytes and cytokines}

CPB is associated with an increased leukocyte recruitment ${ }^{105}$. The white blood cell count is initially reduced due to hemodilution caused by the priming volume in the CPB circuit. The leukocytes are subsequently increased in both number and activity ${ }^{96}$ during bypass. Neutrophils, monocytes and lymphocytes are all affected during CPB.

Neutrophils are activated by complement (C3a and C5a), contact systems (kallikrein and FXII) and through direct contact with endothelial cells. The interaction between the neutrophils and the endothelium occurs with help of specific cell adhesion molecules and plays a key role in the inflammatory response. Higher levels of soluble adhesion molecules, such as vascular cell adhesion molecule -1 (VCAM-1) and intercellular adhesion molecule-1 (ICAM-1), has been seen in patients after $\mathrm{CABG}{ }^{106}$.

When the endothelium is activated, the expression of $\mathrm{P}$ - and E-selectin increases and mediates the rolling of neutrophils along the endothelium (Figure 7). Neutrophils express Macrophage-1 antigen (MAC-1), an integrin receptor, the endothelial cells express ICAM-1 and ICAM-2 and the platelets expresses platelet endothelial cell adhesion molecule 1 . The neutrophils binds firmly to the 
endothelium when these adhesion molecules interact and after shape change the neutrophils transmigrate through the endothelial monolayer ${ }^{42}$. In the extracellular matrix, the neutrophils release cytotoxic contents leading to increased microvascular permeability and interstitial edema. Activated neutrophils secretes inflammatory mediators leading to amplification of the leukocyte activation ${ }^{107}$.

Monocytes are activated more slowly during CPB and the levels peak a few hours after weaning ${ }^{108}$. The mechanism of activation is not entirely clear but C3b, C5b-9, interaction with soluble TF, endotoxins and direct contact with the CPB circuit may contribute to the activation ${ }^{96,109,110}$. Monocytes produce pro- and anti-inflammatory cytokines and when stimulated by pro-inflammatory cytokines, monocytes also produce and presents TF on their surfaces ${ }^{87,111}$ both in the circuit and in the pericardial blood.

The lymphocyte concentration falls during $\mathrm{CPB}$ and the decrease remains $3-7$ days after surgery 112. The reduction results in a weakening of the patients cellular immune response and increases the susceptibility to acquire postoperative infections ${ }^{113}$.

Cytokines are small secreted proteins that acts as a communication between cells. Cytokines are divided into groups depending on how they communicate. When a cytokine is made by one leukocyte and acting on another they are called interleukins and cytokines with chemotactic activities are called chemokines. The cytokines exert either pro-inflammatory or anti-inflammatory effects. Pro-inflammatory cytokines stimulate the inflammatory process. Anti-inflammatory cytokines are immune regulatory molecules controlling the pro-inflammatory cytokine response ${ }^{114}$. The balance between pro-inflammatory and anti-inflammatory cytokines following CPB has been suggested to affect the clinical prognosis ${ }^{115}$.

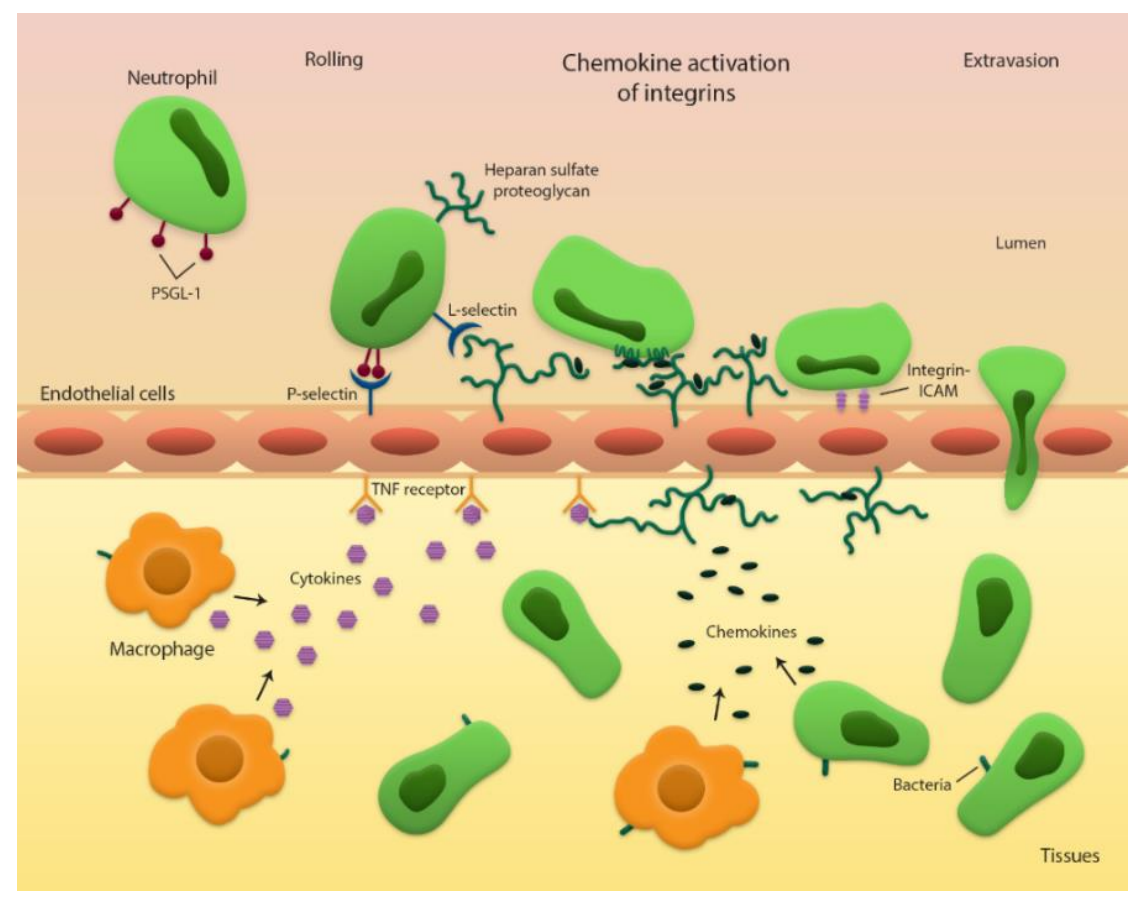

Figure 7. Leukocyte rolling in the endothelium and chemokine activation of integrins. PSGL-1 = P-selectin glycoprotein ligand-1, Integrin-ICAM = Integrin Intercellular Adhesion Molecule 1, TNF-receptor $=$ Tumor necrosis factor 
Chemotactic proteins, chemokines, are important in the inflammatory process ${ }^{116}$ and they are believed to control the circulation of leukocytes through the tissue ${ }^{117}$. CCL2(MCP-1) and CXCL10 also known as interferon-inducible protein 10 (IP-10) increase in response to $\mathrm{CPB}^{116,118}$. They recruit monocytes and T-lymphocytes to the tissue ${ }^{119}$. It has also been suggested that platelets stimulates mesangial cells to produce CCL2(MCP-1), which may contribute to the inflammatory response ${ }^{120}$.

When a phagocyte has ingested a microorganism or a foreign particle, myeloperoxidase (MPO) is released in the phagosome ${ }^{121}$. During the phagocytosis, there is an increase of consumption of glucose and oxygen in the phagocyte, a process called the respiratory burst. MPO reacts with the $\mathrm{H}_{2} \mathrm{O}_{2}$, created from the respiratory burst. The MPO- $\mathrm{H}_{2} \mathrm{O}_{2}$ complex oxidize a large variety of substances with microbicide effects. The complex can also be released to the outside of the cell and induce damage to the adjacent tissue when it reacts with chloride. Atherosclerosis lesions, pulmonary- and renal injury may be caused by the MPO system ${ }^{122}$.

The clinical significance of heparin binding protein (HBP) levels is not known and HBP levels during and after CPB has not been investigated. HBP is a multifunctional protein mainly released from activated neutrophils ${ }^{123}$. During systemic inflammation plasma levels of HBP increases ${ }^{124}$. HBP exerts pro-inflammatory effects ${ }^{125}$ and is a potent inducer of vascular permeability and leukocyte recruitment ${ }^{126}$ which are considered to contribute to organ injury and organ dysfunction.

\section{Hypothesis}

Cardiac surgery with CPB is associated with perioperative platelet dysfunction which is considered to be an important cause of postoperative bleeding $40,41,127$. The cause of the dysfunction is incompletely understood but contact with foreign material, hypothermia, hemodilution and pharmaceuticals are factors that affects the platelets ${ }^{41}$. Previous studies has suggested that the interaction between the heparin-protamine complex and platelets can affect platelet aggregation ${ }^{128}$. Platelet function could be affected at different heparin-protamine ratios ${ }^{6}$, and excessive protamine has been suggested to contribute to the dysfunction ${ }^{34,129}$. How and to what extent protamine itself affects platelet aggregation is not very well studied.

The first hypothesis in this thesis is that protamine itself impairs platelet aggregation, an assumption based on previous findings. This could influence per- and postoperative bleeding. Increased knowledge of the effect of protamine on platelets could be of importance for the clinical management of patients.

The residual pump blood is retransfused after weaning from $\mathrm{CPB}^{23}$ in order to reduce the need for allogenic blood transfusion. The most common technique is to retransfuse the blood by the IB technique, but the RC technique is also used. An evaluation of the possible differences in the quality of the retransfused blood by the IB- and RC technique has not been previously described.

The second hypothesis in this thesis is that retransfusion of the residual pump blood with the RC technique will provide less damage to the blood, based on less stagnation, less exposure to new surfaces beyond the CPB circuit and an unbroken circle. 
Hemostatic function and inflammatory activation after weaning from cardiopulmonary bypass 


\section{AIM OF THE THESIS}

The general aim for this thesis was to investigate the effect of protamine on platelet function and to evaluate the hemostatic function and inflammatory activation of the retransfused residual pump blood after weaning from cardiopulmonary bypass.

The specific aims were:

I. To investigate changes in platelet function in relation to protamine reversal of heparin anticoagulation after cardiopulmonary bypass using impedance aggregometry.

II. To investigate the duration of the inhibitory effect of protamine on platelet function and a possible dose dependence during cardiac surgery.

III. To evaluate possible differences regarding biochemical markers of hemostasis, coagulation and fibrinolysis in the residual blood from the heart-lung machine depending on if it is returned to the patient by the IB or the $\mathrm{RC}$ technique.

IV. To evaluate the quality of the residual pump blood with respect to biochemical markers of inflammatory activity, including the new marker heparin binding protein (HBP).

V. To investigate markers of organ dysfunction, presence of bacteria and signs of postoperative infection using the different techniques for retransfusing the residual pump blood. 
Hemostatic function and inflammatory activation after weaning from cardiopulmonary bypass 


\section{METHODS}

Study I was performed at the cardiothoracic surgical department at Linköping University during 2011-2012 and study II, III and IV were performed at the department of cardio thoracic surgery, Blekinge hospital, Karlskrona, Sweden during 2012 - 2016. The patients were informed and gave their consent, both orally and in writing, by the principal supervisor or by the author (see ethical considerations).

\section{Patients}

The inclusion criteria in study I - IV was planned cardiac surgery with CPB. The surgical interventions vary between $\mathrm{CABG}$ and valve replacements, separate or in combination. The sex distribution was similar in all four studies, $70-85 \%$ men and $15-30 \%$ women, which is fairly similar to the distribution in the total patient cohorts, both in Karlskrona and in Linköping.

\section{Study I}

Totally 25 consecutive adult patients were included, 17 male and 8 female. All 25 patients were studied during in vivo protamine administration after CPB and fifteen of the patients were also studied after heparin and protamine treatment in vitro. The exclusion criteria were known bleeding diathesis, known hemostatic or coagulative disorder and complicated surgery (i.e. deep hypothermia, total circulatory arrest). Treatment with acetylsalicylic acid was given until the day of surgery.

\section{Study II}

Thirty adult patients were included, 24 male and 6 female. The exclusion criteria in this study were known bleeding diathesis, treatment with clopidogrel or ticagrelor, re-heparinization after administration of protamine and reinstitution of CPB. Acetylsalicylic acid was allowed until surgery.

\section{Study III and IV}

These two studies are based on the same patient population. Forty adult patients operated for CABG, were prospectively randomized to receive the residual pump blood by IB or though the RCtechnique. The exclusion criteria in these studies were known bleeding diathesis, treatment with clopidogrel or other $\mathrm{P}_{2} \mathrm{Y}_{12}$ platelet inhibitor therapy within 5 days of surgery, treatment with warfarin or steroids, need for emergency reinstitution of $\mathrm{CPB}$ during the procedure or hemofiltration or transfusion during $\mathrm{CPB}$. Thirty-nine of 40 patients were treated with aspirin until surgery. 


\section{Clinical management}

\section{Study I}

Anesthesia was induced with sodium pentothal $3-6 \mathrm{mg} / \mathrm{kg}$ and $300-500 \mu \mathrm{g}$ fentanyl. Muscle relaxation was achieved with $0.6 \mathrm{mg} / \mathrm{kg}$ rocuronium. Anesthesia was maintained with isoflurane before, during and after CPB.

A heart-lung machine (HL 30, MAQUET Nordic, Sweden) primed with $1500 \mathrm{ml}$ Ringer's acetate, $200 \mathrm{ml}$ mannitol and $5000 \mathrm{U}$ of heparin was used for CPB.

The initial heparin dose was $300 \mathrm{U} / \mathrm{kg}$ body weight and a supplemental dose was given if needed to achieve an activated clotting time (ACT) of $>480 \mathrm{~s}$ before starting CPB. Additional doses of heparin were given during bypass to keep a therapeutic ACT level (>480 s).

After CPB heparin anticoagulation was reversed with protamine. The protamine dose was calculated based on the total initial dose of heparin with $1 \mathrm{mg}$ of protamine to every $100 \mathrm{U}$ of heparin.

Additional doses of protamine were given according to clinical routine if the ACT target of $130 \mathrm{~s}$ or less was not achieved or at the attending physicians discretion. All patients were treated prophylactic with cloxacillin or clindamycin.

All anesthetic, heparin and protamine treatment was given according to clinical routine and the attending physician was blinded to the aggregometry results. The $5000 \mathrm{U}$ heparin present in the extra-corporeal circulation priming fluid was not included in the protamine dose calculation.

\section{Study II - IV}

Anesthesia was induced with propofol $1-3 \mathrm{mg} / \mathrm{kg}$ and $300-500 \mu \mathrm{g}$ fentanyl. Muscle relaxation was achieved with $0.6 \mathrm{mg} / \mathrm{kg}$ rocuronium (all from B. Braun, Melsungen, Germany). Anesthesia was maintained with sevoflurane (Baxter medical AB, Kista, Sweden) during the whole procedure. All patients were given prophylactic cloxacillin or clindamycin.

A S5 heart-lung machine (Sorin Group Deutschland GmbH, München) was used. Cardioplegic arrest was induced with cold blood cardioplegia (4:1), administered into the aortic root. The circuit was primed with $1500 \mathrm{ml}$ of Ringers acetate, $100 \mathrm{ml}$ of mannitol $150 \mathrm{mg} / \mathrm{ml}$ (both from Fresenius Kabi $\mathrm{AB}$, Uppsala, Sweden) and $10000 \mathrm{U}$ of heparin. In paper II the residual pump blood was retransfused with the RC-technique. Mild hypothermia 35-36 degrees Celsius was employed during CPB.

The initial heparin dose was $350 \mathrm{U} / \mathrm{kg}$ bodyweight and the aim was to achieve an ACT of $>480 \mathrm{~s}$ before starting CPB. A supplemental dose was given if needed. Additional doses of heparin were given during bypass to keep an ACT level $>480 \mathrm{~s}$.

Protamine was used to reverse the effect of heparin after CPB. The protamine dose was calculated based on the total initial dose of heparin with $1 \mathrm{mg}$ of protamine to every $100 \mathrm{U}$ of heparin. In study II protamine was administrated according to a specific study protocol. Additional doses of protamine were given if needed to achieve the ACT target of $\leq 130 \mathrm{~s}$ or if deemed needed as judged by the surgeon because of bleeding in the wound. 


\section{Blood samples}

\section{Study I}

Routine coagulation tests, PK-INR and APTT were collected pre-operatively. The hemoglobin concentration and platelet count was measured pre- and post-operatively by the department of clinical chemistry at Linköping University Hospital, Linköping, Sweden. Platelet aggregation was analyzed by the author using the Multiplate device (Dynabyte $\mathrm{GmbH}$, München, Germany).

Activated clotting time (ACT) was measured prior, during and after CPB with a point-of-care device (Hemochron Jr, Signature, ICT, Edison, USA).

The effect of in vivo protamine treatment on platelet function was assessed when reversal of heparin anticoagulation was performed after the end of CPB. The samples in the in vivo part were drawn immediately before and 5 minutes after the reversal dose of protamine was given.

In the in vitro part five samples were taken before induction of anesthesia and diluted as described below. The doses of heparin and protamine added in vitro were chosen to correspond to the clinical condition in vivo. Blood samples of $3 \mathrm{~mL}$ were drawn from the arterial catheter before induction of anesthesia and prepared as follows;

1) Addition of $0,24 \mathrm{~mL} \mathrm{NaCl}$ (diluted control sample);

2) Addition of $0,12 \mathrm{~mL}$ heparin $(100 \mathrm{U} / \mathrm{mL}$ ) and $0,12 \mathrm{~mL} \mathrm{NaCl}$ (heparin sample);

3) Addition of $0,12 \mathrm{~mL}$ protamine $(1 \mathrm{mg} / \mathrm{mL})$ and $0,12 \mathrm{~mL} \mathrm{NaCl}$ (protamine sample);

4) Addition of $0,12 \mathrm{~mL}$ heparin $(100 \mathrm{U} / \mathrm{mL})$ and $0,12 \mathrm{~mL}$ of protamine $(1 \mathrm{mg} / \mathrm{mL})$ (heparin + protamine sample);

5) Blood without any additive (undiluted baseline control sample).

From the heparin dose given in vivo and the subsequent dilution in the CPB circuit a theoretical mean heparin concentration in vivo was calculated to be approximately $3,7 \mathrm{U} / \mathrm{mL}$ in the patient blood. The in vitro tests with heparin were therefore done at a concentration of $3,7 \mathrm{U} / \mathrm{mL}$ and when adding protamine this was done in a 1:1 ratio to a protamine concentration of $37 \mu \mathrm{g} / \mathrm{ml}$. These concentrations also correspond to what has been used in other studies ${ }^{4,34}$.

\section{Study II}

Platelet count and aggregation was analyzed at six time points;

- at baseline (before induction of anesthesia)

- immediately before protamine administration

- three minutes after $70 \%$ of the calculated protamine dose

- three minutes after full protamine dose ( $100 \%$ of the calculated dose)

- 20 minutes after the completed protamine dose

- on arrival in the intensive care unit (ICU).

Hemoglobin and leukocytes concentration were analyzed at three time points 
- at baseline

- three minutes after full protamine administration

- on arrival in the ICU.

All blood samples were drawn from an indwelling arterial catheter. Hemoglobin, leukocyte and platelet concentration was analyzed by the Department of Clinical chemistry, Blekinge hospital, Karlskrona, Sweden. Platelet aggregation was analyzed by the author using the Multiplate device (Dynabyte GmbH, München, Germany).

ACT was measured in the operating theatre before, during and after CPB with a Hemochron $\mathrm{Jr}$, Signature, ICT, Edison, USA.

\section{Study III-IV}

Blood samples were drawn at five time points. Three of the samples were drawn from the patient through an indwelling arterial cannula;

- baseline (before induction of anesthesia)

- before weaning from bypass

- four hours after surgery

A fourth sample was drawn to compare the quality of the retransfused blood. In the IB group the samples were taken directly from the infusion bag after collection, immediately before retransfusion. In the RC group samples were taken from the arterial sample line from the outlet of the oxygenator on the heart-lung machine at the start of the RC-procedure.

A fifth sample of venous blood was drawn from the patients five days after surgery (Study IV). The blood samples were either sent for clinical routine examinations, or were centrifuged within one hour, aliquoted in cryotubes and stored in -70 for subsequent biomarker measurements

During study III analysis of plasmin-antiplasmin complex (PAP), thrombin-antithrombin complex (TAT), soluble fibrin, and soluble P-selectin was performed at the Department of Clinical Chemistry, University Hospital, Linköping. Soluble glycoprotein VI (GPVI) was analyzed by a newly described ELISA ${ }^{130,131}$. ACT was performed in the operating theater with Hemochron Jr, Signature, ICT, Edison, USA.

In study IV analysis of interleukin (IL)-6, C-X-C motif chemokine ligand 8 (CXCL8, also known as IL-8), tumor necrosis factor (TNF), C-C motif chemokine ligand 2 (CCL2) also known as monocyte chemoattractant protein-1 (MCP - 1), CXCL10 (also known as interferon gamma-inducible protein, IP-10), myeloperoxidase (MPO) and heparin binding protein (HBP) were performed at the Division of Neurological and Inflammatory Sciences, Department of Clinical and Experimental Medicine, Linköping University

IL-6, CXCL8(IL-8), TNF, CCL2(MCP-1), CXCL10(IP-10) and MPO were analyzed using multiplex bead assay (Milliplex® MAP kits, EMD Millipore Corporation, St. Charles, Missouri, USA) according to the manufacturers instructions, except that an additional lower standard point was added to the standard curve. The measurements were performed using Luminex ${ }^{\circledR} 200^{\mathrm{TM}}$ (Invitrogen, Merelbeke, Belgium). For data acquisition the software program xPONENT 3.1 ${ }^{\mathrm{TM}}$ (Luminex Corporation, Austin, Texas, USA) was used, and for data analysis MasterPlex® Reader Fit was used. HBP was measured by ELISA (Axis-Shield Diagnostics, Dundee, UK) according to the instructions 
by the manufacturer, the detection limit was $5.9 \mathrm{ng} / \mathrm{ml}$ with Luminex ${ }^{\circledR 200}{ }^{\mathrm{TM}}$ (Invitrogen, Merelbeke, Belgium).

Neutrophil gelatin-associated lipocalin (N-GAL) and procalcitonin (PCT) were performed by the Department of clinical chemistry, University Hospital, Linköping.

Analysis of complement component $\mathrm{C}_{3}$, the complement activation products $\mathrm{C}_{3 \mathrm{a}}, \mathrm{sC} 5 \mathrm{~b}-9$ and thrombospondin (TSP)-1 were performed at the Linnæus Centre for Biomaterials Chemistry, Linnæus University, Kalmar Hospital using ELISA.

All other chemical analysis was performed at the Department of Clinical Chemistry, Blekinge hospital, Karlskrona, Sweden.

\section{Platelet function testing}

Platelet aggregation was measured in study I, II and III by the author using the Multiplate device (Dynabyte $\mathrm{GmbH}$, München, Germany) according to the specifications of the manufacturer. This technique is based on measuring the increase in impedance between two electrodes as stimulated platelets adhere and aggregate on the electrode surfaces ${ }^{132}$.

The test gives reliable results when platelet count is above $100 \times 10^{9} \mathrm{~L}^{133}$. All samples for platelet function analysis were drawn from an arterial cannula into hirudin test tubes as specified by the manufacturer.

After a stabilization period of minimum 30 minutes $300 \mu \mathrm{L}$ of whole blood was mixed with $300 \mu \mathrm{L}$ saline and incubated at 37 degrees Celsius for 3 minutes. The platelets were activated with adenosine diphosphate (ADP-test), thrombin receptor activating peptide-6 (TRAP-test), arachidonic acid (ASPI-test) and collagen (COL-test).

Electrical impedance was registered for 6 minutes. In study I the total aggregation is presented as arbitrary units (AU). In study II and III the aggregation is presented as units of aggregation (U). AU corresponds to $10 \mathrm{x}$ U. In all studies the samples were analyzed within 3 hours as recommended by the manufacturer. In study II and III all samples were analyzed within 1.5 hours.

\section{Blood loss}

In study I - III blood loss during surgery was registered as blood volume in suction bottles and swabs. Swabs were weighed in study II and III. The blood from the cardiotomy suction blood was not taken into account.

In study I postoperative blood loss was measured as bleeding through chest tubes at three hours, twelve hours and at removal of chest tubes.

In study II we measured blood loss in two intervals during surgery, from start of operation until end of $\mathrm{CPB}$ and from end of CPB until end of surgery. Blood loss through chest tubes were measured three hours after surgery.

In study III we measured postoperative blood loos through chest tubes at four hours after surgery. 


\section{Statistical analysis}

Statistical significance was defined as $\mathrm{p}<0.05$. Statistical calculations were made with IBM SPSS statistics v23 (New York, USA) and Statistica 12 (Tulsa, OK, USA).

\section{Study I}

Results are presented as mean \pm SD unless stated otherwise, and parametric tests were used. Normality was tested with the Kolmogorov-Smirnov test. Paired t-test was used in the in vivo samples. ANOVA with repeated measures, followed by Tukey's test was used to evaluate differences between the samples in the in vitro procedure. Linear regression was used to evaluate the correlation between variables. Power analysis indicated a power $>0.90$ for detecting a $25 \%$ reduction of aggregation with an alpha error of 0.05 at $n=25$.

\section{Study II}

Normality was tested with the Kolmogorov-Smirnov test. Normally distributed data are presented as mean $\pm \mathrm{SD}$ and were evaluated with repeated measures ANOVA followed by Bonferroni correction. Platelet aggregometry was not normally distributed and is presented as median values with $25-75$ quartiles, and assessed with Friedmans ANOVA followed by Wilcoxon signed rank-test with Bonferroni correction. Spearman non-parametric correlation was used to evaluate correlation between platelet aggregation and blood loss. Simple regression was used to calculate the relation between platelet aggregation and platelet count. Platelet levels after CPB were corrected for hemodilution using hemoglobin as a marker. Patients who received blood transfusion during surgery were excluded from the calculation.

Power analysis indicated a $85 \%$ power for detecting a reduction of platelet aggregation of $50 \%$ based on our previous study.

\section{Study III}

Results are presented as median values with 25 - 75 quartiles. Mann-Whitney's U-test was used to evaluate differences between the groups. Friedmans ANOVA followed by Wilcoxon match-pair signed rank-test with Bonferroni correction was used within the groups.

Hemostatic parameters that decreased during CPB (platelets, fibrinogen, antithrombin III, TAT and PAP) were corrected for hemodilution using the baseline hemoglobin as a marker. Patients who received blood transfusion during surgery were excluded from the calculation. 


\section{Study IV}

Results are presented as median values with 25 - 75 quartiles unless stated otherwise. Nonparametric tests were used to evaluate the variables. Friedmans ANOVA followed with Wilcoxon signed rank-test with Bonferroni correction was used to evaluate the difference within the groups. Mann-Whitney's U-test was used to evaluate the difference between groups. Fisher's exact test was used to evaluate the blood cultures. Correlations between variables were assessed using Spearman's correlation coefficient.

\section{Combined results from study I, II and III}

Results are presented as median values with $25-75$ quartiles. Non-parametric tests were used to evaluate the variables. Mann-Whitney U-test was used to evaluate the difference between the groups. Platelet aggregation results in AU from study I were recalculated to $U$ by dividing them by 10 . Blood loss was calculated by the hour by dividing the amount of bleeding by the number of hours measured. Spearman non-parametric correlation was used to evaluate correlation between platelet aggregation and blood loss.

\section{Ethical considerations}

All studies were approved by the ethical review board in Linköping, Sweden (Paper I; Dnr M63-09, Paper II; Dnr 2013/455-31 and Paper III and IV; Dnr 2011/322-31) and was performed in agreement with the Helsinki declaration. All patients gave their written consent to participate in the study they were informed and asked about.

All the collected material in the thesis, data and blood samples, were coded with a number that only can be identified through an identification log. Only the investigators have access to the identification log and the data will be stored for 10 years. The samples in study I and II were destroyed after performed analyze. Plasma, obtained after centrifugation, in study III and IV were frozen and stored according to the biobank act and samples were destroyed after analysis.

It is common practice to retransfuse the residual blood after weaning from $\mathrm{CPB}^{23}$ and it is considered to reduce the need for blood transfusion. There are different techniques to do this, where emptying the heart-lung machine and collect the blood in an infusion bag appears to be the most common (IB technique). In Swedish cardio thoracic centers a large number of patients receive the residual pump blood by chasing it in with Ringers acetate through the heart-lung machine, the RCtechnique although the IB technique appears to be more common in other countries ${ }^{23}$.

No evaluation of the RC technique has previous been done. It is therefore not known if the quality of the blood is different depending on if the blood is returned by the IB or the RC technique. In this thesis, we have evaluated hemostatic and inflammatory parameters in the residual pump blood, based on what retransfusion technique that was used. To be randomized to IB or RC does not seem to constitute an ethical problem, since both techniques are accepted in the clinical practice in Sweden and neither has been shown to carry a greater risk. 
Hemostatic function and inflammatory activation after weaning from cardiopulmonary bypass 


\section{RESULTS}

\section{Study I}

Patient characteristics and procedural data are presented in table 1.

Table 1. Patient characteristics $(n=25)$, mean \pm SD or $n(\%)$

\begin{tabular}{lc}
\hline Age, years & $68 \pm 9.6$ \\
Male/female & $17 / 8(68 / 32)$ \\
Weight $(\mathrm{kg})$ & $81.6 \pm 16.7$ \\
Height $(\mathrm{cm})$ & $171 \pm 8.7$ \\
Operative time (min) & $198 \pm 57$ \\
CBP time (min) & $106 \pm 57$ \\
AVR & $9(36)$ \\
CABG & $9(36)$ \\
Combined CABG and AVR & $3(12)$ \\
MVR & $4(16)$ \\
\hline Table 1. Values are expressed as means \pm SD or n (\%). MI = myocardial \\
infarction, CPB = cardiopulmonary bypass, AVR = Aortic valve replacement, \\
CABG = Coronary artery bypass grafting, MVR = Mitral valve replacement
\end{tabular}

There was a marked decrease in platelet aggregation after in vivo protaminisation, when compared to levels immediately before giving protamine (Figure 8). A mean reduction in aggregation of $50 \%$ or more was seen with all activators $(\mathrm{p}<0.001)$.

The aggregometry results of the in vitro heparin and protamine treatment are shown in Figure 9. There was no reduction of platelet aggregation after in vitro addition of heparin except for a slight decrease with arachidonic acid activation (ASPI-test) $(\mathrm{p}<0.01)$. With protamine, platelet aggregation was significantly reduced with adenosine diphosphate activation (ADP-test) $(p<0.001)$ and ASPI-test $(\mathrm{p}<0.01)$. With the combination heparin and protamine in vitro the same effect was seen for ADPtest $(\mathrm{p}<0.001)$, ASPI-test $(\mathrm{p}<0.001)$ and collagen activation (COL-test, $\mathrm{p}<0.05)$. Thrombin receptor activation (TRAP-test) did not significantly change after addition of heparin or protamine. There was no difference in aggregation between the samples with protamine alone and samples with the combination of heparin and protamine with any of the activators $(\mathrm{p}=0.5-0.8)$.

The total dose of heparin given pre-bypass (prime and bolus dose) was $34680 \pm 4843 \mathrm{U}$, and additional $4380 \pm 4475 \mathrm{U}$ were given during bypass. The total dose of protamine given was $402 \pm 72$ $\mathrm{mg}$. The ratio of total protamine to pre-bypass heparin was $1.16 \pm 0.15$. Activated clotting time 
(ACT) before CPB was $436 \pm 37$ and after CPB $112 \pm 13$. Neither absolute dose of protamine given, nor the relative amount of protamine (the protamine/heparin ratio), did correlate to the reduction in aggregometry values or the values found after protaminisation, regardless of activator.
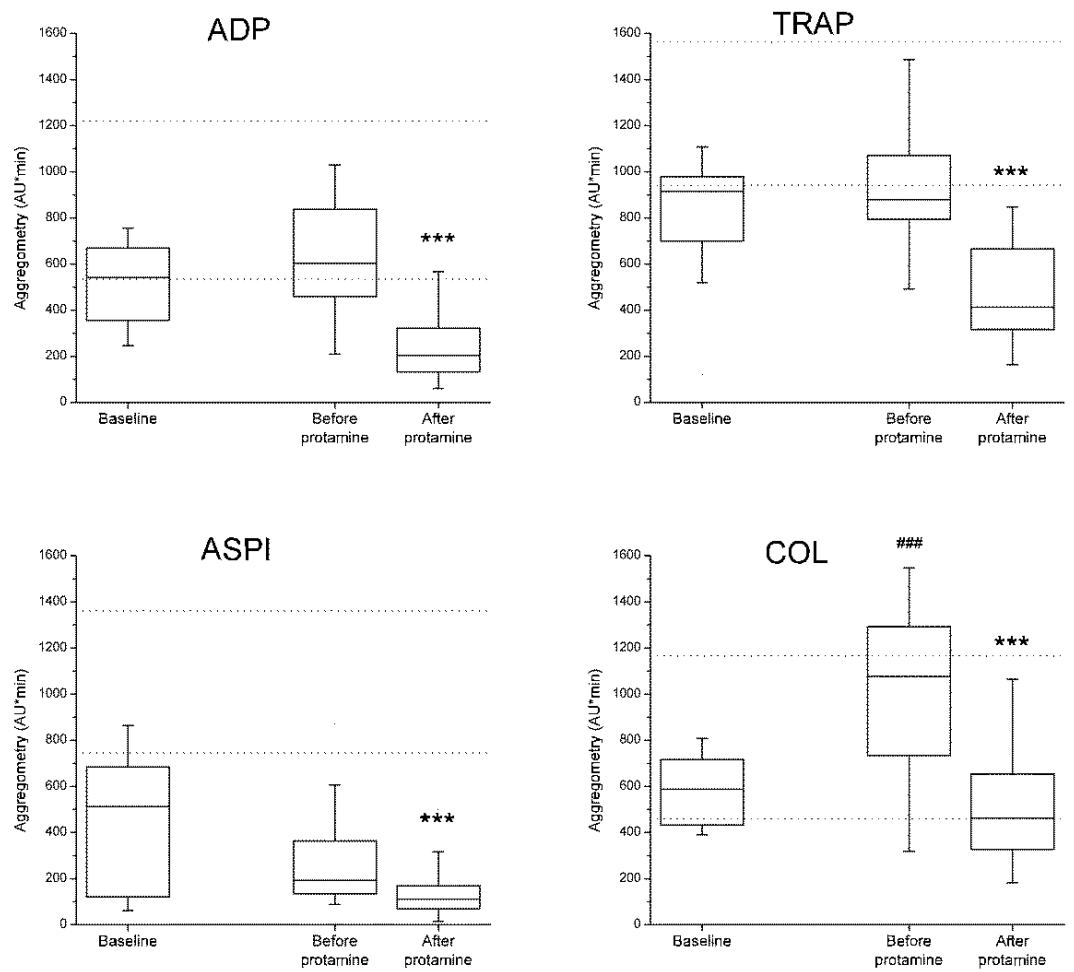

Figure 8. Platelet aggregation during in vivo protaminisation when activated with adenosine phosphate (ADP), thrombin receptor activating peptide-6 (TRAP), arachidonic acid (ASPI-test) and collagen (COL). Baseline is sample taken before surgery, before protamine is after cardiopulmonary bypass before protaminisation, and after protamine is $5 \mathrm{~min}$ after protaminisation. The box indicates $25-75 \%$ quartiles with the line as median and the whiskers total range. Dotted lines indicate normal range, $* * *$ denotes $\mathrm{p}<0.001$ as compared to before protamine, and \#\#\# denotes $\mathrm{p}<0.001$ as compared to baseline.

The mean blood loss $(\mathrm{ml})$ during operation was $854 \pm 366$, after 3 hours $290 \pm 166$ and at 12 hours after surgery $498 \pm 234$. The total postoperative blood loss through chest tubes was $758 \pm 317 \mathrm{ml}$. Postoperative blood loss at 3 hours and at 12 hours showed a negative correlation to aggregometry values after protaminisation with the COL-test $\left(b=-0.28, \mathrm{r}^{2}=0.16, \mathrm{p}<0.05\right.$ for bleeding at $3 \mathrm{~h}$; and $\mathrm{b}=$ $-0.46, \mathrm{r}^{2}=0.21, \mathrm{p}<0.05$ at $12 \mathrm{~h}$ ), while the other activators did not show any correlation. Linear regression also showed a negative correlation between postoperative blood loss at 3 hours and 
preoperative aggregometry values with ADP-test $\left(b=-0.37, \mathrm{r}^{2}=0.44, \mathrm{p}<0.01\right)$; TRAP-test $(\mathrm{b}=-0.21$, $\left.\mathrm{r}^{2}=0.36, \mathrm{p}<0.05\right)$; ASPI-test $\left(\mathrm{b}=-0.17, \mathrm{r}^{2}=0.28, \mathrm{p}<0.05\right)$ and COL-test $\left(\mathrm{b}=-0.46, \mathrm{r}^{2}=0.56, \mathrm{p}<0.01\right)$. Similarly, postoperative blood loss at 12 hours also correlated to preoperative aggregometry with ADP-test $\left(b=-0.66, r^{2}=0.43, p<0.01\right)$; TRAP-test $\left(b=-0.39, r^{2}=0.37, p<0.05\right)$ and COL-test $(b=-$ $\left.0.66, \mathrm{r}^{2}=0.36, \mathrm{p}<0.05\right)$.
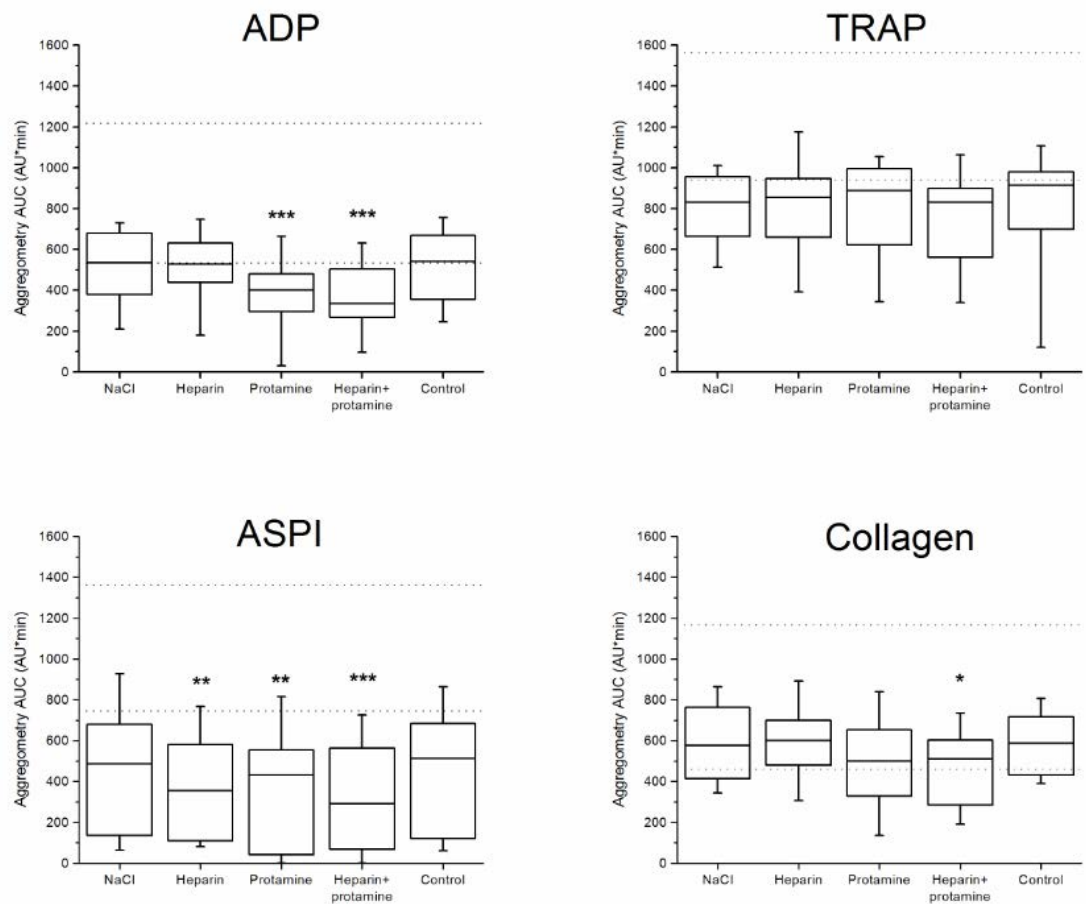

Figure 9. Platelet aggregation in the in vitro tests after activation with adenosine phosphate (ADP), thrombin receptor activating peptide-6 (TRAP), arachidonic acid (ASPI-test) and collagen after addition of equal volumes of $\mathrm{NaCl}$, heparin, protamine and heparin+protamine with final concentration of $3.7 \mathrm{U} / \mathrm{ml}$ and protamine $37 \mu \mathrm{g} / \mathrm{ml}$. Control is undiluted blood sample. The box indicates $25-75 \%$ quartiles with the line as median and the whiskers total range. Dotted lines indicate normal range, * denotes $\mathrm{p}<0.05, * *$ denotes $\mathrm{p}<0.01$ and $* * *$ denotes $\mathrm{p}<0.001$ as compared to $\mathrm{NaCl}$-diluted sample. 


\section{Study II}

The clinical characteristics of the patients and intraoperative data are shown in table 2.

Table 2. Clinical characteristics $(n=30)$, mean \pm SD or $n(\%)$

Age (years)

Gender, male/female

$\operatorname{BMI}\left(\mathrm{kg} / \mathrm{m}^{2}\right)$

CPB time (min)

Aortic cross clamp time (min)

Operation;

\section{CABG}

AVR

Combined CABG and AVR

Total blood loss during surgery $(\mathrm{ml})$

$$
\begin{aligned}
& \text { From start of surgery - end of CPB } \\
& \text { From end of CPB - end of surgery }
\end{aligned}
$$

Postoperative blood loss 3 hours after surgery

Number of patients with red blood cell transfusion during surgery

Number of patients with red blood cell transfusion within 3 hours after surgery

Table 2. Values are presented as mean $\pm \mathrm{SD}$ or number (\%), blood loss is presented as median (25- 75 quartiles), $\mathrm{BMI}=$ body mass index, $\mathrm{CPB}$ time $=$ cardio pulmonary bypass time, $\mathrm{CABG}=$ coronary artery bypass grafting, $\mathrm{AVR}=$ aortic valve replacement

The aggregometry results are presented in table 2 . All baseline levels were within or above the reference values (U) in the ADP-test and TRAP-test. Most patients had baseline values below normal range with the ASPI- test. With the collagen test half of the patients had levels below the normal reference range. The samples taken before protamine did not differ significantly from baseline with any of the activators. When $70 \%$ of the calculated protamine dose was given, platelet aggregation decreased markedly compared to before protamine with all activators, ADP and TRAP (both $\mathrm{p}=0.00)$, ASPI $(\mathrm{p}=0.01)$ and collagen $(\mathrm{p}=0.02)$. 
When the remaining $30 \%$ of the calculated protamine dose was given, no further decrease in aggregation was seen with activators TRAP, ASPI or COL. On the contrary a slight increase in aggregation with the ADP-test compared to the sample taken at $70 \%$ was observed $(p=0.04)$. There was no correlation between the doses of protamine (70 or 100\%) and the decrease in platelet aggregation.

Twenty minutes after full protamine administration, platelet aggregation had started to recover compared to nadir after the initial dose $(70 \%)$ of protamine, with ADP $(\mathrm{p}=0.00)$ and TRAP $(\mathrm{p}=0.01)$. ASPI and collagen stimulated aggregation also increased, but the rise did not reach significance.

On arrival in the ICU TRAP and collagen tests had reached baseline levels, while ADP and ASPI tests remained lower than baseline (both $\mathrm{p}=0.01$ ).

The hemoglobin concentration decreased from $136 \pm 18 \mathrm{~g} / \mathrm{L}$ at baseline to $107 \pm 10 \mathrm{~g} / \mathrm{L}$ after CPB and was $109 \pm 12 \mathrm{~g} / \mathrm{L}$ on arrival in the ICU (both $\mathrm{p}=0.00$ compared to baseline) (table 3 ).

The leukocytes increased during CPB compared to baseline $\left(8.5 \pm 1.9 \times 109 \mathrm{~L}\right.$ to $15.0 \pm 5 \times 10^{9} / \mathrm{L}$, $\mathrm{p}<0.05)$ and were still higher than baseline on arrival in the ICU, $13.8 \pm 4.7 \times 10^{9} / \mathrm{L} \mathrm{p}<0.01$. The platelet count was reduced from $258 \pm 83 \times 10^{9} / \mathrm{L}$ preoperatively to $203 \pm 53$ before protamine, $p=0.00$. When $70 \%$ of the protamine was administered, the platelet count was $159 \pm 37$ and after full dose of protamine $162 \pm 39 \times 10^{9} / \mathrm{L}$. On arrival in the ICU the platelet level had increased to $193 \pm$ $62 \times 10^{9} / \mathrm{L}$ but was still significantly lower than baseline (table 3 ).

The hemodilution during $\mathrm{CPB}$ resulted in a lower platelet count. To evaluate if the aggregometry results could be related to platelet concentration a regression analysis was done. Platelet aggregation was significantly related to platelet count $\left(b=0.3 ; r^{2}=0.38 ; p<0.001\right)$. From this result an expected theoretical reduction of ADP aggregation after protamine in relation to the reduction in platelet count was calculated. The expected decrease of the ADP-test after $70 \%$ of protamine due to lower platelet concentration was $17 \mathrm{U}(27-5)$. However, the actual decrease in platelet aggregation with the ADPtest was $37 \mathrm{U}(47-20)$ after $70 \%$ of protamine. The difference between calculated and actual reduction of aggregometry values was significant $(\mathrm{p}<0.02)$.

When the platelet level had been corrected for hemodilution the platelet count (x 109 $\mathrm{L})$ was $276 \pm$ 76 before protamine, $211 \pm 60$ after $70 \%$ protamine and $216 \pm 59$ after $100 \%$.

\section{Heparin and protamine}

The total dose of heparin, given before CPB, was $31433 \pm 6643$ (mean \pm SD) U and $3500 \pm 5153 \mathrm{U}$ as additional doses during bypass. $70 \%$ of the calculated dose protamine was $219 \pm 47 \mathrm{mg}$, with a protamine - heparin ratio of $0.7: 1 \pm 0.02$. The total dose of protamine given was $312 \pm 64 \mathrm{mg}$ with a ratio of $1: 1 \pm 0.03$ ( $1 \mathrm{mg}$ protamine/100 $\mathrm{U}$ heparin). No additional dose of protamine was given.

ACT before start of CPB was $559 \pm 107 \mathrm{~s}$, the last ACT measured during bypass before weaning was $488 \pm 63 \mathrm{~s}$. ACT after $70 \%$ of the calculated protamine dose was $118 \pm 10 \mathrm{~s}$ and subsequently, after the complete $100 \%$ dose, the ACT was $118 \pm 9 \mathrm{~s}$. 


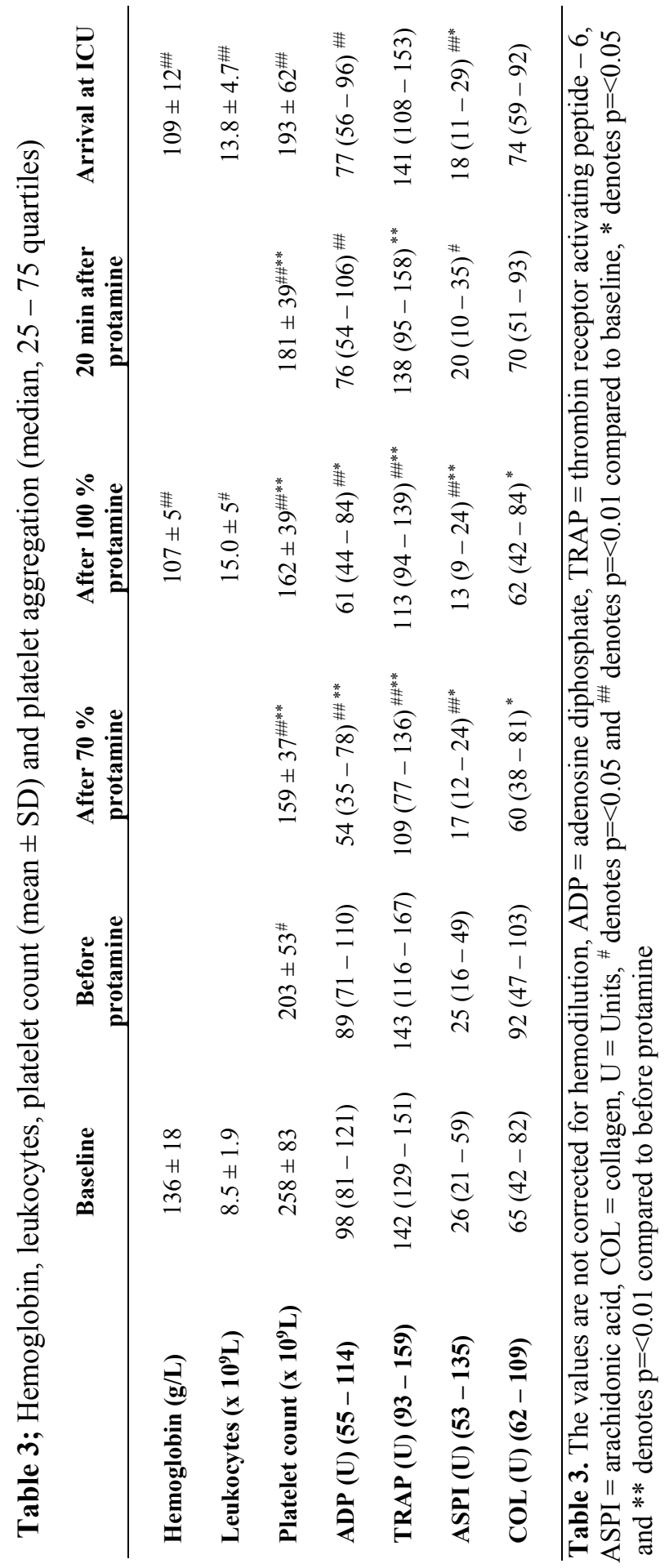




\section{Blood loss and blood transfusion}

The median total blood loss during surgery and postoperatively are shown in table 2 .

Total blood loss during surgery correlated to platelet aggregation before surgery with ADP and collagen tests, both $\mathrm{R}=-0.40, \mathrm{p}=0.03$. Total blood loss during surgery also correlated to aggregometry after $70 \%$ of protamine $(A D P R=-0.425, p<0.05$; ASPI $R=-0.428, p<0.05)$, after 100 $\%$ protamine $(\mathrm{ADP} R=-0.463, \mathrm{p}=0.01$ ) and 20 minutes after full protamine dose; ADP $\mathrm{R}=-0.365$ $\mathrm{p}<0.05$. Blood loss from start of surgery until end of CPB correlated to platelet aggregometry at baseline with TRAP $(\mathrm{R}=-0.465, \mathrm{p}=0.01)$, ASPI $(\mathrm{R}=-0.369, \mathrm{p}<0.05)$, and collagen test $(\mathrm{R}=-0.530$, $\mathrm{p}<0.01)$. There was no correlation between postoperative bleeding and aggregometry results at baseline or before and after protamine with any activator.

Seven patients were transfused with erythrocytes during surgery and one of those patients also received erythrocytes in the ICU within three hours (table 2). 


\section{Study III and IV}

Clinical characteristics for the patients in study III and IV are presented in table 4.

Table 4. Clinical characteristics

\begin{tabular}{lccc}
\hline Variable & $\begin{array}{c}\text { RC } \\
(\mathbf{n}=\mathbf{2 0})\end{array}$ & $\begin{array}{c}\text { IB } \\
(\mathbf{n}=\mathbf{2 0})\end{array}$ & p-value \\
\hline Sex (Male/Female) & $17 / 3$ & $17 / 3$ & 1.0 \\
Age (years) & $73(66-77)$ & $71(65-75)$ & 0.31 \\
BMI $\left(\mathrm{kg} / \mathrm{m}^{2}\right)$ & $26.4(25.1-30.1)$ & $26.7(24.6-30.3)$ & 0.88 \\
& & & \\
Diabetic & 5 & 4 & 0.80 \\
Myocardial infarction & 5 & 8 & 0.43 \\
Previous PCI/CABG & 2 & 4 & 0.60 \\
Hypertension & 8 & 5 & 0.43 \\
Smoker & 2 & 19 & 0.21 \\
Treatment with Aspirin & 20 & & 0.80 \\
& & & \\
Total Heparin dose (U/kg) & $427(381-532)$ & $453(411-553)$ & 0.33 \\
CPB time (min) & $88(72-105)$ & $3(67-106)$ & 0.88 \\
Aortic cross-clamp time (min) & $47(34-55)$ & $2(1-4)$ & 0.99 \\
Distal anastomoses & $3(3-4)$ & & 0.70 \\
Proximal anastomoses & $2(1-2)$ & $750(605-965)$ & 0.66 \\
& & $323(236-418)$ & 0.38 \\
Blood loss during operation (ml) & $645(250-1055)$ & $178(122-268)$ & 0.72 \\
Blood loss four hours after surgery (ml) & $258(201-395)$ & 2 & 0.58 \\
Ventilator time (min) & $158(120-324)$ & & \\
Number of patients with red blood cell & 4 & & \\
transfusion within 4 hours after surgery & & & \\
\hline
\end{tabular}

Table 4. Values are presented in numbers or as median ( $25-75$ percentiles). BMI $=$ Body Mass Index, $\mathrm{PCI}=$ Percutaneous Coronary Intervention, $\mathrm{CABG}=$ Coronary Artery Bypass Grafting, $\mathrm{CPB}=$ Cardio Pulmonary Bypass, $\min =$ minutes, $\mathrm{RC}=$ Ringer chase, $\mathrm{IB}=$ Infusion bag

Hematology and kidney function in the patient (Study III and IV)

Hemoglobin and platelet count decreased during CPB and were still significantly lower four hours after surgery in comparison to baseline (Table 5). Leukocytes nearly doubled during CPB and were still elevated four hours after surgery (Table 5 and Figure 13).

Hematology in the retransfused blood (Study III and IV)

No difference was seen in hemoglobin, platelets or leukocytes between the IB or RC blood but when comparing the hemoglobin concentration during $\mathrm{CPB}$ with the retransfused blood, there was a significant decrease in the IB but not in the RC blood (IB from 95 (85-105) to 87 (80-97), $\mathrm{p}<0.01$; $\mathrm{RC}$ from 98 (88-102) to 93 (83-101), $\mathrm{p}=0.08)$. 


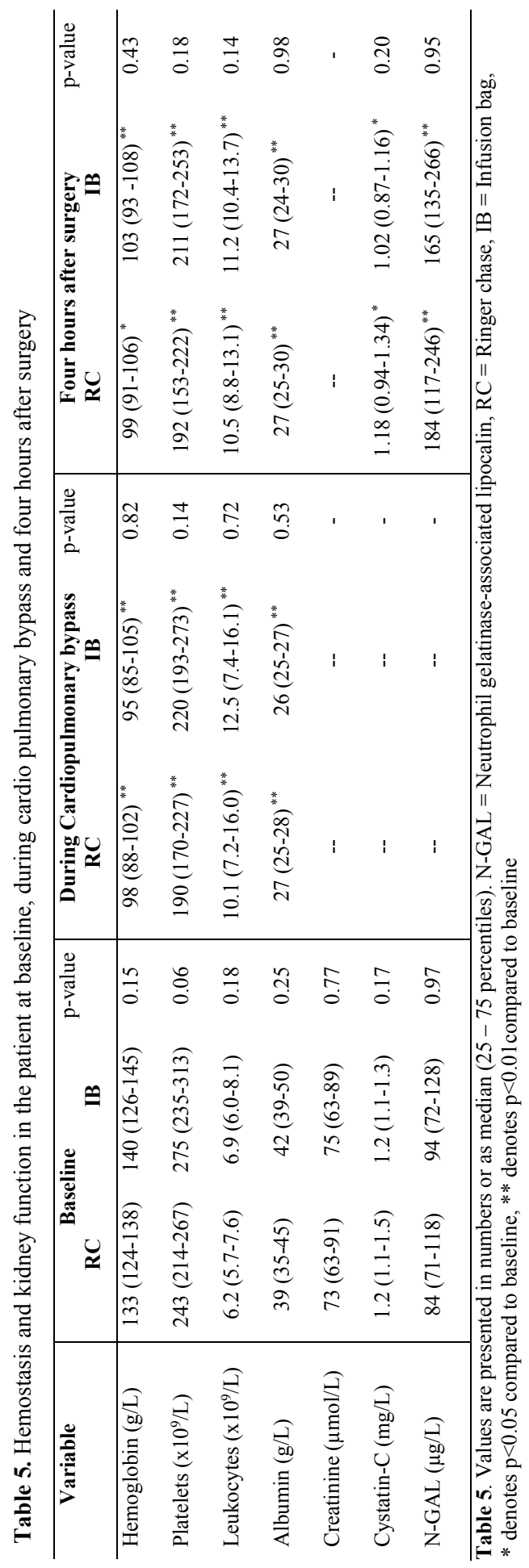


Hemostatic and fibrinolytic activity in the patient (Study III)

Platelet aggregation did not change during CPB except with collagen stimulation where there was increased aggregation at the end of $\mathrm{CPB}, \mathrm{p}=0.001$. (Figure 10).

Fibrinogen and antithrombin III (AT III) decreased significantly during bypass whereas D-dimer was stable and soluble fibrin increased (figure 12). Soluble P-selectin decreased during CPB compared to baseline, whereas the levels of GPVI increased (figure 11). Levels of PAP complexes did not differ significantly from baseline. TAT complexes decreased compared to baseline (Table 6).

After correcting for hemodilution using hemoglobin as a marker, the platelet levels were higher compared to baseline $\left(290(252-352) \times 10^{9} / \mathrm{L}\right)$. Fibrinogen levels corrected for hemodilution were lower than baseline, but still within normal range $(2.5(2.3-3.1) \mathrm{g} / \mathrm{L})$. The decrease of fibrinogen during CPB was significant both before and after correction for hemodilution, both $\mathrm{p}<0.01$.

When the ATIII (kIE/L) was corrected for hemodilution the reduction was still significant compared to baseline $(0.86(0.79-0.93), \mathrm{p}=0.00)$. TAT and PAP corrected for hemodilution also increased compared to baseline TAT $4.2(3.2-6.5) \mu \mathrm{g} / \mathrm{L}, \mathrm{p}<0.05$; PAP 35 (28-52) ng/L, p=0.00.

No differences regarding laboratory values were observed in the groups four hours after surgery, except for a significantly higher APTT in the RC-group (Table 6). Platelet levels were significantly lower than baseline, but platelet aggregation had risen slightly above the baseline values in both groups (Table 6).

Soluble P-selectin and GPVI levels were higher than baseline (Table 6), while TAT levels decreased four hours after surgery (to about $30 \%$ of baseline). PAP levels were about 15 times higher than baseline (Table 6). 


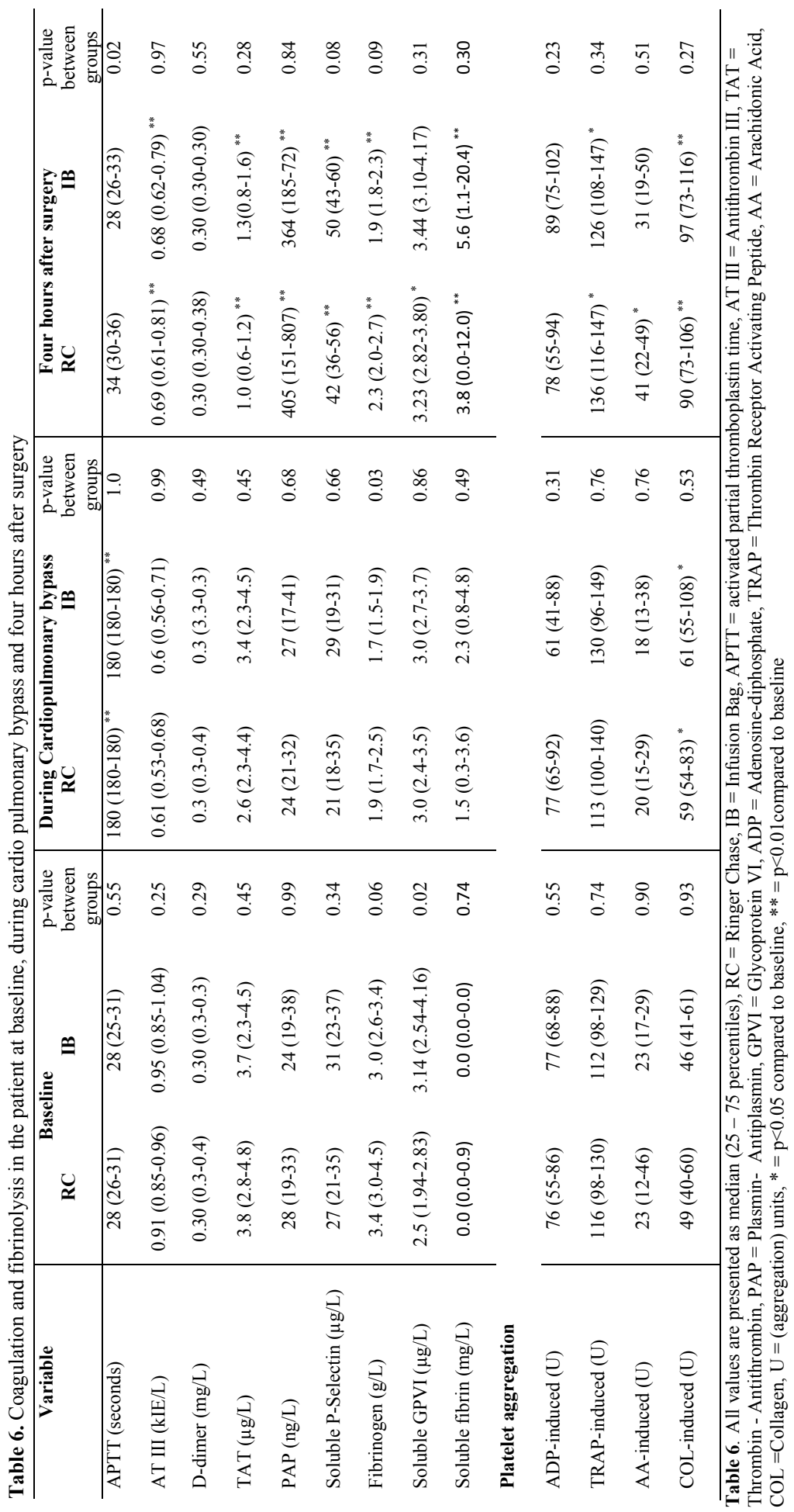


Hemostatic and fibrinolytic activity in the retransfused pump blood (Study III)

A decrease in platelet aggregation was seen in the retransfused blood in both groups and with all activators (ADP, TRAP, AA and collagen) as demonstrated in Figure 10. A significantly lower platelet aggregation was found in the IB blood compared to the RC blood when activated with ADPTRAP and collagen (Figure 10).
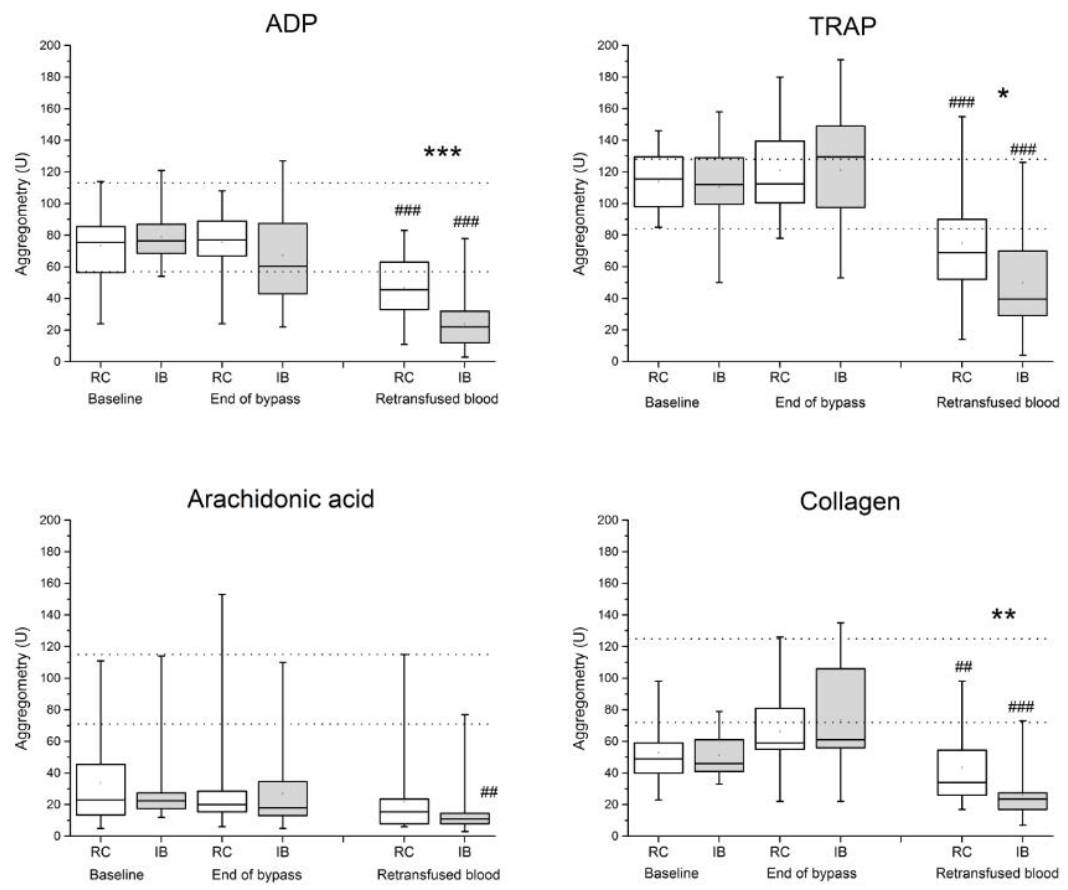

Figure 10. Box-plots (25-75\% quartiles with the line as median and the whiskers total range) for platelet aggregation at baseline, at the end of bypass and in the retransfused blood. Clear boxes are Ringer chase technique (RC), shaded boxes infusion bag (IB). * denotes $\mathrm{p}<0.05, * * \mathrm{p}<0.01$ and $* * * \mathrm{p}<0.001$ between groups, \# denotes $\mathrm{p}<0,05$, \#\# $\mathrm{p}<0.01$ and \#\#\# $\mathrm{p}<0.001$ compared to end of bypass.

Soluble P-selectin was higher in the retransfused blood in both groups, but there was no difference between the IB and RC blood. Soluble GPVI in the retransfused blood tended to be higher in the IB group compared to the RC group (Figure 11) and was significantly increased in retransfused blood compared to patient blood before weaning with IB but not with RC. 

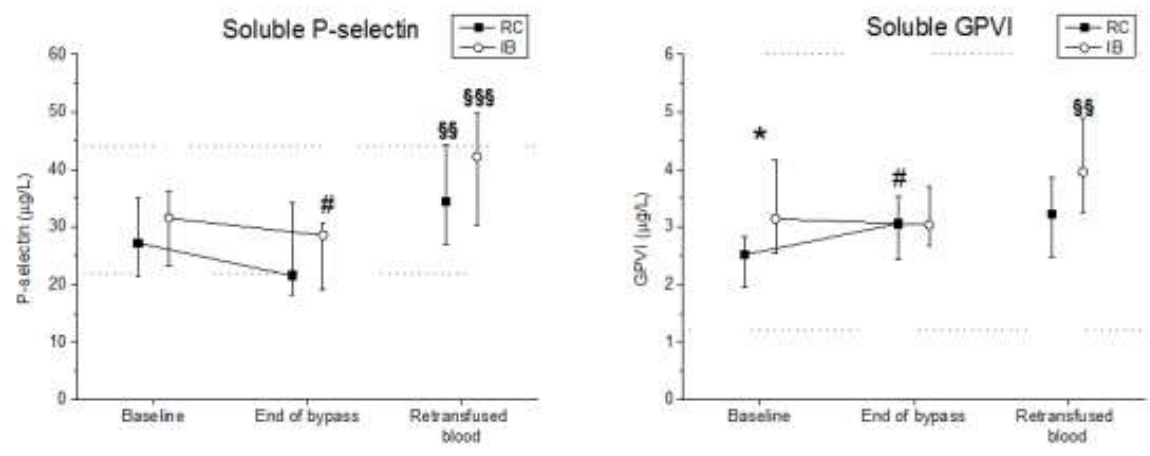

Figure 11. P-selectin and glycoprotein VI (GPVI) at baseline, at the end of cardiopulmonary bypass and in the retransfused blood (median and IQR). RC is Ringer chase technique, IB is infusion bag. * denotes $\mathrm{p}<0.05$ between groups, \# denotes $\mathrm{p}<0.05$ vs baseline; $\S \S$ is $\mathrm{p}<0.01$ and $\S \S \S \mathrm{p}<0.001$ compared to end of bypass.

Soluble fibrin and D-dimer were higher in the retransfused IB blood compared to during bypass, and significantly higher in the IB than in the RC blood. Levels of ATIII and fibrinogen were no different compared to during CPB (Figure 12). The level of free hemoglobin $(\mathrm{mg} / \mathrm{L})$ was almost double in IB compared to RC blood (IB 1085 (891-1716); RC 591 (517-646), $\mathrm{p}<0.001)$.

PAP and TAT was markedly increased in retransfused blood compared to during CPB but there were no differences between the two groups. TAT $(\mu \mathrm{g} / \mathrm{L})$ IB 9.8 (7.2-11.7), $\mathrm{p}=0.00$ compared to CPB; RC 8.0 (6.2-11.8), $\mathrm{p}=0.00$ compared to $\mathrm{CPB}, \mathrm{p}=0.30$ between the groups. PAP (ng/L) IB 46 (34-63), $\mathrm{p}=0.00$ compared to $\mathrm{CPB}$; $\mathrm{RC} 42(35-49), \mathrm{p}=0.00$ compared to baseline, $\mathrm{p}=0.48$ between the groups

\section{Heparin and protamine (Study III)}

There was no difference in heparin administration U/kg before CPB (IB 363 (351-414) vs. RC 368 (357-393), $\mathrm{p}=0.65)$ or in additional doses heparin during CPB (IB $5000 \mathrm{U}(0-7500)$; RC 5000 (09375), $\mathrm{p}=0.62)$. The ratio of protamine to heparin was higher in the IB group (1.3:1 (0.9:1 - 1.5:1)) than in the RC group (1.0:1 (0.9:1 -1.2:1) ( $\mathrm{p}=0.01)$, with 4.8 (4.1-5.5) $\mathrm{mg}$ protamine $/ \mathrm{kg}$ with IB compared to $4.0(3.7-4.5) \mathrm{mg}$ protamine $/ \mathrm{kg}$ with $\mathrm{RC}$. The main dose of protamine was similar in the two groups (IB $325 \mathrm{mg}(262-350)$; RC $350 \mathrm{mg}(300-350), \mathrm{p}=0.39)$ but the amount of additional protamine given after CPB was significantly higher in the IB group with a median of $50 \mathrm{mg}(50-$ $100)$. None of the patients in the RC group received additional doses of protamine.

\section{Blood loss and erythrocyte transfusion (Study III)}

There was no difference between the groups in blood loss during operation or four hours after surgery. Blood loss and transfusion of erythrocytes within four hours are presented in table 4 . 

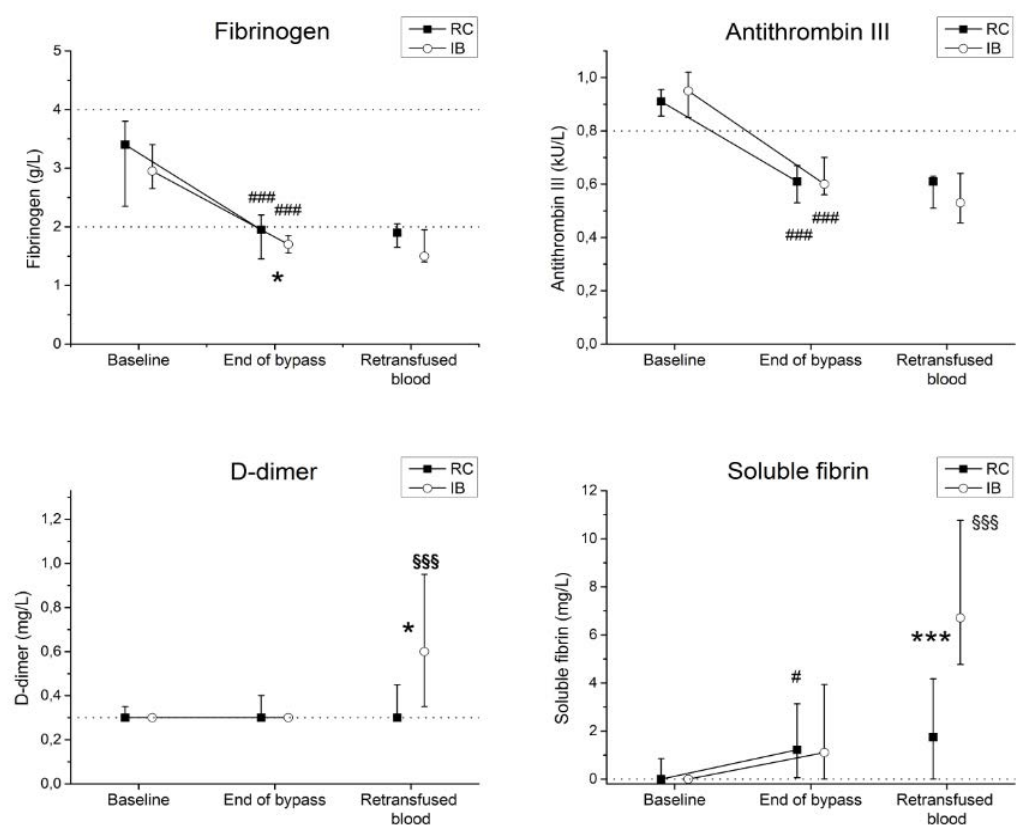

Figure 12. Fibrinogen, antithrombin III, D-dimer and soluble fibrin at baseline, at the end of bypass and in the retransfused blood (median and IQR). RC is Ringer chase technique, IB is infusion bag. * denotes $\mathrm{p}<0.05$ and $* * * \mathrm{p}<0.001$ between groups, \# denotes $\mathrm{p}<0,05$ and \#\#\# $\mathrm{p}<0.001$ compared to baseline, and $\S \S \S \mathrm{p}<0.001$ compared to end of bypass.

\section{Inflammatory activity in response to surgery and CPB (Study IV)}

The inflammatory response in the patients followed the same pattern in both groups with no statistical differences during CPB or four hours after surgery between the groups. The median values and $25-75$ percentiles in the groups are presented in table 7.

There was a marked activation of the complement system with decreasing $\mathrm{C} 3$ levels, followed by a marked increase of $\mathrm{C} 3 \mathrm{a}$ and $\mathrm{sC} 5 \mathrm{~b}-9$. The $\mathrm{C} 3$ level continued to decrease slightly after surgery whereas $\mathrm{C} 3 \mathrm{a}$ and $\mathrm{sC} 5 \mathrm{~b}-9$ was markedly reduced. $\mathrm{sC} 5 \mathrm{~b}-9$ had nearly reached the baseline level four hours after surgery (Figure 13).

IL-6 and CXCL8(IL-8) increased almost 20 times during CPB, compared to baseline. IL-6 continued to increase after surgery, and was 40 times higher than baseline four hours after surgery. CXCL8(IL8) decreased somewhat after CPB but where still elevated four hours after surgery. TNF doubled during CPB and continued to increase after surgery (Figure 13). 

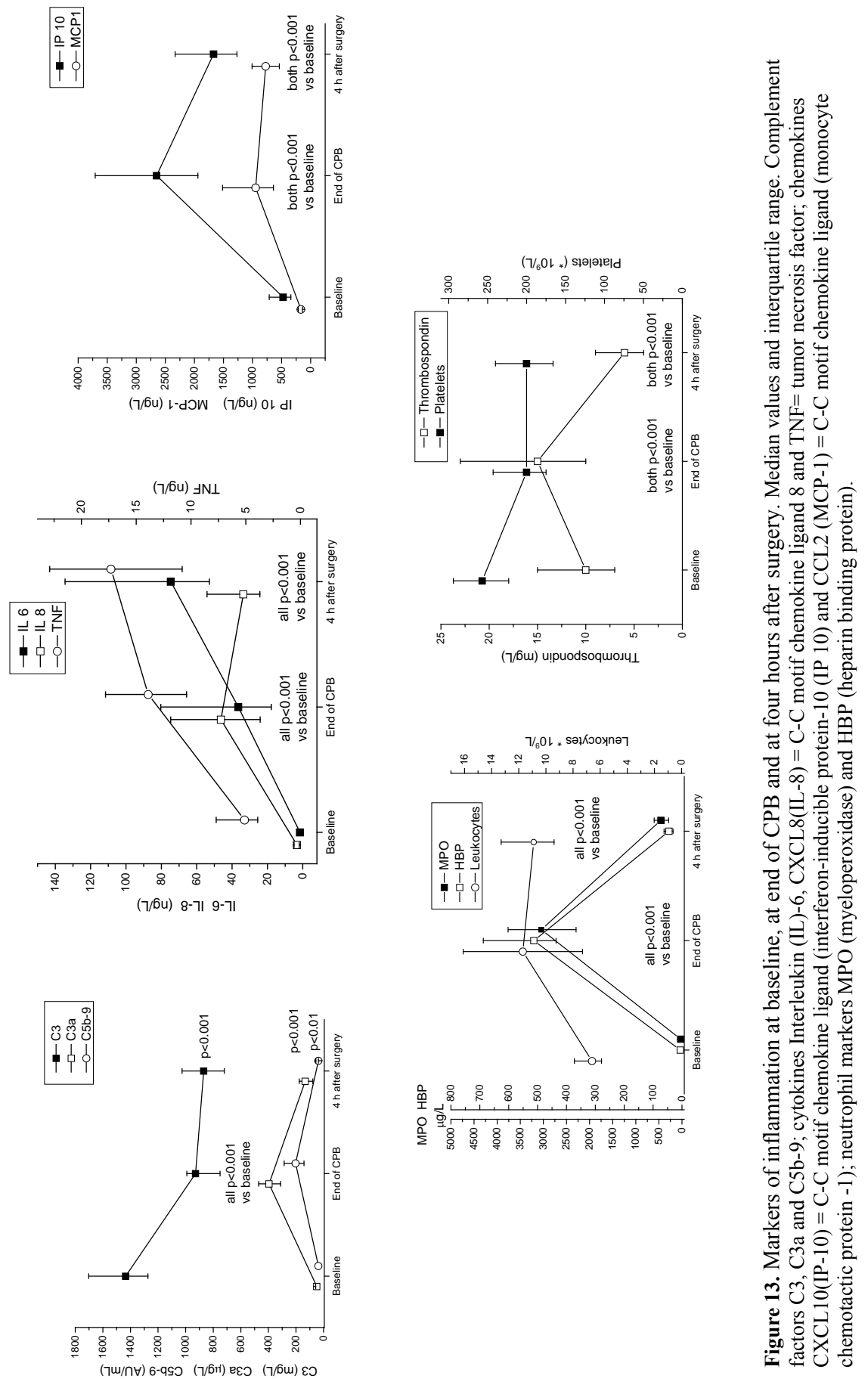


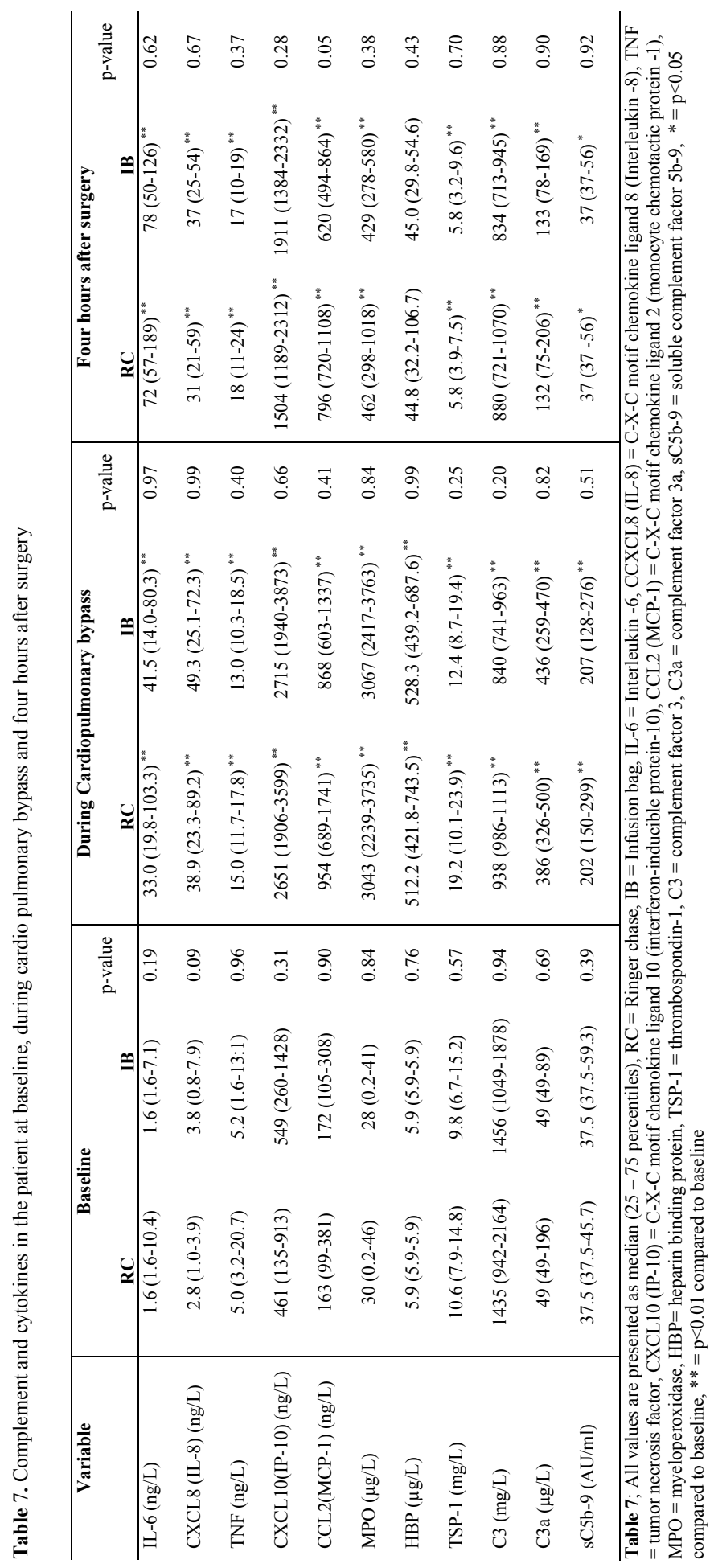


Chemokines CXCL10(IP-10) and CCL2(MCP-1) increased during CPB. The levels decreased after bypass but were still above baseline four hours after surgery (Figure 13). Markers of neutrophil activation peaked during CPB. MPO increased 100-fold and HBP 80 times compared to baseline. Both MPO and HBP had decreased four hours after surgery in comparison to bypass, but were still above baseline values (Figure 13).

TSP-1 increased slightly during CPB although four hours after surgery, the level had decreased below baseline (Figure 13).

Correlations during $\mathrm{CPB}$ are shown in table 8. MPO also correlated to HBP four hours after surgery $(\mathrm{R}=0.83, \mathrm{p}<0.01)$. A weak correlation between TSP-1 and the platelet level at baseline $(\mathrm{R}=0.37$, $\mathrm{p}=0.02)$, during $\mathrm{CPB} ;(\mathrm{R}=0.43, \mathrm{p}=0.01)$ and four hours after surgery $(\mathrm{R}=0.47, \mathrm{p}=0.01)$ was seen.

Table 8. Correlation during Cardiopulmonary bypass

\begin{tabular}{|c|c|c|c|c|c|c|}
\hline \multirow[b]{2}{*}{ Variable } & \multicolumn{6}{|c|}{ During CPB (R, p-value) } \\
\hline & $\begin{array}{l}\text { Aortic } \\
\text { cross clamp } \\
\text { time }\end{array}$ & $\begin{array}{l}\text { Time on } \\
\text { bypass }\end{array}$ & HBP & Leukocytes & $\begin{array}{l}\text { CCL2(MCP- } \\
1 \text { ) }\end{array}$ & Platelets \\
\hline TSP-1 (mg/L) & & & & & & $0.43, \mathrm{p}=0.01$ \\
\hline Il-6 (ng/L) & $0.63, \mathrm{p}<0.01$ & $0.71, \mathrm{p}<0.01$ & & $0.46, \mathrm{p}<0.05$ & $0.72, p=<0.01$ & \\
\hline CXCL8(IL-8) (ng/L) & $0.48, \mathrm{p}<0.01$ & $0.56, \mathrm{p}<0.01$ & & & $0.71, \mathrm{p}<0.01$ & \\
\hline TNF (ng/L) & $0.43, p=0.01$ & $0.42, p<0.01$ & & & $0.73, p=<0.01$ & \\
\hline CCL2(MCP-1) ng/L) & $0.62, \mathrm{p}<0.01$ & $0.68, \mathrm{p}<0.01$ & & & & \\
\hline MPO $(\mu \mathrm{g} / \mathrm{L})$ & $0.57, \mathrm{p}<0.01$ & $0.52, p=0.01$ & $0.64, p<0.01$ & $0.47, p=0.01$ & & \\
\hline
\end{tabular}

Table 8. Correlations during cardiopulmonary bypass by Spearman correlation, TSP-1 = Thrombospondin-1, IL-6 = Interleukin -6, CXCL8(IL-8) = Interleukin -8, TNF = Tumor Necrosis Factor, CCL2(MCP-1) = C-C motif chemokine ligand 2 (Monocyte Chemotactic Protein -1$)$, MPO = Myeloperoxidase, $\mathrm{HBP}=$ Heparin binding protein

\section{Inflammatory activity in the retransfused blood (Study IV)}

The $\mathrm{C} 3$ levels was lower in the retransfused blood compared to during CPB while C3a increased in both groups. Soluble C5b-9 was also increased compared to during bypass with a significantly higher increase in the IB blood than in the RC blood (Table 9).

Levels of IL-6 increased further in the retransfused blood compared to during CPB. The increase was substantially higher in the IB blood resulting in a significant difference between the groups (Figure 
14, Table 9). The increase of CXCL8(IL-8) and TNF was also significantly higher in the IB blood than in the RC blood but the difference did not reach significance between the groups (Figure 14, Table 9).

CCL2(MCP-1) increased compared to CPB in both groups whereas the increase of MPO was slightly higher in the retransfused blood, but the increase was only significant in the IB blood (Table 9).

CXCL10(IP-10) decreased compared to CPB. The reduction was more pronounced in the IB blood than in the RC blood and with a significant difference in absolute levels between the groups.

HBP and TSP-1 increased further in the retransfused blood compared to CPB. The levels of HBP and TSP-1 was similar in the groups (Table 9).

MPO and HBP in the retransfused blood correlated in both groups (IB $\mathrm{R}=0.67, \mathrm{p}=0.001 ; \mathrm{RC} \mathrm{R}=0.68$, $\mathrm{p}=0.001$ as did IL-6 and CCL2(MCP-1) (IB R=0.90, $\mathrm{p}<0.01 ; \mathrm{RC} \mathrm{R}=0.77, \mathrm{p}<<0.01)$.
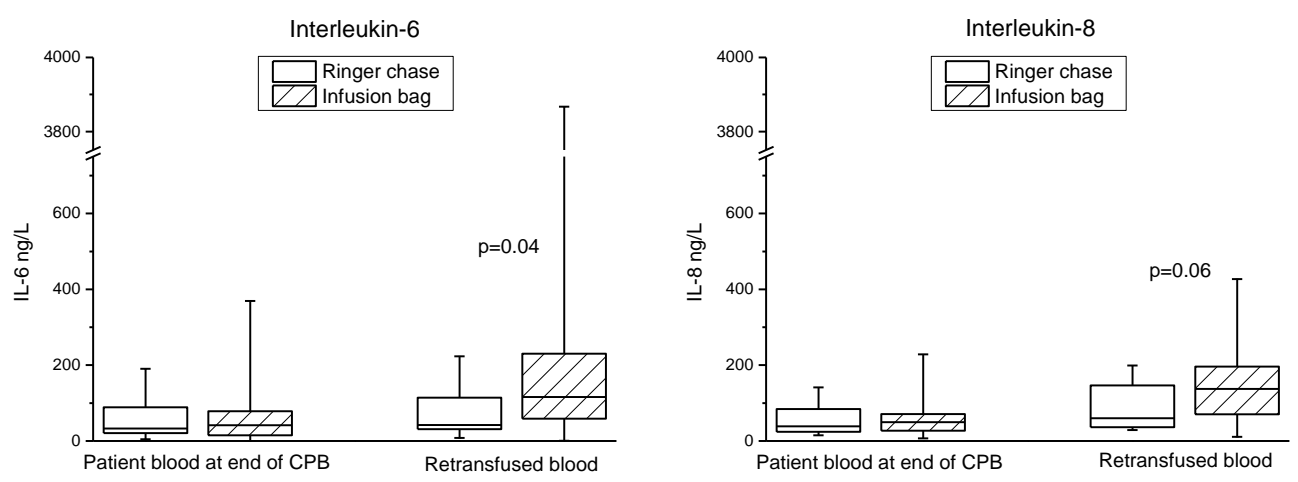

Figure 14. Cytokines in retransfused blood and in patient blood at the end of cardiopulmonary bypass. Boxes are 25-75 percentiles, line is median and whiskers are range. 


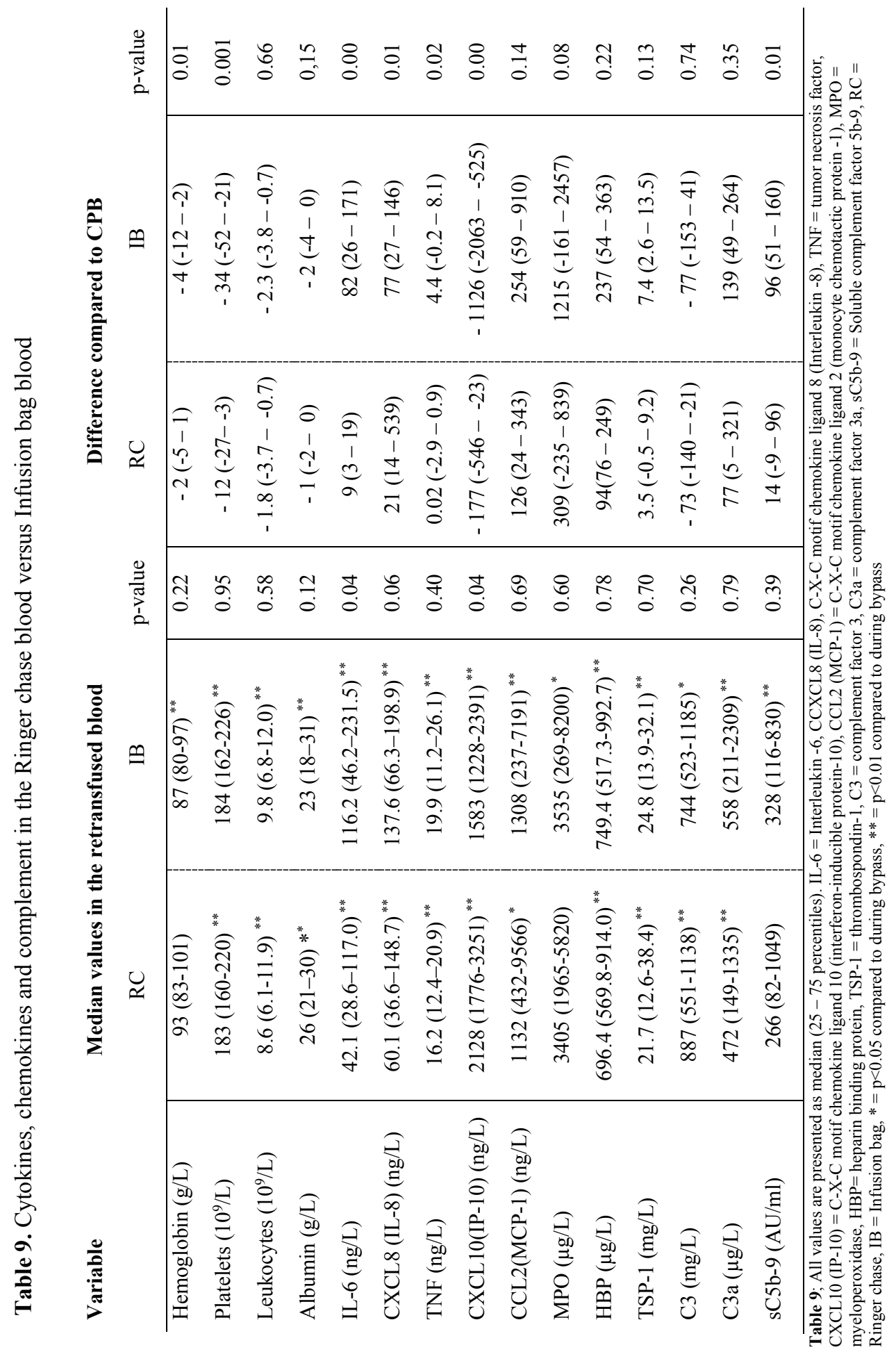




\section{Bacterial cultures (Study IV)}

In blood cultures taken from the patients at the end of CPB eleven of forty patients had positive cultures, four patients $(20 \%)$ in the IB group and seven patients $(35 \%)$ in the RC group, $\mathrm{p}=0.43$. In the blood with positive cultures the levels of IL-6, CXCL8(IL-8), TNF, CXCL10(IP-10) and CCL2(MCP-1) were significantly lower than in the blood without bacterial growth (Table 10). The majority of cultures were Propionebacteria and Staphylococci (Table 11).

In the blood cultures taken from the retransfused blood, seventeen of forty samples were positive, eleven were found in the IB group (55\%) compared to five in the RC group $(25 \%), p=0.06$. The microorganisms found in the blood cultures are listed in table 11. The same bacterial agents were found both in the patient at the end of bypass and in the retransfused blood in four of the patients in the IB-group and two in the RC-group.

Table 10. Cytokines, chemokines and complement in in blood with or without bacterial growth

\begin{tabular}{|c|c|c|c|c|c|c|}
\hline \multirow[t]{2}{*}{ Variable } & \multicolumn{2}{|c|}{ During CPB } & \multirow[b]{2}{*}{$\mathrm{p}$ value } & \multicolumn{2}{|c|}{ Retransfused blood } & \multirow[b]{2}{*}{$\mathrm{p}$ value } \\
\hline & $\begin{array}{c}\text { Negative culture } \\
(\mathrm{n}=29)\end{array}$ & $\begin{array}{c}\text { Positive culture } \\
(\mathrm{n}=11)\end{array}$ & & $\begin{array}{c}\text { Negative culture } \\
(\mathrm{n}=24)\end{array}$ & $\begin{array}{c}\text { Positive culture } \\
(\mathrm{n}=16)\end{array}$ & \\
\hline Leukocytes $\left(10^{9} / \mathrm{L}\right)$ & $11.5(7.9-15.9)$ & $12.7(6.9-16.5)$ & 0.95 & $9.0(6.3-11.9)$ & $10.2(6.7-12.4)$ & 0.67 \\
\hline IL-6 (ng/L) & $42(24-110)$ & $22(10-33)$ & 0.03 & $90(38-163)$ & $73(28-219)$ & 0.40 \\
\hline CXCL8(IL-8) (ng/L) & $62(32-80)$ & $22(11-33)$ & $<0.01$ & $121(59-182)$ & $70837-176)$ & 0.03 \\
\hline TNF (ng/L) & $17(12-19)$ & $10(8-15)$ & 0.01 & $17(14-24)$ & $14(10-24)$ & 0.13 \\
\hline CXCL10(IP-10) (ng/L) & $3003(1982-4313)$ & $2150(1729-2499)$ & 0.04 & $1813(1376-2760)$ & $1878(1558-2689)$ & 0.80 \\
\hline CCL2(MCP-1)) (ng/L) & $1212(803-1912)$ & $535(397-941)$ & $<0.01$ & $1364(1039-2335)$ & $800(531-1746)$ & $<0.01$ \\
\hline MPO $(\mu \mathrm{g} / \mathrm{L})$ & $3049(2308-3717)$ & $2733(1783-3817)$ & 0.65 & $3524(2532-5203)$ & $3113(2598-5000)$ & 0.59 \\
\hline $\operatorname{HBP}(\mu \mathrm{g} / \mathrm{L})$ & $501(437-763)$ & $525(379-649)$ & 0.63 & $745(515-1013)$ & 707 (587-949) & 0.95 \\
\hline TSP-1 (mg/L) & $13(10.1-23.5)$ & $16.7(8.7-22.5)$ & 0.68 & $25.5(14-38.4)$ & $19.1(11.4-31.1)$ & 0.29 \\
\hline $\mathrm{C} 3(\mathrm{mg} / \mathrm{L})$ & $932(744-1030)$ & $874(760-954)$ & 0.51 & $790(638-978)$ & $817(664-933)$ & 0.73 \\
\hline $\mathrm{C} 3 \mathrm{a}(\mu \mathrm{g} / \mathrm{L})$ & $347(247-467)$ & $436(400-523)$ & 0.08 & 443 (294-973) & $611(422-815)$ & 0.40 \\
\hline $\mathrm{sC} 5 \mathrm{~b}-9(\mathrm{AU} / \mathrm{ml})$ & $213(165-302)$ & $172(126-269)$ & 0.37 & $304(175-441)$ & $277(164-377)$ & 0.09 \\
\hline
\end{tabular}

Table 10. All values are presented as median (25 - 75 percentiles). IL-6 = Interleukin -6, CXCL8(IL-8) = C-C motif chemokine ligand 8 (Interleukin -8), TNF = Tumor Necrosis Factor, CXCL10(IP-10) = C-C motif chemokine ligand (interferon-inducible $~$ protein-10), CCL2 MCP-1)) = C-C motif chemokine ligand (Monocyte Chemotactic Protein -1), MPO = Myeloperoxidase, HBP= Heparin binding protein, TSP-1 = Thrombospondin-1, C3 = Complement factor 3, C3a = complement factor 3a, sC5b-9= Soluble complement factor $5 \mathrm{~b}-9$ 
Of the twenty-nine patients with negative cultures during $\mathrm{CPB}$, ten had positive cultures in the retransfused blood. Seven patients with negative cultures during CPB and positive cultures in the retransfused blood where in the IB group ( $35 \%)$ and three were in the RC group (15\%), p=0.29.

Table 11. Microorganisms in blood cultures

\begin{tabular}{|c|c|c|c|c|}
\hline Microorganism & $\mathrm{RC}(\mathrm{n}=20)$ & \multicolumn{2}{|c|}{ IB $(n=20)$} & P-value \\
\hline $\begin{array}{l}\text { Patients with positive blood cultures } \\
\text { before weaning }\end{array}$ & $7(35)$ & \multicolumn{2}{|c|}{$4(20)$} & 0.43 \\
\hline $\begin{array}{l}\text { Patients with positive blood cultures in } \\
\text { the retransfused blood }\end{array}$ & $5(25)$ & \multicolumn{2}{|c|}{$11(55)$} & 0.06 \\
\hline $\begin{array}{l}\text { Positive culture during CPB - Positive } \\
\text { culture in retransfused blood }\end{array}$ & $2(10)$ & \multicolumn{2}{|c|}{$4(20)$} & 0.60 \\
\hline $\begin{array}{l}\text { Negative culture during CPB - Positive } \\
\text { culture in retransfused blood }\end{array}$ & $3(15)$ & \multicolumn{2}{|c|}{$7(35)$} & 0.29 \\
\hline $\begin{array}{l}\text { Positive culture during CPB - Negative } \\
\text { culture in retransfused blood }\end{array}$ & $5(25)$ & \multicolumn{2}{|c|}{$0(0)$} & 0.18 \\
\hline $\begin{array}{l}\text { Negative culture during CPB - } \\
\text { Negative culture in retransfused blood }\end{array}$ & $10(50)$ & \multicolumn{2}{|c|}{$9(45)$} & 0.80 \\
\hline & \multicolumn{2}{|c|}{ RC blood } & \multicolumn{2}{|c|}{ IB blood } \\
\hline $\begin{array}{l}\text { Number of positive cultures and } \\
\text { bacteria in the cultures; }\end{array}$ & Before Weaning & Residual blood & Before weaning & Residual blood \\
\hline Propionibacterium Species & 3 & 1 & 3 & 7 \\
\hline Staphylococcus epidermidis & 1 & 2 & 0 & 1 \\
\hline Unspecified gram-positive Staphylococci & 1 & 1 & 0 & 3 \\
\hline Coagulase-negative staphylococci & 2 & 1 & 1 & 1 \\
\hline Streptococci sanguinis & 1 & 0 & 0 & 0 \\
\hline
\end{tabular}

Table 11. Values are expressed as numbers of patients with positive cultures in the group. $\mathrm{RC}=$ Ringer chase, IB Infusion bag. One sample was positive for both coagulase-negative staphylococci and Staphylococci and one sample was positive for both Staphylococcus epidermidis and Propionibacterium species. 
Five days after surgery (study IV)

We found no difference between the groups in postoperative ventilator time (Table 4) or in markers of kidney function, cystatin-C and N-gal postoperatively. Cystatin-C was significantly lower than baseline four hours after surgery but had increased above baseline in both groups five days after surgery whereas $\mathrm{N}$-gal was higher four hours after surgery in both groups and still significantly higher in the IB group five days after surgery (Table 12).

CRP and Procalcitonin five days after surgery were still elevated (Table 12) but no difference was seen between the groups. None of the patients suffered from an infection at this time point.

Table 12. Laboratory values five days after surgery

\begin{tabular}{l|c|c|c} 
Variable & RC & IB & $\begin{array}{c}\text { p-value } \\
\text { between groups }\end{array}$ \\
\hline Hemoglobin $(\mathrm{g} / \mathrm{L})$ & $102(95-110)^{* *}$ & $104(97-112)^{* *}$ & 0.76 \\
Platelets $\left(\mathrm{x} 10^{9} / \mathrm{L}\right)$ & $298(253-349)^{* *}$ & $328(254-385)^{*}$ & 0.46 \\
Leukocytes $\left(\mathrm{x} 10^{9} / \mathrm{L}\right)$ & $8.4(7.7-9.7)^{* *}$ & $9.4(7.4-10.8)^{* *}$ & 0.48 \\
CRP $(\mathrm{mg} / \mathrm{L})$ & $101(71-123)^{* *}$ & $113(61-188)^{* *}$ & 0.46 \\
Procalcitonin $(\mu \mathrm{g} / \mathrm{L})$ & $0.35(0.16-0.53)^{* *}$ & $0.27(0.14-0.46)^{* *}$ & 0.43 \\
Albumin $(\mathrm{g} / \mathrm{L})$ & $34(33-36)^{* *}$ & $33(32-36)^{* *}$ & 0.86 \\
Creatinine $(\mu \mathrm{mol} / \mathrm{L})$ & $77(66-95)$ & $75(61-90)$ & 0.58 \\
Cystatin-C $(\mathrm{mg} / \mathrm{L})$ & $1.30(1.14-1.70)^{* *}$ & $1.17(1.05-1.43)^{* *}$ & 0.53 \\
N-GAL $(\mu \mathrm{g} / \mathrm{L})$ & $125(84-179)$ & $113(84-172)^{*}$ & 0.92
\end{tabular}

Table 12. All values are presented as median ( $25-75$ percentiles), $\mathrm{RC}=$ Ringer chase, $\mathrm{IB}=$ Infusion bag, $\mathrm{CRP}=\mathrm{C}$ reactive protein, $\mathrm{N}-\mathrm{GAL}=$ Neutrophil Gelatinase-associated lipocalin, ${ }^{*}=\mathrm{p}<0.05$ compared to baseline, $* *=\mathrm{p}<0.01$ compared to baseline

\section{Three months follow-up (Study IV)}

Thirty-two of 40 patients responded the 3 months follow-up regarding postoperative infection and treatment with antibiotics, 18 in the IB-group and 14 in the RC-group. Two patients in the IB-group and five patients in the RC-group stated that they had problems from the sternal wound (pain, exuding, redness) and four patients from both groups stated that they had problems (pain, redness, swelling) from the surgical wound on the leg, two from each group had been treated with antibiotic because of the symptoms from the leg. Two patients in the RC group and one in the IB group had been treated with antibiotics after their hospital stay due to other indications (urinary tract infection, pneumonia). We found no correlation between the postoperative symptoms and the positive blood cultures in the patients before weaning from $\mathrm{CPB}$ or in the retransfused blood with IB or RC. 


\section{Combined data from studies I, II and III}

\section{Platelet aggregation}

The reduction in platelet aggregation after protaminisation in combined data from study I and II was between $35-45 \%$ with all activators ADP, TRAP, ASPI and COL (all $\mathrm{p}<0.001$ ) see Figure 15.
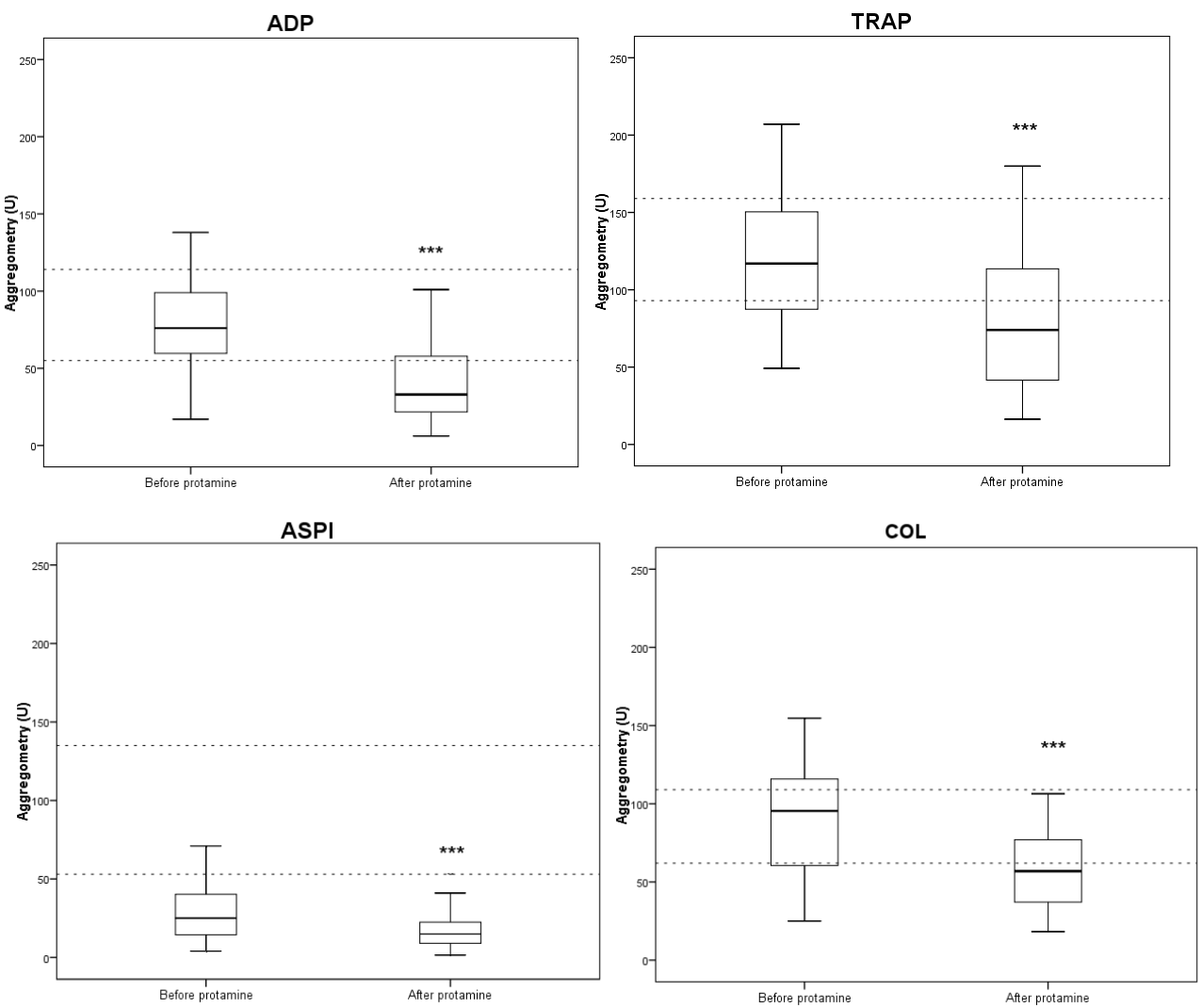

Figure 15. Box-plots (25-75\% quartiles with the line as median and the whiskers total range) for platelet aggregation before and after protamine. Platelet aggregation was stimulated with adenosine phosphate (ADP-test), thrombin receptor activating peptide-6 (TRAP-test), arachidonic acid (ASPI-test), collagen (COL-test), $* * * \mathrm{p}<0.001$ 
When combining platelet aggregation results from study I, II and III there was a significantly increased collagen stimulated aggregation at the end of CPB. Aggregation with TRAP and ASPI tests at the end of CPB were similar to baseline whereas ADP induced aggregation tended to be lower. (Table 13).

Table 13. Platelet aggregation at baseline and at the end of cardiopulmonary bypass

\begin{tabular}{lccc} 
Variable & Baseline & End of CPB & P value \\
\hline ADP induced (U) & $79(63-98)$ & $74(57-95)$ & 0.09 \\
TRAP induced (U) & $118(97-137)$ & $117(92-149)$ & 0.16 \\
AA induced (U) & $24(17-50)$ & $22(14-37)$ & 0.17 \\
COL induced (U) & $54(42-72)$ & $73(57-108)$ & $<0.001$
\end{tabular}

Table 13. Results are presented as median ( $25-72 \%$ quartiles), CPB = cardiopulmonary bypass, Platelet aggregation induced with ADP = Adenosine-diphosphate (ADP-test), TRAP = Thrombin Receptor Activating Peptide (TRAP-test), AA = Arachidonic Acid (ASPI-test), COL =Collagen (COL-test)

\section{Blood loss}

The median blood loss in the combined material was $740 \mathrm{ml}$ (475 -1000) during surgery and $75 \mathrm{ml}$ (58-99) per hour during the first postoperative hours (3 hours in study I and II, 4 hours in study III).

In the combined material from study I and II there was a negative correlation between blood loss during surgery and platelet aggregation after protamine administration with activators ADP R= 0.385 and ASPI $\mathrm{R}=-0.349$, both $\mathrm{p}<0.001$. We also found a correlation between postoperative blood loss at 3 hours and platelet aggregation after protamine administration with activators TRAP $\mathrm{R}=-$ 0.294 , ASPI $\mathrm{R}=-0.271$ and collagen $\mathrm{R}=-0.315$, all $\mathrm{p}<0.05$.

There was a weak negative correlation between blood loss during surgery and TRAP-stimulated aggregation at baseline in the combined results from study I, II and III, R= $-0.241, p<0.05$. No other correlations between blood loss and platelet aggregation was found in the combined material from study I, II and III. 


\section{DISCUSSION}

There are two major findings in this thesis. The first is that protamine reduces platelet aggregation in vivo when given after CPB to reverse heparin anticoagulation. It also reduces platelet aggregation in whole blood when added in vitro, by itself or in combination with heparin. The negative effect on platelet aggregation in vivo is transient, and 20 minutes after the protamine administration the platelet aggregation has started to recover.

The second finding is that for retransfusion the RC-technique is less damaging for the residual pump blood than the IB technique. The RC technique had less hemolysis, less signs of activation of coagulation and fibrinolysis, better preserved platelet function and less pronounced inflammatory activity.

\section{Platelet level and platelet aggregation}

The effect of protamine on platelet aggregation has been studied before, but the results vary from no provable effect ${ }^{36}$ to a direct inhibitory effect ${ }^{4,6}$.

In this thesis platelet aggregation after protamine administration was reduced with $50 \%$ or more in vivo (study I) with all activators. The effect was transient and had begun to recover 20 minutes after the protamine administration (study II). The half-life of protamine is short, approximately 5 minutes after a dose of $250 \mathrm{mg}^{134}$. This could maybe explain the short duration of protamine effect on the platelet aggregation. It is possible that the recovery of platelet function starts immediately when the protamine concentration in the blood is diminished. In study II, the interval between the $70 \%$ and $100 \%$ of the calculated dose, was approximately $3-4$ minutes. This means that the protamine concentration in the blood had diminished with approximately $30-40 \%$ when the additional $30 \%$ of protamine were given. The additional dose will then increase the protamine concentration in the blood once again. This might explain why the platelet aggregation was not more impaired after the additional $30 \%$ dose of protamine. ADP stimulated aggregation differed from other activators though and had even started to recover three minutes after the additional $30 \%$ of protamine. The negative effect on the platelets seems to be transient. It is however not clear whether a new exposure to protamine after a longer period of time would again result in reduced platelet aggregation or not. This needs to be further investigated.

It is often stated that platelet count is decreased during $\mathrm{CPB}{ }^{135-137}$. This is not consistent with the results in this thesis. When the platelet level was corrected for hemodilution, the consumption of platelets seemed to be insignificant during $\mathrm{CPB}$, when comparing the samples taken before protamine with baseline. The decrease in the platelet level was significantly lower first after the initial dose of protamine. This indicates a consumption of platelets in connection to reversal of the heparin effect, since no further hemodilution could be expected to occur during that short time frame.

It has previously been concluded that platelet sensitivity to ADP and collagen decreased towards the end of $\mathrm{CPB}{ }^{138}$. This is not consistent with the results from this thesis. At the beginning of CPB there is an expected decrease in platelet aggregation that can be related to the hemodilution, but this thesis 
indicates a recovery of the platelet function during bypass measured by impedance aggregometry. In study I, II and III the platelet aggregation, immediately after weaning from CPB and before protamine administration, was not significantly changed from the aggregation at baseline with three of four activators (ADP, TRAP and ASPI). The platelet aggregation at the end of CPB seems to vary between different receptors. ADP-test in the combined data tended to be lower at the end of bypass whereas collagen test showed an increase in platelet aggregation that, to our knowledge, has not been observed before.

Platelet aggregation was markedly reduced after protaminisation compared to before protamin administration. There was also a reduction in platelet numbers after protamine administration, indicating a consumption of platelets. It could be argued that the reduced aggregation seen after protamine could be a result of the lower platelet concentration at that measuring point, and not an inhibiting effect on the function of the remaining platelets. When calculating an expected corrected ADP stimulated aggregation at the measured platelet concentration, the expected reduction in aggregation after protamine administration would be $17 \mathrm{U}(6-27)$, whereas the actual measured reduction in ADP stimulated aggregation was $37 \mathrm{U}(20-47)$. This points to a reduced function of the remaining platelets. This could, in turn, be the result of protamine inhibiting all platelets, or it could indicate that the platelets remaining in the circulation are a less reactive subpopulation of platelets, and that the more reactive platelets were consumed after protamine administration.

It has been concluded that low preoperative values of impedance aggregometry induced with ADP correlates to blood loss ${ }^{139,140}$. Low preoperative platelet aggregation in study I correlated with increased postoperative blood loss at 3 and 12 hours. In study II we found a similar correlation between blood loss during and after surgery and platelet aggregation when the ADP-test was used. When the results from study I, II and III was combined there was a week negative correlation between blood loss during surgery and TRAP-induced aggregation at baseline, but no correlation to other platelet activators could be found.

In study III we measured platelet aggregometry in the blood from the different retransfusion techniques and found that the platelet aggregation was markedly reduced in both the RC blood and in the IB blood. Platelet aggregation is related to the number of platelets in the blood ${ }^{133}$. Platelet concentration was about $10 \%$ lower in the retransfused blood compared to in the circulation at the end of CPB but the platelet aggregation was significantly more reduced. The decrease in aggregometry was, in addition, significantly more pronounced in the IB blood compared to the RC blood indicating that the IB technique used for retransfusion had greater effect on platelet aggregation. It is possible that more reactive platelets had adhered, and that the remaining platelets left in the samples then would show a lower reactivity. The higher degree of fibrinolysis in the IB blood might influence the ADP- and ASPI test since plasmin can reduce platelet responsiveness to ADP and arachidonic acid (AA) ${ }^{79,80}$. No protamine had been administrated to the patients at that time, which otherwise could influence aggregometry.

Four hours after surgery platelet aggregation had increased compared to during CPB and was above baseline values with all activators. It is unknown if the platelets in the retransfused blood have the possibility to recover and be stimulated to aggregation after retransfusion. 


\section{Markers of platelet activation}

P-selectin and GPVI were markedly increased in the retransfused blood (study III) indicating an increased platelet activation which is consistent with the lower platelet aggregation. P-selectin is shed from activated platelets in vivo ${ }^{84}$. No difference was seen between the groups during $\mathrm{CPB}$ or in the retransfused blood, but the increase of P-selectin was more pronounced in the IB group. This could indicate an increased platelet activation and consumption in the IB blood. Activated endothelium will also shed P-selectin, making it a less specific marker for platelet activation. GPVI is more platelet-specific marker ${ }^{141}$ and the levels increased significantly compared to during bypass in the IB blood, an increase that was not seen in the RC blood.

TSP-1, measured in study IV, increased in the retransfused blood compared to end of CPB and was more pronounced in the IB blood than in the RC blood. TSP-1 is important for platelet aggregation and stabilizes the fibrinogen binding. Theoretically, an increased level of TSP-1 could also be related to a more pronounced activation and consumption of platelets resulting secondary in low platelet aggregation. The increase in TSP-1 did not correlate to other markers for platelet activation or inflammatory response but there was a weak correlation to the platelet count (Study IV).

This is the first time these two retransfusion techniques has been compared and evaluated. Both the aggregometry results and all different markers for platelet activation in study III and IV supports a more pronounced platelet activation in the IB blood. This suggests that the RC technique is less damaging for the platelets.

\section{Heparin reversal with protamine}

The reversal of heparin with protamine in study II was made in two steps, using the ACT value as a marker for adequate reversal. The protamine dose was calculated based on the initial dose of heparin given before start of bypass, $1 \mathrm{mg}$ of protamine for every $100 \mathrm{U}$ of heparin. Initially $70 \%$ was given followed by the remaining $30 \%$. The effect of the reversal was assessed with activated clotting time (ACT) after $70 \%$ and after $100 \%$. ACT measures whole-blood coagulation and is known to be affected by hemodilution ${ }^{142}$ and does not seem to correlate to actual plasma heparin concentration

${ }^{143}$. Falsely elevated ACT values are often caused by depletion of coagulation factors during CPB ${ }^{144}$. In study II the ACT values were not elevated and were below 130 after $70 \%$ of the calculated dose of protamine, with no further decrease after the remaining $30 \%$. This might be an indication that a 0.7:1 ratio of protamine-heparin could be enough to reverse the effect of heparin after CPB, since a part of the heparin has been metabolized at the time of reversal. None of the 30 patients in study II was deemed to need any additional protamine after the full calculated dose protamine and no excessive bleeding was observed. No tests with thromboelastometry were made to evaluate if there was any remaining heparin in the blood after $70 \%$ or $100 \%$ of the calculated protamine dose. If a protamine-heparin ratio of $0.7: 1$ is enough to reverse the heparin effect needs to be further investigated, but is has been suggested that patients with lower protamine doses has less bleeding 145,146 .

In study III, additional protamine was given in the IB group, even though there was no significant difference in peroperative bleeding. This was in excess of the calculated main dose, and was given after retransfusion of the machine blood. The reason for the additional doses is unknown, but could relate to the IB technique, where $50 \mathrm{mg}$ of protamine administration is administered after the IB is 
transfused. Retransfusion with $500-600 \mathrm{ml}$ blood, anticoagulated with heparin might interfere with coagulation. If the surgeon visually experiences increased bleeding in the operating field, additional doses of protamine may be administered. No patient in the RC group was deemed to need an additional dose of protamine. The protamine dose is reflected by the difference in activated partial thromboplastin time (APTT) between the groups. The IB group had a significantly lower APTT than the RC group four hours after surgery, although it did not generate any difference in blood loss.

\section{Coagulation and immunological response during CPB and after weaning}

We found a high activation of the coagulation and fibrinolytic system in the IB blood. Fibrin is formed during coagulation in wounds, but can also be formed as soluble fibrin in the blood ${ }^{75}$. During CPB, the total fibrin formation is reduced due to high doses of heparin. The CPB produces non-hemostatic thrombin which in turn produces soluble fibrin. Normally fibrin stays in the wound and only $1 \%$ circulates in the body as soluble fibrin ${ }^{75}$. The formation of non-hemostatic soluble fibrin will increase approximately $35 \%$ during CPB because of dysregulation in the hemostasis ${ }^{75}$. The level of soluble fibrin (study III) was significantly higher in the IB blood compared to during bypass, indicating a higher activation in the coagulation system with non-hemostatic thrombin formation as a result. The level of soluble fibrin in the RC blood was comparable to levels during $\mathrm{CPB}$ and was significantly lower compared to levels in the IB blood. D-dimer was also significantly higher in the IB blood compared to end of CPB as a sign of increased fibrinolysis. The levels of Ddimer in the RC blood did not differ compared to end of bypass. The almost doubled level of free hemoglobin in the IB blood could also contribute to the increased thrombin generation ${ }^{147}$. This suggests that the RC technique has less influence on the coagulation, fibrinolysis and levels of free hemoglobin then the IB technique.

The activation of the complement system, increase of leukocytes, cytokines and chemokines followed a well-known and expected pattern during CPB and no differences were observed between the groups (study IV). The levels of C3 in study IV decreased during CPB with a corresponding increase in $\mathrm{C} 3 \mathrm{a}$ and $\mathrm{sC} 5 \mathrm{~b}-9$, probably as a consequence of contact with the foreign material in the circuit and reperfusion of ischemic tissues. Complement activation continued in the retransfused blood with decreasing $\mathrm{C} 3$ levels and a corresponding increase in $\mathrm{C} 3 \mathrm{a}$ and $\mathrm{sC} 5 \mathrm{~b}-9$. sC5b-9 has been shown to be a determinant of platelet activation during CPB ${ }^{148}$. Although $\mathrm{sC} 5 \mathrm{~b}-9$ increased in retransfused blood in both groups, the increase was more substantial, and significant only in the IB blood, suggesting a more intense activation of the complement system and the platelets with this technique. The more pronounced increase in $\mathrm{sC} 5 \mathrm{~b}-9$ reflects the formation of $\mathrm{C} 5 \mathrm{a}$. One reason could be the new surface in the infusion bag. The level of sC5b-9 thus is consistent with higher inflammatory activity with increased cytokine production found in the IB blood. The more prominent increase of platelet markers in the IB blood is also consistent with the sC5b-9.

In previous studies ${ }^{12,13}$ TNF was elevated early and IL-6 and CXCL8(IL-8) peaked later but in study IV both IL-6 and TNF seems to peak after surgery. IL- 6 and TNF continued to increase after surgery and were higher four hours after surgery compared to levels at the end of CPB, whereas CXCL8(IL8 ) peaked during CPB. There were also a correlation between the secretion of cytokines and chemokines to duration of CPB and aortic occlusion time, as previously demonstrated ${ }^{13}$. IL-6 in the retransfused blood correlated strongly to CCL2(MCP-1) in both groups (IB and RC) indicating an activation of monocytes ${ }^{149}$. The monocytes could be activated after contact with the 
material of the $\mathrm{CPB}$ circuit and the infusion bag, initiated through the alternative pathway in the complement system ${ }^{95}$.

Although the levels were similar in the RC- and IB blood, IL-6, CXCL8(IL-8), TNF, CXCL10(IP10) and MPO was markedly increased in the IB blood with significant changes compared to during $\mathrm{CPB}$. The more intense increase of markers for neutrophil activation in the IB blood indicates that the handling of the residual pump blood results in further inflammatory activation and damage of the blood.

HBP increases endothelial permeability ${ }^{126}$ and can be seen as another marker for inflammatory activity. High levels of HBP has been found in patients with septic shock ${ }^{150,151}$ and respiratory failure ${ }^{152}$. HBP can also be released when bacterial proteins directly activate neutrophils ${ }^{152,153}$. As could be expected there was a strong correlation between HBP and MPO both during CPB and four hours after surgery reflecting the leukocyte activation ${ }^{126}$. It has been discussed whether HBP can be used as a marker for severity of sepsis or if it is more a marker of severe inflammatory disease. The prominent increase in HBP, of short duration and in parallel to increase of both MPO and leukocytes, implicates HBP as a marker of neutrophil activation and not necessarily connected to bacterial infection. It is unclear if the prominent increase of HBP is due to inflammatory activation by $\mathrm{CPB}$ itself or could be initiated by bacteria or endotoxin in the blood. There was however no difference in HBP levels between the patients with cultured bacteria in the blood during CPB and those without. We did not, on the other hand, find any correlation between HBP levels and time on bypass. The significance of the pronounced increase in HBP levels during CPB needs to be evaluated in further studies. Whether the amount of heparin circulating during bypass has importance for the measured levels of HBP is not clear. HBP bound to circulating heparin could possibly result in high measured levels of inactive HBP. Both HBP and MPO peaked during CPB but had a rapid decline. The levels were still high four hours after surgery, with levels comparable to those measured during septic conditions ${ }^{124,151,152}$.

Theoretically it should be possible to detect a correlation between coagulation and inflammatory measurements since the systems interact with each other, but no clear correlations between platelet aggregation, coagulation values and analysis of the inflammatory response was observed between the different variables in study III and IV.

The oxygenator has been proven to have an impact on the inflammatory response, leukocyte activation and organ dysfunction ${ }^{154}$. Any differences in impact on coagulation or inflammatory response between different brands of oxygenators has not been evaluated. All patients in study III and IV was perfused with the same oxygenator during CPB.

\section{Presence of bacteria in the patient and in the retransfused blood}

We found a higher presence of positive cultures in the IB blood than in the RC blood, although the difference was not significant. Four of the patients in the IB group with positive cultures in their blood during CPB had corresponding positive cultures in their IB blood. Additionally, seven bags with positive cultures were found in the IB group, resulting in totally eleven infusion bags with positive cultures of bacteria. In the RC group, only two patients with positive cultures in their blood during $\mathrm{CPB}$ had corresponding positive cultures in the machine during the $\mathrm{RC}$ retransfusion. Another 
three patients received blood through the machine that tested positive for bacteria, resulting in totally five positive blood cultures from the $\mathrm{RC}$ blood during retransfusion.

Positive cultures in the priming of the bypass circuit and blood samples drawn from the circuit during CPB has been frequently encountered ${ }^{65}$. The bacteria in the CPB blood were mainly the same as those colonizing skin. The positive cultures taken in study IV is consistent with cultures found in previous studies ${ }^{155}$ therefore it is reasonable to assume that they are derived from the patient itself.

When comparing the levels of cytokines and chemokines in relation to presence of bacteria in the blood (Study IV) we found significantly lower levels in the blood with positive cultures.

No correlation between positive cultures in the blood from the CPB circuit and postoperative infection have been established in previous studies ${ }^{65,156}$ and were also not found in study IV. Positive cultures and postoperative infections needs to be evaluated in larger studies.

\section{Postoperative clinical course}

We found no difference in clinical outcome related to which retransfusion technique was used. Postoperative ventilator time, markers of kidney function and signs of infection were similar in the groups. Positive cultures in the patient during CPB or in the retransfused blood did not correlate to infections in the postoperative phase. None of the patients suffered from an infection at discharge from the hospital, although several patients stated symptoms such as pain, fluid discharge and redness from the operating wound, both from sternum and the leg, within three months. Treatment with antibiotics was similar in both groups.

\section{Residual pump blood}

Retransfusion of the residual pump blood is considered to be one method to reduce the need for allogenic blood transfusion ${ }^{10,23}$ and to raise the hemoglobin levels ${ }^{10,22}$. Today there are three methods for transfusion available. Transfusion of unprocessed residual pump blood is often applied ${ }^{23,157}$, washing the blood in a cell saver device before it is transfused are also common and finally retransfusing by the RC-technique which is a common technique in Swedish thoracic centers. There are conflicting theories on the quality of the blood and the opinion varies between surgeons and anesthetists. Some believes that the residual pump blood is no different from the blood in the patients circulation while others believes that it is "dirty" and needs to be washed in a cell salvage device before retransfusion ${ }^{23}$.

\section{Infusion bag and Ringer chase technique}

The cause of the inflammatory activity in the residual pump blood is probably multifactorial. The reason for the increased hemolysis and fibrinolysis, lower platelet function and increased inflammatory activity in the IB blood is unknown but different markers of coagulation and 
inflammation indicates that the IB technique could further damage the residual pump blood when it is emptied from the machine and collected in the infusion bag.

The IB blood can be collected in many ways but regardless of if the blood is collected passively or actively with the help of the main pump of the heart-lung machine, there are some common factors that could have an impact on the blood.

Before the blood can be collected in the infusion bag, the surgeon needs to decannulate the patient. During this time, the risk for stagnant blood in the circuit is increased in comparison to when the RC technique is used, since retransfusion with RC usually begins directly after weaning from bypass. When the blood is emptied from the machine with the IB technique, the direction of the flow is reversed. The retrograde flow through the filters could dislodge trapped leucocytes and flush them with the blood in to the infusion bag. With the RC-procedure the blood is more or less continuously pumped forward in the circuit and the flow direction is never reversed.

With the IB-technique the blood is exposed to the new surfaces in the infusion bag, and to the residual air in the bag, which both might trigger the immune- and coagulation system further. During the $\mathrm{RC}$ technique, the blood will not come in contact with new surfaces beyond those in the CPB circuit. During active drainage with the main pump on the machine as during the IB procedure, a negative pressure will be created and contribute to a damaging effect, augmenting the inflammatory response in the blood ${ }^{27}$.

Another advantage with the $\mathrm{RC}$ technique, compared to the IB technique is that after completion of the $\mathrm{RC}$ procedure, the $\mathrm{CPB}$ circuit will still be primed. If reinstitution of $\mathrm{CPB}$ is needed, the venous line can be filled and the perfusionist can easily go back on bypass. Furthermore, all blood is retransfused at the same time and no anticoagulated blood will be given to the patient after decannulation, which decreases the risk for heparin rebound after protamine administration.

With the $\mathrm{RC}$ technique there is no Ringer acetate transfused into the patient. The risk for hemodilution is minimal if the added volume is not greater than the calculated volume in the circuit. It is possible to increase the added volume in the reservoir if the patient requires more volume to keep an adequate blood- and filling pressure.

The vast majority of patients can safely receive the residual pump blood with the RC technique. Care has to be taken, however, not to overfill the right ventricle by returning the blood to fast. Overdistention can be avoided by keeping the vascular bed properly dilated, or putting the patient in the head up position.

During the $\mathrm{RC}$ technique, the $\mathrm{CPB}$ circuit will be unbroken and the residual blood will remain in the heart-lung machine until it is retransfused to the patient. During the IB technique the blood needs to be transferred from the machine into the infusion bag which then is connected to the patient, which increases the risk for contamination of the blood.

When the differences between the transfusion techniques are added together and combined with the results of the quality in the blood from this thesis, the $\mathrm{RC}$ technique appears to be far less damaging for the blood compared to the more common IB technique. 


\section{Limitations}

The patients were enrolled from two hospitals in Sweden, Linköping University hospital (study I) and Karlskrona hospital (study II, III and IV). In all four studies, patients were included subsequently and the inclusion was dependent on the logistic possibility for obtaining and analyzing the different blood samples. No screening log has been performed at either hospital which makes the number of eligible patient's unknown. The patient who met the inclusion criteria and was included is still considered to be random. None of the patients enrolled met the exclusion criteria's and none of the patients asked to participate in a study declined to be enrolled.

The small sample size can represent a weakness, especially since there are many confounding factors during cardiac surgery that cannot be eliminated and could affect the outcome in any direction. Examples of such factors are gender and anamnesis of the patient. A strength of these studies is the individual, paired samples where every patient is its own control. A weakness is the difficulty to draw clinical conclusions on the small material.

We limited the inclusion criteria to two types of cardiac surgery, CABG and AVR in study I and II and to only CABG in study III and IV. This might not be representative for all types of surgery, but anticoagulation with heparin and reversal with protamine is used in some form in all heart surgery procedures utilizing cardiopulmonary bypass. Any differences between the different surgeries has not been evaluated.

The exclusion criteria eliminated patients with previous, known conditions that could have an impact on the result in the small patient groups. Patients with known bleeding diathesis and treatment with antiplatelet drugs were excluded since it could have an impact on platelet aggregation already at baseline. Treatment with acetylic acid was allowed, since it is clinical practice not to discontinue the treatment before surgery. This is reflected in the baseline values in the ASPI-test. Patients, where the operation required hypothermia, were also excluded because of the impact hypothermia has on the coagulation system. Treatment with steroids was not allowed to ensure that no pharmacologic inhibition of the immune system was created.

Platelet aggregometry is only one of the function of the platelets and is the only function tested in this thesis. To get a more comprehensive picture of the platelet function, other measurement methods must be used.

All patients were treated according to local routines, both in Linköping and in Karlskrona. Operations were performed by different surgeons and anesthesiologists; this could be a strength as well as a weakness. All surgeons have different operating techniques which could theoretically influence the blood loss during the procedure. Study III did not reveal a difference in blood loss between the two randomized groups suggesting that the groups were comparable.

The differences between the two retransfusion techniques had not been evaluated before, making it hard to estimate possible differences between the two groups. Because of this, study III and IV are pilot studies. The findings in this thesis provide a baseline difference between the techniques and could be used for power calculations in further studies. The quality of the retransfused blood was evaluated between the groups and in comparison, to the values during CPB. No differences were seen between the groups during CPB which minimize the importance of the oxygenator's 
contribution to the inflammatory response in the studies. Instead the process of retransfusion and handling of the residual pump blood seemed to be of importance.

\section{Clinical relevance}

Previous studies indicate that excessive protamine should be avoided because of its effects on platelet function and coagulation. Lower protamine-heparin ratios are a benefit for the patient since protamine has a dose dependent negative effect on clot initiation. The effect of protamine on platelet aggregation is supported by the results in this thesis.

Retransfusion of the residual blood is performed in an attempt to reduce allogenic blood transfusion. Therefore, the goal must to be to preserve as much red blood cells as possible. The hemoglobin level will decrease significantly compared to during CPB. When the RC technique is used this reduction in hemoglobin concentration is less pronounced and the level of free hemoglobin is lower compared to the IB technique.

The RC technique generates less inflammatory activation in the blood. Retransfusion of blood with high levels of cytokines, especially IL-6, could enhance the inflammatory activity ${ }^{15,16}$ and make the patient more prone to postoperative infection ${ }^{158}$.

In the event of cell salvage not being feasible, it is suggestable that the $\mathrm{RC}$ technique is preferable to the IB technique, but with an acknowledgement that the clinical importance needs to be assessed in further larger studies 
Hemostatic function and inflammatory activation after weaning from cardiopulmonary bypass 


\section{CONCLUSIONS}

Protamine given after previous heparin administration during CPB has a negative effect on platelet aggregation measured by whole blood impedance aggregometry

Protamine reduces aggregation in whole blood in vitro, by itself or in combination with heparin

Protamine induces a marked but transient decrease in platelet aggregation already at a protamineheparin ratio of $0.7: 1$.

The inflammatory response during CPB is substantial and levels of HBP are high and is considerably higher than previously shown levels during sepsis and respiratory failure.

The RC technique generates retransfused blood with better preserved platelets, less hemolysis, less signs of activation of coagulation and fibrinolysis than the commonly used IB technique.

The RC technique is associated with a less pronounced inflammatory activation in the retransfused blood.

Bacterial contamination of the retransfused blood is common. 
Hemostatic function and inflammatory activation after weaning from cardiopulmonary bypass 


\section{ACKNOWLEDGEMENTS}

The research in this thesis was performed at the Department of Medical and Health Sciences, Linköping University, Linköping, Sweden, Blekinge Institute of Technology, Department of Health Science, Karlskrona, Sweden, Department of Cardio-Thoracic and Vascular Surgery, Linköping, Sweden and at the Department of Cardio-Thoracic Surgery Blekinge Hospital, Karlskrona, Sweden. I wish to express my appreciation and sincere gratitude to the following individuals and groups.

First of all, to my principle supervisor Sören Berg at the Department of Cardio-Thoracic and Vascular Surgery, and Department of Medical and Health Sciences, Linköping University, Linköping, Sweden. A warm and sincere thank you for believing in me and for guiding me with an incredible patience throughout my doctoral studies. Thank you for making me do all my statistics, sometimes repeatedly. I also value your constructive criticism and our discussions that helped me improve my manuscripts and write my dissertation.

To my co-supervisors Joakim Alfredsson, Rolf Svedjeholm and Erik Håkansson for sharing your knowledge and for your valuable contribution to my research.

A special thank you to my co-supervisor at Blekinge Institute of Technology, Department of Health Science, Karlskrona, Johan Sanmartin Berglund for sharing your knowledge, your contribution to my research and for being a valuable link between Linköping University and Blekinge Institute of Technology.

To Blekinge research council who granted me research grants, making it possible to do my thesis.

To all my colleges at the Department of Health Science, Blekinge Institute of Technology, Karlskrona for all their support and encouragement.

To the staff in the operation section at the Department of Cardio-Thoracic and Vascular Surgery, Linköping University, who helped me in with the blood samples in the first study, and to the Cardiac intensive care unit, Linköping University for letting me use their Multiplate.

A very warm thank you to the staff in the operating section at the Department of Cardio-Thoracic Surgery in Karlskrona for your endless support and efforts in my research. I could not have done it without you! A special thank you to Helena Palmgren, Yvonne Björnlund Eliasson and Petter Etzén who helped me with the logistics.

A very special and sincere thank you to Ingrid Larsson and Dada Merdan who both made it possible for me to do my dissertation and allowed me to take partly leave of absence from the Department of Cardio Thoracic surgery in Karlskrona during my doctoral studies.

A warm thank you to my perfusionist colleagues Ulf Johansson, Anders Lindberg and Martin Thelander for their endless patience and willingness to support my work.

A warm and very special thank you to Martin Thelander for your valuable support and interesting discussions. I could not have done it without you! 
A special thank you to thoracic surgeon Anders Ericsson for helping me with my projects and for sharing your knowledge of research.

A special thank you to the nurses in the thoracic intensive care unit in the Department of CardioThoracic Surgery in Karlskrona for your valuable help.

A warm and special thank you to my parents, Stig and Astrid, for their endless support!

A warm and loving thank you to my husband and children (as mentioned below) and grandchildren for their support during my doctoral studies. Thank you for simplifying things, such as green button on and red button off and how hard can it be?! I am grateful to have you all in my life!

My daughter, Kitty (my Caroline), for her support, patience and eminent work with the illustrations in my thesis. To my son-in-law, Robin, for his help with the illustrations and for making the cover of my thesis. I am very grateful and appreciate it very much!

My oldest son, Christoffer, for showing interest and for trying to understand and discuss my work. I enjoy our discussions and appreciate it very much!

My youngest son, Christian, for just being there and light up my life with a joke or a magic trick with cards. To my daughter-in-law, Sofia for her support and sense of humor, with or without Tequila. I always appreciate the time we spend together!

To my grandchildren Elion and Noah for reminding me of what is important in life. You are simply the best!

Finally, a very special warm and loving thank you to my husband Thomas for his endless support in all my projects. And a very special thank you for picking me up at different places, when the trains fail to transport me to the designated location. I could not have done this work without your support! 


\section{REFERENCES}

1. Paparella D, Brister SJ, Buchanan MR. Coagulation disorders of cardiopulmonary bypass: a review. Intensive Care Med 2004; 30: 1873-1881.

2. Cremer J, Martin M, Redl $\mathrm{H}$, et al. Systemic inflammatory response syndrome after cardiac operations. Ann Thorac Surg 1996; 61: 1714-1720.

3. Paparella D, Yau TM, Young E. Cardiopulmonary bypass induced inflammation: pathophysiology and treatment. An update. Eur J Cardiothorac Surg 2002; 21: 232-244.

4. Griffin MJ, Rinder HM, Smith BR, et al. The effects of heparin, protamine, and heparin/protamine reversal on platelet function under conditions of arterial shear stress. Anesth Analg 2001; 93: 20-27.

5. Ortmann E, Klein AA, Sharples LD, et al. Point-of-Care Assessment of Hypothermia and ProtamineInduced Platelet Dysfunction with Multiple Electrode Aggregometry (Multiplate(R)) in Patients Undergoing Cardiopulmonary Bypass. Anesth Analg 2013; 116: 533-540.

6. Gertler R, Wiesner G, Tassani-Prell P, et al. Are the point-of-care diagnostics MULTIPLATE and ROTEM valid in the setting of high concentrations of heparin and its reversal with protamine? J Cardiothorac Vasc Anesth 2011; 25: 981-986.

7. Murphy GJ, Reeves BC, Rogers CA, et al. Increased mortality, postoperative morbidity, and cost after red blood cell transfusion in patients having cardiac surgery. Circulation 2007; 116: 2544-2552.

8. Ferraris VA, Brown JR, Despotis GJ, et al. 2011 Update to The Society of Thoracic Surgeons and the Society of Cardiovascular Anesthesiologists Blood Conservation Clinical Practice Guidelines*. Ann Thorac Surg 2011; 91: 944-982.

9. Engoren $\mathrm{MC}$, Habib $\mathrm{RH}$, Zacharias $\mathrm{A}$, et al. Effect of blood transfusion on long-term survival after cardiac operation. Ann Thorac Surg 2002; 74: 1180-1186.

10. Sirvinskas $E$, Lenkutis $T$, Raliene $L$, et al. Influence of residual blood autotransfused from cardiopulmonary bypass circuit on clinical outcome after cardiac surgery. Perfusion 2005; 20: 71-75.

11. Paparella D, Whitlock R. Safety of Salvaged Blood and Risk of Coagulopathy in Cardiac Surgery. Semin Thromb Hemost 2016; 42: 166-171.

12. McBride WT, Armstrong MA, Crockard AD, et al. Cytokine balance and immunosuppressive changes at cardiac surgery: contrasting response between patients and isolated CPB circuits. Br J Anaesth 1995; 75: 724-733.

13. Kawamura $\mathrm{T}$, Wakusawa $\mathrm{R}$, Okada $\mathrm{K}$, et al. Elevation of cytokines during open heart surgery with cardiopulmonary bypass: participation of interleukin 8 and 6 in reperfusion injury. Can J Anaesth 1993; 40: 1016-1021. 
14. de Haan J, Boonstra PW, Monnink SH, et al. Retransfusion of suctioned blood during cardiopulmonary bypass impairs hemostasis. Ann Thorac Surg 1995; 59: 901-907.

15. Westerberg M, Bengtsson A, Jeppsson A. Coronary surgery without cardiotomy suction and autotransfusion reduces the postoperative systemic inflammatory response. Ann Thorac Surg 2004; 78: 54-59.

16. Svenmarker S, Engström KG. The inflammatory response to recycled pericardial suction blood and the influence of cell-saving. Scand Cardiovasc J SCJ 2003; 37: 158-164.

17. Gibbon JH. Application of a mechanical heart and lung apparatus to cardiac surgery. Minn Med 1954; 37: 171-185; passim.

18. Edmunds LH, Colman RW. Thrombin during cardiopulmonary bypass. Ann Thorac Surg 2006; 82: 2315-2322.

19. Ranucci M, Balduini A, Ditta A, et al. A systematic review of biocompatible cardiopulmonary bypass circuits and clinical outcome. Ann Thorac Surg 2009; 87: 1311-1319.

20. Johnell M, Elgue $\mathrm{G}$, Larsson $\mathrm{R}$, et al. Coagulation, fibrinolysis, and cell activation in patients and shed mediastinal blood during coronary artery bypass grafting with a new heparin-coated surface. $J$ Thorac Cardiovasc Surg 2002; 124: 321-332.

21. Westerberg M, Gäbel J, Bengtsson A, et al. Hemodynamic effects of cardiotomy suction blood. J Thorac Cardiovasc Surg 2006; 131: 1352-1357.

22. Schotola H, Wetz AJ, Popov AF, et al. The effects of residual pump blood on patient plasma free haemoglobin levels post cardiac surgery. Anaesth Intensive Care 2016; 44: 587-592.

23. Issitt $R$, Sheppard S. Dealing with pericardial suction blood and residual pump volume: a review of current practices in the UK. Perfusion 2011; 26: 51-55.

24. Walpoth BH, Eggensperger N, Hauser SP, et al. Effects of unprocessed and processed cardiopulmonary bypass blood retransfused into patients after cardiac surgery. Int J Artif Organs 1999; 22: 210-216.

25. Catalá Bauset JC, de Andrés Ibáñez J, Grau Real F, et al. Comparative study of two methods for salvaging red blood cells: centrifugation techniques (cell-saver) versus filtration through a 100,000dalton filter. Rev Esp Anestesiol Reanim 1999; 46: 338-343.

26. Vonk $A B$, Muntajit $W$, Bhagirath $P$, et al. Residual blood processing by centrifugation, cell salvage or ultrafiltration in cardiac surgery: effects on clinical hemostatic and ex-vivo rheological parameters. Blood Coagul Fibrinolysis Int J Haemost Thromb 2012; 23: 622-628.

27. Pohlmann JR, Toomasian JM, Hampton CE, et al. The Relationships between Air Exposure, Negative Pressure and Hemolysis. ASAIO J Am Soc Artif Intern Organs 1992 2009; 55: 469-473.

28. Gravlee GP, Angert KC, Tucker WY, et al. Early anticoagulation peak and rapid distribution after intravenous heparin. Anesthesiology 1988; 68: 126-129. 
29. Ofosu FA, Fernandez F, Gauthier D, et al. Heparin cofactor II and other endogenous factors in the mediation of the antithrombotic and anticoagulant effects of heparin and dermatan sulfate. Semin Thromb Hemost 1985; 11: 133-137.

30. Sarkar M, Prabhu V. Basics of cardiopulmonary bypass. Indian J Anaesth 2017; 61: 760-767.

31. Despotis GJ, Joist JH, Hogue CW, et al. More effective suppression of hemostatic system activation in patients undergoing cardiac surgery by heparin dosing based on heparin blood concentrations rather than ACT. Thromb Haemost 1996; 76: 902-908.

32. Salzman EW, Rosenberg RD, Smith MH, et al. Effect of heparin and heparin fractions on platelet aggregation. J Clin Invest 1980; 65: 64-73.

33. Khuri SF, Valeri CR, Loscalzo J, et al. Heparin causes platelet dysfunction and induces fibrinolysis before cardiopulmonary bypass. Ann Thorac Surg 1995; 60: 1008-1014.

34. Mochizuki T, Olson PJ, Szlam F, et al. Protamine reversal of heparin affects platelet aggregation and activated clotting time after cardiopulmonary bypass. Anesth Analg 1998; 87: 781-785.

35. Mclaughlin KE, Dunning J. In patients post cardiac surgery do high doses of protamine cause increased bleeding? Interact Cardiovasc Thorac Surg 2003; 2: 424-426.

36. Lindblad B, Wakefield TW, Whitehouse WM Jr, et al. The effect of protamine sulfate on platelet function. Scand J Thorac Cardiovasc Surg 1988; 22: 55-59.

37. Khan NU, Wayne CK, Barker J, et al. The effects of protamine overdose on coagulation parameters as measured by the thrombelastograph. Eur J Anaesthesiol 2010; 27: 624-627.

38. Vonk $A B A$, Veerhoek $D$, van den Brom $C E$, et al. Individualized heparin and protamine management improves rotational thromboelastometric parameters and postoperative hemostasis in valve surgery. J Cardiothorac Vasc Anesth 2014; 28: 235-241.

39. Koster A, Börgermann J, Gummert J, et al. Protamine overdose and its impact on coagulation, bleeding, and transfusions after cardiopulmonary bypass: results of a randomized double-blind controlled pilot study. Clin Appl Thromb Off J Int Acad Clin Appl Thromb 2014; 20: 290-295.

40. Harker LA. Bleeding after Cardiopulmonary Bypass. N Engl J Med 1986; 314: 1446-1448.

41. Woodman RC, Harker LA. Bleeding complications associated with cardiopulmonary bypass. Blood 1990; 76: 1680-1697.

42. Warren OJ, Smith AJ, Alexiou C, et al. The Inflammatory Response to Cardiopulmonary Bypass: Part 1-Mechanisms of Pathogenesis. J Cardiothorac Vasc Anesth 2009; 23: 223-231.

43. Karkouti K, Beattie WS, Wijeysundera DN, et al. Hemodilution during cardiopulmonary bypass is an independent risk factor for acute renal failure in adult cardiac surgery. $J$ Thorac Cardiovasc Surg 2005; 129: 391-400.

44. Swaminathan M, Phillips-Bute BG, Conlon PJ, et al. The association of lowest hematocrit during cardiopulmonary bypass with acute renal injury after coronary artery bypass surgery. Ann Thorac Surg 2003; 76: 784-791; discussion 792. 
45. Karkouti K, Djaiani G, Borger MA, et al. Low Hematocrit During Cardiopulmonary Bypass is Associated With Increased Risk of Perioperative Stroke in Cardiac Surgery. Ann Thorac Surg 2005; 80: 1381-1387.

46. Schofield ZV, Woodruff TM, Halai R, et al. Neutrophils--a key component of ischemia-reperfusion injury. Shock Augusta Ga 2013; 40: 463-470.

47. Moens AL, Claeys MJ, Timmermans JP, et al. Myocardial ischemia/reperfusion-injury, a clinical view on a complex pathophysiological process. Int J Cardiol 2005; 100: 179-190.

48. Tsao PS, Aoki N, Lefer DJ, et al. Time course of endothelial dysfunction and myocardial injury during myocardial ischemia and reperfusion in the cat. Circulation 1990; 82: 1402-1412.

49. Jordan JE, Zhao ZQ, Vinten-Johansen J. The role of neutrophils in myocardial ischemia-reperfusion injury. Cardiovasc Res 1999; 43: 860-878.

50. Xiao CY, Hara A, Yuhki K, et al. Roles of prostaglandin I(2) and thromboxane A(2) in cardiac ischemiareperfusion injury: a study using mice lacking their respective receptors. Circulation 2001; 104: 22102215.

51. Gupta S, Gupta MM. No reflow phenomenon in percutaneous coronary interventions in ST-segment elevation myocardial infarction. Indian Heart J 2016; 68: 539-551.

52. Jönsson $\mathrm{H}$, Eyjolfsson A, Scicluna $\mathrm{S}$, et al. Circulating particles during cardiac surgery. Interact Cardiovasc Thorac Surg 2009; 8: 538-542.

53. Merkle F, Boettcher W, Schulz F, et al. Reduction of microemboli count in the priming fluid of cardiopulmonary bypass circuits. J Extra Corpor Technol 2003; 35: 133-138.

54. Brooker RF, Brown WR, Moody DM, et al. Cardiotomy suction: a major source of brain lipid emboli during cardiopulmonary bypass. Ann Thorac Surg 1998; 65: 1651-1655.

55. Challa VR, Moody DM, Troost BT. Brain embolic phenomena associated with cardiopulmonary bypass. J Neurol Sci 1993; 117: 224-231.

56. Brondén B, Dencker $M$, Allers $M$, et al. Differential distribution of lipid microemboli after cardiac surgery. Ann Thorac Surg 2006; 81: 643-648.

57. Engström KG. The embolic potential of liquid fat in pericardial suction blood, and its elimination. Perfusion 2003; 18 Suppl 1: 69-74.

58. Kincaid EH, Jones TJ, Stump DA, et al. Processing scavenged blood with a cell saver reduces cerebral lipid microembolization. Ann Thorac Surg 2000; 70: 1296-1300.

59. Jewell AE, Akowuah EF, Suvarna SK, et al. A prospective randomised comparison of cardiotomy suction and cell saver for recycling shed blood during cardiac surgery. Eur J Cardio-Thorac Surg Off J Eur Assoc Cardio-Thorac Surg 2003; 23: 633-636.

60. Muth CM, Shank ES. Gas Embolism. N Engl J Med 2000; 342: 476-482.

61. Jones TJ, Deal DD, Vernon JC, et al. How effective are cardiopulmonary bypass circuits at removing gaseous microemboli? J Extra Corpor Technol 2002; 34: 34-39. 
62. Bennett-Guerrero E, Ayuso L, Hamilton-Davies C, et al. Relationship of preoperative antiendotoxin core antibodies and adverse outcomes following cardiac surgery. JAMA 1997; 277: 646-650.

63. Hamilton-Davies C, Barclay GR, Cardigan RA, et al. Relationship between preoperative endotoxin immune status, gut perfusion, and outcome from cardiac valve replacement surgery. Chest 1997; 112: 1189-1196.

64. Oudemans-van Straaten HM, Jansen PG, Hoek FJ, et al. Intestinal permeability, circulating endotoxin, and postoperative systemic responses in cardiac surgery patients. J Cardiothorac Vasc Anesth 1996; 10: 187-194.

65. Hamers LAC, Linssen CFM, Lancé MD, et al. Positive cultures from cardiopulmonary bypass: prevalence and relevance regarding postoperative infection. Eur J Cardiothorac Surg 2011; 40: 372378.

66. Aydin NB, Gercekoglu H, Aksu B, et al. Endotoxemia in coronary artery bypass surgery: a comparison of the off-pump technique and conventional cardiopulmonary bypass. J Thorac Cardiovasc Surg 2003; 125: 843-848.

67. Kühme T, Isaksson B, Dahlin L-G. Wound contamination in cardiac surgery. A systematic quantitative and qualitative study of the bacterial growth in sternal wounds in cardiac surgery patients. APMIS Acta Pathol Microbiol Immunol Scand 2007; 115: 1001-1007.

68. George JN. Platelets. Lancet Lond Engl 2000; 355: 1531-1539.

69. Michelson AD. Platelets. Second edition. Oxford: Elsevier Inc., 2007.

70. Bouvard D, Brakebusch C, Gustafsson E, et al. Functional consequences of integrin gene mutations in mice. Circ Res 2001; 89: 211-223.

71. Staatz WD, Rajpara SM, Wayner EA, et al. The membrane glycoprotein la-lla (VLA-2) complex mediates the Mg++-dependent adhesion of platelets to collagen. J Cell Biol 1989; 108: 1917-1924.

72. Nieswandt B, Brakebusch C, Bergmeier W, et al. Glycoprotein VI but not alpha2beta1 integrin is essential for platelet interaction with collagen. EMBO J 2001; 20: 2120-2130.

73. Offermanns S. Activation of platelet function through G protein-coupled receptors. Circ Res 2006; 99: 1293-1304.

74. Dahlbäck B. Blood coagulation. Lancet Lond Eng/ 2000; 355: 1627-1632.

75. Sniecinski RM, Chandler WL. Activation of the hemostatic system during cardiopulmonary bypass. Anesth Analg 2011; 113: 1319-1333.

76. Chandler WL, Velan T. Secretion of tissue plasminogen activator and plasminogen activator inhibitor 1 during cardiopulmonary bypass. Thromb Res 2003; 112: 185-192.

77. Tanaka K, Takao M, Yada I, et al. Alterations in coagulation and fibrinolysis associated with cardiopulmonary bypass during open heart surgery. J Cardiothorac Anesth 1989; 3: 181-188.

78. Chandler WL, Alessi MC, Aillaud MF, et al. Formation, inhibition and clearance of plasmin in vivo. Haemostasis 2000; 30: 204-218. 
79. Slaughter TF, Sreeram G, Sharma AD, et al. Reversible shear-mediated platelet dysfunction during cardiac surgery as assessed by the PFA-100 platelet function analyzer. Blood Coagul Fibrinolysis Int J Haemost Thromb 2001; 12: 85-93.

80. Velik-Salchner C, Maier S, Innerhofer P, et al. An Assessment of Cardiopulmonary Bypass-Induced Changes in Platelet Function Using Whole Blood and Classical Light Transmission Aggregometry: The Results of a Pilot Study: Anesth Analg 2009; 108: 1747-1754.

81. Gersh BJ. Current issues in reperfusion therapy. Am J Cardiol 1998; 82: 3P-11P.

82. Christensen U, Bangert K, Thorsen S. Reaction of human alpha2-antiplasmin and plasmin stoppedflow fluorescence kinetics. FEBS Lett 1996; 387: 58-62.

83. Chang GMT, Atkinson HM, Berry LR, et al. Inhibition of plasmin generation in plasma by heparin, low molecular weight heparin, and a covalent antithrombin-heparin complex. Blood Coagul Fibrinolysis Int J Haemost Thromb. Epub ahead of print 24 November 2016. DOI: 10.1097/MBC.0000000000000611.

84. Kondo C, Tanaka K, Takagi K, et al. Platelet dysfunction during cardiopulmonary bypass surgery. With special reference to platelet membrane glycoproteins. ASAIO J Am Soc Artif Intern Organs 1992 1993; 39: M550-553.

85. Vandendries ER, Furie BC, Furie B. Role of P-selectin and PSGL-1 in coagulation and thrombosis. Thromb Haemost 2004; 92: 459-466.

86. Neumann FJ, Marx N, Gawaz M, et al. Induction of cytokine expression in leukocytes by binding of thrombin-stimulated platelets. Circulation 1997; 95: 2387-2394.

87. Maugeri N, Brambilla M, Camera M, et al. Human polymorphonuclear leukocytes produce and express functional tissue factor upon stimulation. J Thromb Haemost JTH 2006; 4: 1323-1330.

88. Borensztajn K, Peppelenbosch MP, Spek CA. Factor Xa: at the crossroads between coagulation and signaling in physiology and disease. Trends Mol Med 2008; 14: 429-440.

89. Adams JC. Thrombospondins: multifunctional regulators of cell interactions. Annu Rev Cell Dev Biol 2001; 17: 25-51.

90. Lawler JW, Slayter HS, Coligan JE. Isolation and characterization of a high molecular weight glycoprotein from human blood platelets. J Biol Chem 1978; 253: 8609-8616.

91. Fang L-L, Yu H-Q, Wu R-J, et al. Thrombospondin 1 Modulates Monocyte Properties to Suppress Intestinal Mucosal Inflammation. J Innate Immun 2015; 7: 601-611.

92. Lopez-Dee Z, Pidcock K, Gutierrez LS. Thrombospondin-1: multiple paths to inflammation. Mediators Inflamm 2011; 2011: 296069.

93. Kyriakides TR, Maclauchlan S. The role of thrombospondins in wound healing, ischemia, and the foreign body reaction. J Cell Commun Signal 2009; 3: 215-225.

94. Böckmann S, Paegelow I. Kinins and kinin receptors: importance for the activation of leukocytes. J Leukoc Biol 2000; 68: 587-592. 
95. Wan S, LeClerc JL, Vincent JL. Inflammatory response to cardiopulmonary bypass: mechanisms involved and possible therapeutic strategies. Chest 1997; 112: 676-692.

96. Edmunds LH. Inflammatory response to cardiopulmonary bypass. Ann Thorac Surg 1998; 66: S12-16; discussion S25-28.

97. Wiedmer T, Esmon CT, Sims PJ. Complement proteins C5b-9 stimulate procoagulant activity through platelet prothrombinase. Blood 1986; 68: 875-880.

98. Bruins $\mathrm{P}$, te Velthuis $\mathrm{H}$, Eerenberg-Belmer AJ, et al. Heparin-protamine complexes and C-reactive protein induce activation of the classical complement pathway: studies in patients undergoing cardiac surgery and in vitro. Thromb Haemost 2000; 84: 237-243.

99. Downing SW, Edmunds LH. Release of vasoactive substances during cardiopulmonary bypass. Ann Thorac Surg 1992; 54: 1236-1243.

100. Scholz W, McClurg MR, Cardenas GJ, et al. C5a-mediated release of interleukin 6 by human monocytes. Clin Immunol Immunopathol 1990; 57: 297-307.

101. Steinberg JB, Kapelanski DP, Olson JD, et al. Cytokine and complement levels in patients undergoing cardiopulmonary bypass. J Thorac Cardiovasc Surg 1993; 106: 1008-1016.

102. Martel $C$, Cointe $S$, Maurice $P$, et al. Requirements for membrane attack complex formation and anaphylatoxins binding to collagen-activated platelets. PloS One 2011; 6: e18812.

103. Moat NE, Shore DF, Evans TW. Organ dysfunction and cardiopulmonary bypass: the role of complement and complement regulatory proteins. Eur J Cardio-Thorac Surg Off J Eur Assoc CardioThorac Surg 1993; 7: 563-573.

104. Tegla CA, Cudrici C, Patel S, et al. Membrane attack by complement: the assembly and biology of terminal complement complexes. Immunol Res 2011; 51: 45-60.

105. Rossaint J, Berger C, Van Aken H, et al. Cardiopulmonary bypass during cardiac surgery modulates systemic inflammation by affecting different steps of the leukocyte recruitment cascade. PloS One 2012; 7: e45738.

106. Kalawski R, Bugajski P, Smielecki J, et al. Soluble adhesion molecules in reperfusion during coronary bypass grafting. Eur J Cardio-Thorac Surg Off J Eur Assoc Cardio-Thorac Surg 1998; 14: 290-295.

107. Fujishima S, Aikawa N. Neutrophil-mediated tissue injury and its modulation. Intensive Care Med 1995; 21: 277-285.

108. Chung JH, Gikakis N, Rao AK, et al. Pericardial blood activates the extrinsic coagulation pathway during clinical cardiopulmonary bypass. Circulation 1996; 93: 2014-2018.

109. Hattori T, Khan MMH, Colman RW, et al. Plasma tissue factor plus activated peripheral mononuclear cells activate factors VII and X in cardiac surgical wounds. J Am Coll Cardiol 2005; 46: 707-713.

110. Asimakopoulos G. Mechanisms of the systemic inflammatory response. Perfusion 1999; 14: 269-277.

111. Nijziel $M$, van Oerle R, van 't Veer C, et al. Tissue factor activity in human monocytes is regulated by plasma: implications for the high and low responder phenomenon. Br J Haematol 2001; 112: 98-104. 
112. DePalma L, Yu M, Mclntosh CL, et al. Changes in lymphocyte subpopulations as a result of cardiopulmonary bypass. The effect of blood transfusion. J Thorac Cardiovasc Surg 1991; 101: 240 244.

113. Roth JA, Golub SH, Cukingnan RA, et al. Cell-mediated immunity is depressed following cardiopulmonary bypass. Ann Thorac Surg 1981; 31: 350-356.

114. Zhang J-M, An J. Cytokines, Inflammation and Pain. Int Anesthesiol Clin 2007; 45: 27-37.

115. McBride WT, McBride SJ. The balance of pro- and anti-inflammatory cytokines in cardiac surgery. Curr Opin Anaesthesiol 1998; 11: 15-22.

116. de Mendonça-Filho HTF, Pereira KC, Fontes M, et al. Circulating inflammatory mediators and organ dysfunction after cardiovascular surgery with cardiopulmonary bypass: a prospective observational study. Crit Care Lond Engl 2006; 10: R46.

117. Luster AD. Chemokines--chemotactic cytokines that mediate inflammation. N Engl J Med 1998; 338 : 436-445.

118. Buziashvili YI, Ambat'ello SG, Aleksakhina YA, et al. Influence of cardiopulmonary bypass on the state of cognitive functions in patients with ischemic heart disease. Neurosci Behav Physiol 2006; 36: 107113.

119. Lahrtz F, Piali L, Nadal D, et al. Chemotactic activity on mononuclear cells in the cerebrospinal fluid of patients with viral meningitis is mediated by interferon-gamma inducible protein-10 and monocyte chemotactic protein-1. Eur J Immunol 1997; 27: 2484-2489.

120. Tanaka $\mathrm{T}$, Kuroiwa $\mathrm{T}$, Ikeuchi $\mathrm{H}$, et al. Human platelets stimulate mesangial cells to produce monocyte chemoattractant protein-1 via the CD40/CD40 ligand pathway and may amplify glomerular injury. $J$ Am Soc Nephrol JASN 2002; 13: 2488-2496.

121. Klebanoff SJ. Myeloperoxidase: friend and foe. J Leukoc Biol 2005; 77: 598-625.

122. Klebanoff SJ. Myeloperoxidase. Proc Assoc Am Physicians 1999; 111: 383-389.

123. Tapper $\mathrm{H}$, Karlsson A, Mörgelin M, et al. Secretion of heparin-binding protein from human neutrophils is determined by its localization in azurophilic granules and secretory vesicles. Blood 2002; 99: 17851793.

124. Chew MS, Linder A, Santen S, et al. Increased plasma levels of heparin-binding protein in patients with shock: a prospective, cohort study. Inflamm Res Off J Eur Histamine Res Soc Al 2012; 61: 375-379.

125. Soehnlein $\mathrm{O}$, Zernecke A, Eriksson EE, et al. Neutrophil secretion products pave the way for inflammatory monocytes. Blood 2008; 112: 1461-1471.

126. Gautam N, Olofsson AM, Herwald H, et al. Heparin-binding protein (HBP/CAP37): a missing link in neutrophil-evoked alteration of vascular permeability. Nat Med 2001; 10: 1123-1127.

127. Samson S, Shore-Lesserson L. Platelet Function and Cardiopulmonary Bypass. Semin Cardiothorac Vasc Anesth 2001; 5: 273-281. 
128. Ellison N, Edmunds LH Jr, Colman RW. Platelet aggregation following heparin and protamine administration. Anesthesiology 1978; 48: 65-68.

129. Carr ME Jr, Carr SL. At high heparin concentrations, protamine concentrations which reverse heparin anticoagulant effects are insufficient to reverse heparin anti-platelet effects. Thromb Res 1994; 75: 617-630.

130. Connolly-Andersen A-M, Sundberg E, Ahlm C, et al. Increased Thrombopoiesis and Platelet Activation in Hantavirus-Infected Patients. J Infect Dis 2015; 212: 1061-1069.

131. Egan K, Dillon A, Dunne E, et al. Increased soluble GPVI levels in cirrhosis: evidence for early in vivo platelet activation. J Thromb Thrombolysis. Epub ahead of print 14 July 2016. DOI: 10.1007/s11239016-1401-0.

132. Cardinal DC, Flower RJ. The electronic aggregometer: a novel device for assessing platelet behavior in blood. J Pharmacol Methods 1980; 3: 135-158.

133. Hanke AA, Roberg $\mathrm{K}$, Monaca $\mathrm{E}$, et al. Impact of platelet count on results obtained from multiple electrode platelet aggregometry (Multiplate). Eur J Med Res 2010; 15: 214-219.

134. Butterworth J, Lin YA, Prielipp RC, et al. Rapid disappearance of protamine in adults undergoing cardiac operation with cardiopulmonary bypass. Ann Thorac Surg 2002; 74: 1589-1595.

135. Rahe-Meyer N, Solomon C, Tokuno M-L, et al. Comparative assessment of coagulation changes induced by two different types of heart-lung machine. Artif Organs 2010; 34: 3-12.

136. Rinder $\mathrm{CS}$, Bohnert J, Rinder $\mathrm{H}$, et al. Platelet activation and aggregation during cardiopulmonary bypass. Anesthesiology 1991; 75: 388-93.

137. Rinder CS, Mathew H., Rinder $\mathrm{H}$, et al. Modulation of platelet surface adhesion receptors during cardiopulmonary bypass. Anesthesiology 1991; 75: 563-70.

138. Zilla P, Fasol R, Groscurth $\mathrm{P}$, et al. Blood platelets in cardiopulmonary bypass operations. Recovery occurs after initial stimulation, rather than continual activation. J Thorac Cardiovasc Surg 1989; 97: 379-388.

139. Rubak P, Villadsen K, Hvas A-M. Reference intervals for platelet aggregation assessed by multiple electrode platelet aggregometry. Thromb Res 2012; 130: 420-423.

140. Ranucci M, Baryshnikova E, Soro G, et al. Multiple electrode whole-blood aggregometry and bleeding in cardiac surgery patients receiving thienopyridines. Ann Thorac Surg 2011; 91: 123-129.

141. Miura Y, Takahashi T, Jung SM, et al. Analysis of the Interaction of Platelet Collagen Receptor Glycoprotein VI (GPVI) with Collagen. J Biol Chem 2002; 277: 46197-46204.

142. Ichikawa J, Hagihira S, Mori T, et al. In vitro and in vivo effects of hemodilution on kaolin-based activated clotting time predicted heparin requirement using a heparin dose-response technique. $J$ Anesth 2016; 30: 923-928.

143. Culliford AT, Gitel SN, Starr N, et al. Lack of correlation between activated clotting time and plasma heparin during cardiopulmonary bypass. Ann Surg 1981; 193: 105-111. 
144. Ural K, Owen C. Pro: The Hepcon HMS Should Be Used Instead of Traditional Activated Clotting Time (ACT) to Dose Heparin and Protamine for Cardiac Surgery Requiring Cardiopulmonary Bypass. J Cardiothorac Vasc Anesth 2016; 30: 1727-1729.

145. Despotis GJ, Joist JH, Hogue CW, et al. The impact of heparin concentration and activated clotting time monitoring on blood conservation. A prospective, randomized evaluation in patients undergoing cardiac operation. J Thorac Cardiovasc Surg 1995; 110: 46-54.

146. Guffin AV, Dunbar RW, Kaplan JA, et al. Successful use of a reduced dose of protamine after cardiopulmonary bypass. Anesth Analg 1976; 55: 110-113.

147. Jeffers A, Gladwin MT, Kim-Shapiro DB. Computation of plasma hemoglobin nitric oxide scavenging in hemolytic anemias. Free Radic Biol Med 2006; 41: 1557-1565.

148. Rinder CS, Rinder HM, Smith MJ, et al. Selective blockade of membrane attack complex formation during simulated extracorporeal circulation inhibits platelet but not leukocyte activation. $J$ Thorac Cardiovasc Surg 1999; 118: 460-466.

149. Deshmane SL, Kremlev S, Amini S, et al. Monocyte chemoattractant protein-1 (MCP-1): an overview. J Interferon Cytokine Res Off J Int Soc Interferon Cytokine Res 2009; 29: 313-326.

150. Bentzer $\mathrm{P}$, Fisher J, Kong $\mathrm{HJ}$, et al. Heparin-binding protein is important for vascular leak in sepsis. Intensive Care Med Exp 2016; 4: 33.

151. Johansson J, Brattström O, Sjöberg F, et al. Heparin-binding protein (HBP): an early marker of respiratory failure after trauma? Acta Anaesthesiol Scand 2013; 57: 580-586.

152. Fisher J, Linder A. Heparin-binding protein: a key player in the pathophysiology of organ dysfunction in sepsis. J Intern Med 2017; 281: 562-574.

153. Li L, Pian Y, Chen S, et al. Phenol-soluble modulin $\alpha 4$ mediates Staphylococcus aureus-associated vascular leakage by stimulating heparin-binding protein release from neutrophils. Sci Rep 2016; 6: 29373.

154. Rungatscher A, Tessari M, Stranieri C, et al. Oxygenator Is the Main Responsible for Leukocyte Activation in Experimental Model of Extracorporeal Circulation: A Cautionary Tale. Mediators Inflamm 2015; 2015: 484979.

155. Tammelin A, Hambraeus A, Ståhle E. Source and route of methicillin-resistant Staphylococcus epidermidis transmitted to the surgical wound during cardio-thoracic surgery. Possibility of preventing wound contamination by use of special scrub suits. J Hosp Infect 2001; 47: 266-276.

156. Freeman R, Hjersing N. Bacterial culture of perfusion blood after open-heart surgery. Thorax 1980; 35 : 754-758.

157. Daane CR, Golab HD, Meeder JHJ, et al. Processing and transfusion of residual cardiopulmonary bypass volume: effects on haemostasis, complement activation, postoperative blood loss and transfusion volume. Perfusion 2003; 18: 115-121.

158. Sander M, von Heymann C, von Dossow V, et al. Increased interleukin-6 after cardiac surgery predicts infection. Anesth Analg 2006; 102: 1623-1629. 


\section{Papers}

The papers associated with this thesis have been removed for copyright reasons. For more details about these see:

http://urn.kb.se/resolve?urn=urn:nbn:se:liu:diva-146224 